\title{
An Investigation of Tendon Sheathing Filler Migration Into Concrete
}

Manuscript Completed: January 1998

Date Published: March 1998

Prepared by

D.J. Naus, C.B. Oland

Oak Ridge National Laboratory

Managed by Lockheed Martin Energy Research Corporation

Oak Ridge, TN 37831

J.F. Costello, NRC Project Manager

Prepared for

Division of Engineering Technology

DISTRIBUTION OF THIS DOCUAENT IS UNLIMITED

Office of Nuclear Regulatory Research

U.S. Nuclear Regulatory Commission

Washington, DC 20555-0001

NRC Job Code W6536

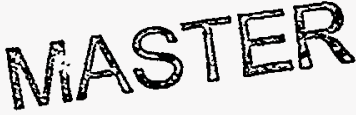

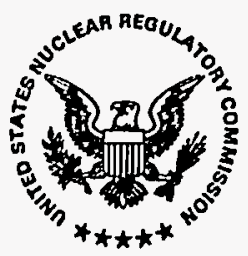




\section{DISCLAIMER}

Portions of this document may be illegible electronic image products. Images are produced from the best available original document. 


\begin{abstract}
During some of the inspections performed at nuclear power plants with prestressed concrete containments, it was observed that the containments had experienced leakage of the tendon sheathing filler (i.e., streaks). The objective of this research activity was to provide an indication of the extent of tendon sheathing filler leakage into the concrete of a prestressed concrete containment and if it affects the concrete properties (tensile and compressive) to an extent that the containment structural capacity could be affected. In meeting this objective pertinent literature was reviewed relative to the effect of tendon sheathing filler intrusion on concrete mechanical properties. Also, concrete core samples were obtained from the Trojan Nuclear Plant and tested to determine the extent of tendon sheathing filler migration into the concrete, and the concrete tensile and compressive strengths. Although several articles were identified related to evaluation of the effects of organic-based materials on concrete, these studies generally involved the use of crude or lubricating oils that are known to cause damage to concrete, particularly at elevated temperature. However, these materials have significantly different characteristics relative to the materials that are used as tendon sheathing fillers (e.g., sheathing fillers contain microcrystalline waxes as well as a number of other additives to improve performance). Only one study was identified that specifically addressed the interaction of tendon sheathing filler with concrete and its potential impact on structural integrity. Examination and testing of concrete core samples removed from the containment at the Trojan Plant indicated that the appearance of tendon sheathing filler on the concrete surface was due to leakage of the filler from the conduits and its subsequent migration to the concrete surface through cracks that were present. Migration of the tendon sheathing filler was confined to the cracks and there was no perceptible movement into the concrete. Results of compressive strength tests performed on several concrete cores indicated that the concrete quality was consistent in the containment and that the concrete compressive strength had increased over $40 \%$ in 25.4 years relative to the average compressive strength at 28-days age. This increase in compressive strength with age is consistent with that obtained from other nuclear power plant concrete structures.
\end{abstract}


CONTENTS

Page

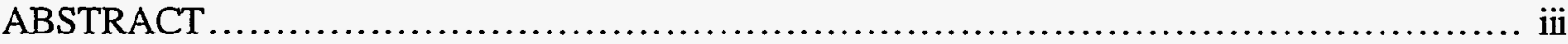

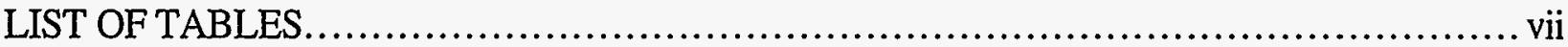

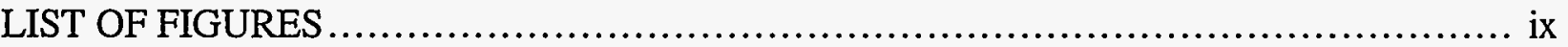

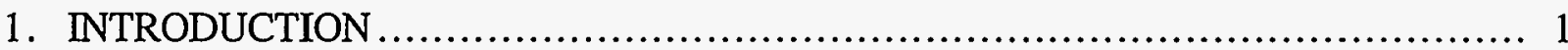

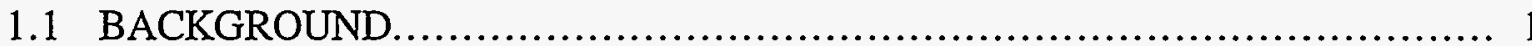

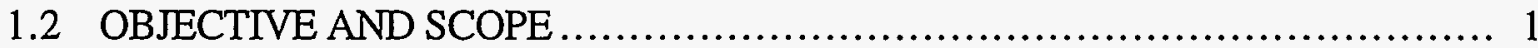

2. PRESTRESSING TENDON SHEATHING FILLER MATERIALS ...................... 3

2.1 EVOLUTION OF TENDON SHEATHING FILLERS ............................ 3

2.2 EFFECTS OF ORGANIC-BASED MATERIALS ON CONCRETE ................. 3

2.2 .1 General ..................................................................... 3

2.2.2 Compressive Strength and Modulus of Elasticity .............................. 3

2.2 .3 Bond Strength ....................................................... 4

2.2.4 Nuclear Power Plant-Related Studies...................................... 5

2.3 COMMENTARY ......................................................................... 5

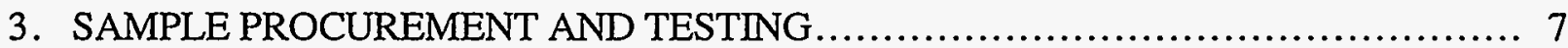

3.1 BACKGROUND.................................................................... 7

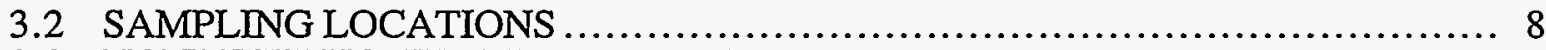

3.3 NONDESTRUCTIVE EXAMINATIONS ...................................... 8

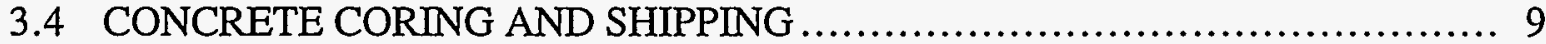

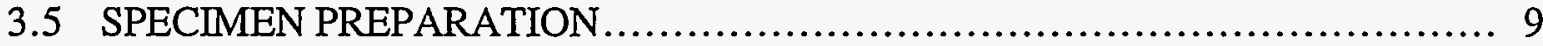

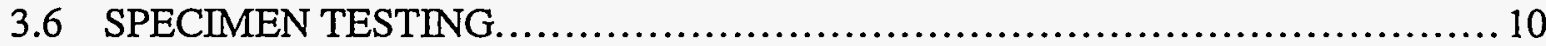

3.6.1 Uncracked Specimens ............................................. 10

3.6.1.1 Compressive strength testing ................................. 10

3.6.1.2 Splitting-tensile strength testing ............................... 10

3.6.2 Cracked Specimens ............................................... 11

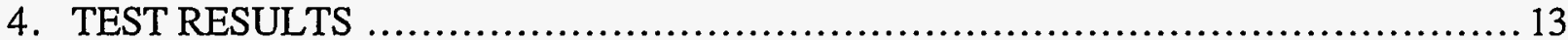

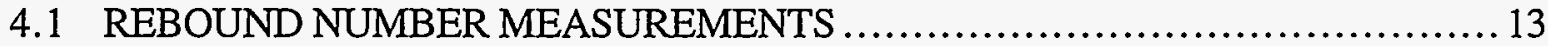

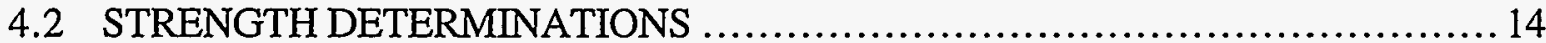

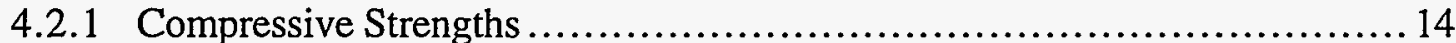

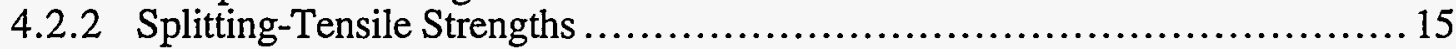

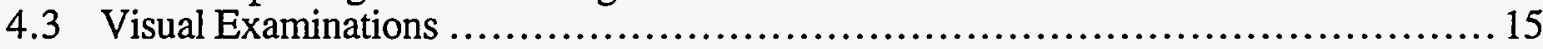

5. SUMMARY, CONCLUSIONS, AND OBSERVATIONS............................... 17

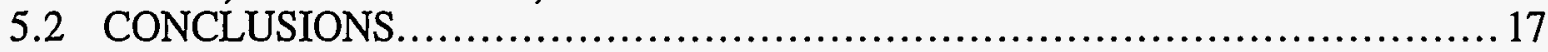

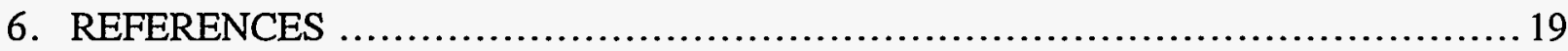

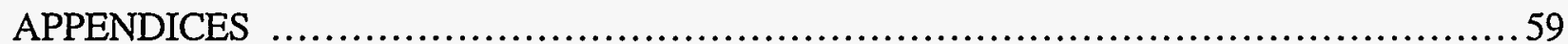

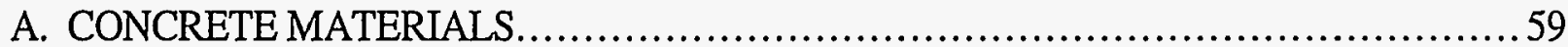

B. REBOUND NUMBER FOR CONCRETE SURFACES ...................................6 65

C. CONCRETE REINFORCING BAR SURVEY.......................................... 69 
$\ldots$ 


\section{LIST OF TABLES}

Table

Page

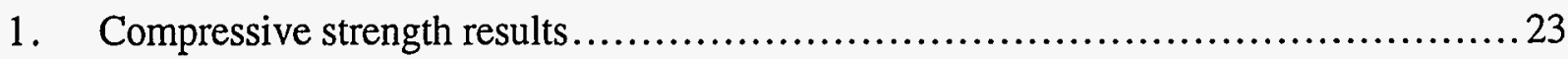

2. Splitting-tensile strength results................................................ 24

3. Dimensions and maximum applied loads for cracked specimens loaded to fracture using compression test procedure ....

4. Dimensions and maximum applied loads for cracked specimens loaded to fracture using splitting-tensile test procedure 


\section{LIST OF FIGURES}

Figure

Page

1. Trojan nuclear power plant

2. Elevation view of Trojan containment presenting steel reinforcement information ..... 28

3. Example of staining of outer containment surface due to leakage of tendon sheathing filler

4. Coupling of tendon sheaths at Trojan Plant ................................... 30

5. Plan view of Trojan containment showing coring locations...................... 31

6. Leakage of tendon sheathing filler at sites selected for examination.................. 32

7. Additional locations where leakage of tendon sheathing filler was observed........... 33

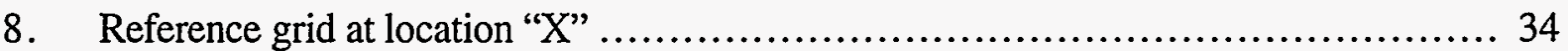

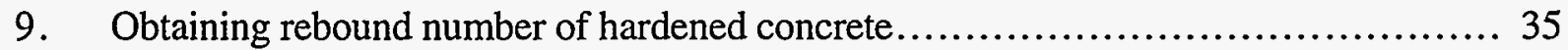

10. Use of covermeter to locate embedded steel ..................................... 35

11. Coring to obtain concrete test articles ........................................ 36

12. Typical steel reinforcement and tendon sheathing arrangement of Trojan Plant containment ....................................................... 37

13. Grid placement and coring locations for location "W" ............................ 38

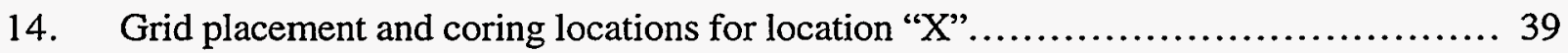

15. Grid placement and coring locations for location "Y".......................... 40

16. Grid placement and coring locations for location " $\mathrm{Z}$ " ......................... 41

17. Concrete cores obtained from location " $\mathrm{W}$ " ....................................... 42

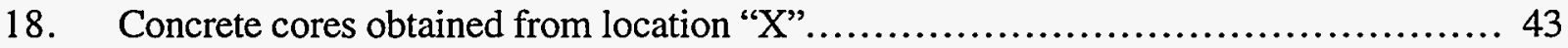

19. Concrete cores obtained from location "Y". ..................................... 44

20. Concrete cores obtained from location " $Z$ " ...................................... 45

21. Sawing of specimen to obtain a test article that had relatively smooth ends that were perpendicular to the longitudinal axis......................................... 46

22. Test fixture for capping specimen ends prior to compressive strength testing.... 


\section{LIST OF FIGURES (cont'd)}

$\begin{array}{lll}\text { Figure } & \text { Page }\end{array}$

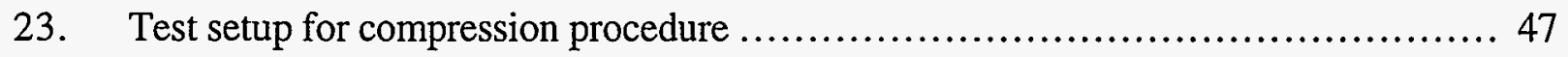

24. Test setup for splitting-tensile procedure $\ldots \ldots \ldots \ldots \ldots \ldots \ldots \ldots \ldots \ldots \ldots \ldots \ldots \ldots . \ldots \ldots$

25. Rebound hammer results for location " $W$ " ................................ 49

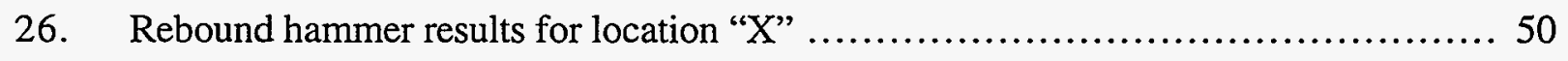

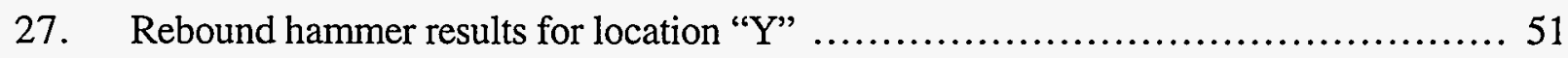

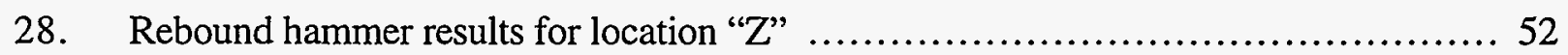

29. Effect of tendon sheathing filler on rebound number readings..................... 53

30. Comparison of Trojan Plant compressive strength data with

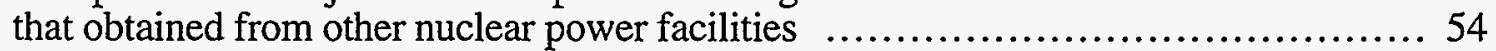

31. Cracked specimens W-1 and W-2 before and after

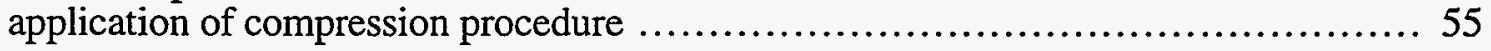

32. Cracked specimens Z-1, Z-2, and Z-3 before and after

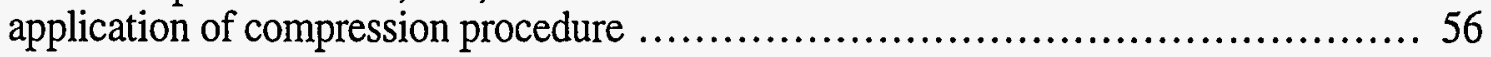

33. Typical "cone or hourglass" fracture for concrete tested in compression $\ldots . \ldots \ldots . . .57$

34. Fracture surface after application of splitting-tensile procedure.................. 58

35. Fracture surface after application of phenolphthalein indicator $\ldots \ldots \ldots \ldots \ldots \ldots \ldots \ldots . . .58$ 


\section{INTRODUCTION}

\subsection{BACKGROUND}

Prestressed concrete has been used in U.S. nuclear power plants (NPPs) for a number of structures (i.e., containment, reactor pressure vessel, missile shield members, reactor cavity walls, spent fuel pool girders, and structural support for ice condenser floors). Its primary application, however, has been in the construction of containment structures. Of the 109 NPPs licensed for commercial operation in the U.S., 41 have prestressed concrete containments (PCCs). References $(1,2)$ describe the evolution of NPP PCCs in the U.S.

The prestressing system plays a vital role in ensuring the structural integrity of the PCC throughout its service life (normally 40 years initial operating period plus a potential continued service period of 20 years or more). However, because the prestressing tendons and their anchorage hardware are fabricated from high-strength, high hardness materials that are subjected to sustained high stresses, they are susceptible to stress-corrosion cracking and hydrogen embrittlement. In all but two of the PCCs in the U.S. (Three Mile Island 2 and H.B. Robinson 2), corrosion protection of the prestressing system is provided by a tendon sheathing filler (petroleum petrolatum wax type base plus additives). The use of sheathing fillers (unbonded tendons), as opposed to grouting with Portland cement (grouted tendons), has gained prominence in the U.S. because of the relative ease with which the tendons can be inspected and tested (3). Additional advantages include (1) encapsulation provides about $50 \%$ reduction in the friction factor thus permitting the use of longer tendons, and fewer buttresses and anchorages; (2) tendons may be relaxed, retensioned, and replaced, as required; and (3) application of a corrosion-protection medium in the shop prior to shipment permits installation and tensioning of tendons, and installation of sheathing filler to be scheduled efficiently during the construction sequence.

In general, the performance of the NPP PCCs has been very good $(4,5)$. However, during inspections performed at some of the plants several years ago, tendon sheathing filler (i.e., streaks) was observed on the outer surfaces of the containment structures at Calvert Cliffs and Arkansas Nuclear One Unit 1. Thinking that these might be isolated incidences in certain areas of the containments, the NRC Staff included as a precautionary measure a provision in the proposed (at that time) Revision 3 to Regulatory Guide 1.35 that covers in-service inspection of ungrouted tendons in PCCs (6). The provision addressed measurement of voids in the tendon ducts of tendons selected for lift-off load testing. Since that time leakage of tendon sheathing filler has occurred through the concrete in PCCs of at least four additional plants (Point Beach, Trojan, Palisades, and Fort Calhoun). Reference 7 provides information on the tendon sheathing filler leakage found at the Trojan and Point Beach plants.

\subsection{OBJECTIVE AND SCOPE}

The overall objective of this activity was to provide an indication if leakage of the tendon sheathing filler into the concrete of the PCC affects the concrete properties (tensile and compressive) to an extent that the containment structural capacity could be affected. In meeting this objective pertinent literature was reviewed relative to the effect of tendon sheathing filler intrusion on concrete mechanical properties. Also, concrete core samples were obtained from the Trojan Nuclear Plant and tested to determine the extent of tendon sheathing filler migration into the concrete, and the concrete tensile and compressive strengths. Limited nondestructive examinations using a rebound hammer were also conducted. 


$$
\text { . }
$$




\section{PRESTRESSING TENDON SHEATHING FILLER MATERIALS}

\subsection{EVOLUTION OF TENDON SHEATHING FILLERS}

The petroleum-petrolatum wax type base plus additives that are used as tendon sheathing filler materials have evolved over the years to make the products more suitable for application to PCCs in nuclear power plants. Initially, "off-the-shelf" industrial materials, such as from the automotive industry, that contained additives (e.g., low molecular weight sulfonate materials) were utilized. Early products were sheathing fillers containing polar wetting agents, rust-prevention additives, microcrystalline waxes, and proprietary constituents formulated to be water displacing, self healing, and resistant to electrical conductivity. The next generation of materials was formed by adding a plugging agent to raise the low-flow point of the product to $39^{\circ} \mathrm{C}$ to keep them from seeking loose tendon sheathing joints and flowing into hairline cracks in the concrete. A subsequent refinement involved incorporation of a light base number to provide alkalinity ( $3 \mathrm{mg}$ $\mathrm{KOH} / \mathrm{gm}$ product) for improved corrosion protection. The current generation of products has had the original additives modified by chemical reactions of organic compounds with microcrystalline waxes and petroleum oils to (1) increase the viscosity without sacrificing long distance pumpability, (2) raise the congealing point to $57^{\circ} \mathrm{C}$ so that it remains firm and does not bleed out of the tendon sheathing or through hairline cracks in concrete, (3) remain soft enough to remove tendon wires or strands for surveillance, (4) increase water-displacing characteristics, (5) raise the base number (35 mg KOH/gm product) to provide higher alkalinity, and (6) be self healing $(8,9)$.

\subsection{EFFECTS OF ORGANIC-BASED MATERIALS ON CONCRETE}

\subsubsection{General}

Reference 10 provides results of a literature review on the effects of organic-based products (i.e., crude oils, boiled linseed oil/mineral spirits mixtures, and aircraft engine lubricating oils and hydraulic fluids) on concrete materials. Results of this review indicate that exposure to organic-based materials can produce changes in concrete properties, and even damage the concrete. Additional information on the effects of various chemicals on concrete are provided in Reference 11. In addition, since the literature review reported in Reference 10 two additional references have been identified related to the interaction of organic materials and concrete $(12,13)$. A summary of pertinent information contained in these references is provided below. Unfortunately only limited information could be found relative to the effect on concrete of tendon sheathing fillers such as used for NPP applications (14).

\subsubsection{Compressive Strength and Modulus of Elasticity}

References 15 and 16 report results of an investigation to examine the effects of concrete exposure to crude oil at temperatures of $20,45,60$, and $80^{\circ} \mathrm{C}$. Two mixes were investigated, one with ordinary Portland cement and one in which $30 \%$ of the cement had been replaced with a pozzolan. After an initial curing period of 14 days at $100 \%$ relative humidity and $20^{\circ} \mathrm{C}$, the specimens were divided into two groups and cured an additional 351 days ( 365 days total). Half of the specimens were cured in sea water while the other half remained in the moist room. Specimens were then removed from their curing environment and either kept saturated or oven dried at $105^{\circ} \mathrm{C}$ prior to storing in crude oil at temperatures of either $20,45,60$, or $80^{\circ} \mathrm{C}$ for up to 450 days prior to testing for compressive strength. Results obtained for the specimens that had been oven dried and stored in crude oil showed an initial 10-20\% reduction in compressive strength relative to control specimens during the first 30 days of soaking. After this the strength reduction reduced and stabilized after about 90 days. In general, as the exposure temperature 
increased the strength losses occurred earlier and became more severe (e.g., 30\% strength loss at $80^{\circ} \mathrm{C}$ ). Similar initial results were observed for the specimens that remained saturated prior to soaking in crude oil, however, except for the specimens soaked at $80^{\circ} \mathrm{C}$, the strength recovered to presoak levels or higher after 365 days soaking in crude oil.

References 12,17 , and 18 present results on the effects of lubricating oil and hydraulic fluids on airport-related concrete pavements. Reference 12 notes that cyclic heat application in the presence of lubricating oils, hydraulic fluids, and distilled water caused these fluids to move into and out of the concrete (reflux) and react with the calcium hydroxide, silicates, and aluminates. Laboratory studies conducted at a maximum reflux temperature of $100-110^{\circ} \mathrm{C}$ have shown that ordinary Portland cement loses up to $55 \%$ of its compressive strength after seven days of refluxing with lubricating oils, and $17 \%$ after refluxing with hydraulic fluid for the same time period. Distilled water was utilized to demonstrate that the :refluxing process by itself did not have an adverse effect on ordinary Portland cement. Seven day compressive strength losses after refluxing with distilled water were about $1 \%$. The difference in performance was attributed to different ester contents (95\% in the lubricating oil versus $30 \%$ in the hydraulic fluid). References 17 and 18 reported results also related to scaling of airport-related concrete pavements. In these tests two circular concrete slabs were constructed in the laboratory. They were subjected to thermal cycles to $190^{\circ} \mathrm{C}$ lasting up to three hours per day. After each heat cycle lubricating oil was poured onto one of the slabs and hydraulic fluid onto the other. Scaling of the concrete occurred similar to damage observed in the field. It was concluded that ester-based lubricating oils and hydraulic fluids react chemically with the hydroxyl ions from the calcium hydroxide and/or the calcium silicate hydrates in concrete to destroy the cement paste-aggregate bond. Elevated temperature accelerates the process.

Reference 19 presents results of an experimental study of the changes in dynamic modulus of elasticity of concrete due to exposure to crude oil. Concrete prisms were made from four different concrete mixes (water-cement ratios of $0.40,0.50,0.55$, and 0.60 ). The specimens were cured for 27 days prior to soaking in crude oil, with four curing procedures utilized. Initially the specimens were cured in water for either $6,13,20$, or 27 days. The balance of curing (where applicable) was in a constant temperature and humidity room. After exposure to crude oil for up to 540 days the prisms were vibrated longitudinally to obtain the resonant frequency for determination of the dynamic modulus of elasticity. Results obtained indicate that for the conditions considered there was no significant effect on dynamic modulus of elasticity resulting from exposure to crude oil (i.e., after 540 days exposure the dynamic modulus of specimens soaked in crude oil increased $5-10 \%$ whereas the increase for control prisms that remained saturated with water was 10-20\%). Specimens that had remained in the constant temperature and humidity room after an initial 28-day moist cure period exhibited a $10-15 \%$ decrease in dynamic modulus of elasticity.

\subsubsection{Bond Strength}

Reference 20 investigated the effect of organic-based materials on bond between concrete and mild steel reinforcement. Two concrete mixtures were used to fabricate cylindrical specimens that were laterally reinforced and contained a mild steel reinforcing bar (smooth or deformed) that was centrally located and aligned with the longitudinal axis of the specimen. After water curing for 7 days, the specimens were dried at $105^{\circ} \mathrm{C}$ for $14-18$ days until they reached an equilibrium weight. One-third of the specimens were then soaked in crude oil at atmospheric pressure, onethird were soaked in water, and the remaining one-third were sealed in polyethylene bags and used as control specimens. Pull-out tests were performed at 120,300, and 750 days after casting. Results obtained showed that the pull-out strength decreased as the length of oil soaking increased, with the smooth bars experiencing larger decreases than the deformed bars. The average pull-out 
strength for specimens that had been soaked in oil for 750 days was $13-27 \%$ less than that obtained from sealed specimens and 34-51\% less than obtained from specimens that had been soaked in water.

Reference 13 presents results of a literature survey to investigate research into the affect of impurities in the form of oil on the bond strength of smooth profiled and deformed mild steel reinforcing bars. Results of the survey indicate that the bond strength of smooth profiled bars and deformed bars was reduced approximately $50 \%$ and $35 \%$, respectively, due to the presence of oil. It was also noted that the presence of oil on concrete floor slabs over a prolonged period of time may eventually affect the bond properties of the reinforcement due to absorption of oil by the concrete.

\subsubsection{Nuclear Power Plant-Related Studies}

Although, as noted earlier, there have been several incidences where leakage of tendon sheathing filler have been observed on the outer concrete surfaces of the PCC, only one study has been identified related to this occurrence (14). In 1978 a study was conducted to investigate the cause of tendon sheathing filler leakage at the San Onofre Nuclear Generating Station. The occurrence of stains was observed on the exterior surface of the Unit 2 containment about three days after injection of the sheathing filler. Based on field observations and structural analysis, it was concluded that the leakage was due to the high fluidity of the sheathing filler (petroleumpetrolatum base product) at elevated temperatures, and the separation of oil from the petroleum waxes. The separated oil leaked from the tendon sheathing through non-leaktight sheathing couplers and spiral seams and migrated to the exterior PCC surface through cracks that were present in the concrete. The concrete cracks were thermally induced due to the generation of heat as the cement hydrated and subsequent cooling that produced a thermal gradient across the containment wall. Dead load effects and the post-tensioning process were not considered to have caused the concrete cracking. The study concluded that the presence of sheathing filler in the radial concrete cracks did not compromise the structural integrity of the PCC and the sheathing filler was non-reactive with the concrete. Also, as a result of the investigation the tendon sheathing filler being used was replaced with a current generation sheathing filler. No new exterior surface leakage has been detected since the product change.

\subsection{COMMENTARY}

Since their first use in the 1960's, there have been significant changes in the formulation of tendon sheathing fillers for application to nuclear power plant PCCs. Early applications utilized materials that contained low molecular weight sulfonate additives that were in use for many years in industrial products, but had not been formulated to provide specialized characteristics needed by the nuclear construction industry. As a consequence, these materials tended to have lower congealing points and viscosities, and the oil could separate from the microcrystalline waxes. Current generation casing fillers have modified the original additives by chemical reactions of organic and inorganic compounds with microcrystalline waxes and petroleum oils to provide a product specially formulated for the nuclear industry (8). These products have higher congealing points, improved water displacing characteristics, higher reserve alkalinity, lower tendency for oil separation (improved cohesiveness and plugging capability), capability for self healing, and a number of other desirable attributes. A review of the final safety analysis reports for the six plants noted in Section 1.1 indicates that all these plants initially used an early formulation of tendon sheathing filler (Visconorust $2090 \mathrm{P}$ from Viscosity Oil) that had a lower congealing point $\left(43^{\circ} \mathrm{C}\right.$ versus $57^{\circ} \mathrm{C}$ for current product) and a greater tendency for oil separation than the current generation product (Visconorust 2090P-4 from Viscosity Oil). No known incidences of leakage of tendon sheathing filler have occurred where the current formulation of tendon sheathing filler had been utilized. 
Although literature searches have identified several articles related to evaluation of the effects of organic-based materials on concrete, these studies generally involved the use of crude oil or lubricating oils. Natural oils and fats, or synthetic ester-based oils are known to cause damage to concrete (11). These materials have significantly different characteristics relative to the materials that are used as tendon sheathing fillers (e.g., sheathing fillers contain microcrystalline waxes plus additives). Also, the effects of these materials were most significant when elevated temperatures were present. No known studies have been identified that specifically address the interaction of tendon sheathing filler with concrete or the potential migration of tendon sheathing filler through concrete. 


\section{SAMPLE PROCUREMENT AND TESTING}

\subsection{BACKGROUND}

The Trojan nuclear power plant is owned by Portland General Electric Company (PGE) and is located about 42 miles north and east of Portland, Oregon (Fig. 1). The plant received its operating license on November 21, 1975 and formally began commercial operation on May 20, 1976. The architect-engineer for the plant was Bechtel Corporation. The containment is a Seismic Category I post-tensioned concrete structure in the shape of a cylinder with a hemispherical roof and a flat foundation slab. Dimensions of the containment are $37.8-\mathrm{m}$ (124-ft) inside diameter, 61.9-m (203-ft) inside height, $1.07-\mathrm{m}(3.5-\mathrm{ft})$ wall thickness and 0.74-m (2-ft 5.25-in.) dome thickness. Concrete materials used in fabrication of the containment had a design compressive strength at 28-days age of $41.4 \mathrm{MPa}(6000 \mathrm{psi})$. Concrete slump at point of placement was to be either 63.5 or $76.2 \mathrm{~mm}$ (2.5 or $3 \mathrm{in}$.) plus or minus $38.1 \mathrm{~mm}(1.5 \mathrm{in}$.$) . Two basic mix designs$ were utilized, one with a maximum aggregate size of $19.1 \mathrm{~mm}(0.75 \mathrm{in}$.$) and the other with a$ maximum aggregate size of $38.1 \mathrm{~mm}(1.5 \mathrm{in}$.). The smaller maximum size aggregate mix primarily was used in areas of steel reinforcement congestion. Appendix A provides more information on the concrete materials. Post-tensioning of the containment was provided by a BBRV (Prescon) prestressing system. Each tendon was composed of 180 stress-relieved, highstrength wires of 0.25-in diameter conforming to ASTM A-421 (21). The cylindrical portion was prestressed by a post-tensioning system consisting of horizontal and vertical tendons. The vertical tendons are anchored into the base slab and are continuous across the hemispherical dome (i.e., inverted-U). The dome has a two-way post-tensioning system consisting of hoop tendons and the continuous vertical tendons. There are three buttresses equally spaced around the containment. Hoop tendons are anchored at buttresses 240 degrees apart, bypassing the intermediate buttress. Each hoop tendon is progressively offset 120 degrees from the one beneath. The tendons are housed in spiral wrapped, semirigid, corrugated tubing [26-gage cold-rolled carbon steel conforming to ASTM A-366 (22) having an outside diameter of $13.3 \mathrm{~cm}$ (5.25 in.)]. A coupler of galvanized, semirigid, corrugated tubing $0.46-\mathrm{m}(1.5 \mathrm{ft})$ long was used to join the tubing to make it continuous. Leaktightness of the coupler during concrete placement and filling with corrosion inhibitor was provided by wrapping each joint with duct tape. Corrosion protection of the prestressing tendons prior to shipment was provided by a thin film of petrolatum containing rust inhibitors (e.g., Dearborn Chemical Co. Product No-Ox-Id 500). After post-tensioning, corrosion protection was provided by filling the tendon sheaths with Visconorust 2090P or 2090P-2 material $^{*}$ (Viscosity Oil Co.). Reinforcing steel used in the containment was Grade 60 [414 MPa $(60,000 \mathrm{psi})$ minimum yield strength) deformed billet steel conforming to ASTM A-615 (23). Figure 2 presents information on the reinforcing materials in the region where concrete test samples (i.e., cores) were obtained for examination and testing.

Leakage of corrosion inhibitor (i.e., tendon sheathing filler) from tendon sheaths has been noted at the Trojan post-tensioned concrete containment. The leakage became evident when sheathing filler streaks were observed on the outside surfaces of the concrete containment as shown in Fig. 3. The time when the leakage was first observed and the exact reasons for the grease leakage are uncertain. During site visits and obtaining test articles it was noted that a vertical crack was visible in the containment concrete over most, if not all, of the vertical tendons. Although the cause of the cracking was uncertain, it possibly could be attributed to loadings during the initial structural integrity test or subsequent integrated leakage-rate testing; however, the containment concrete is designed to remain in compression under these loading conditions. The cracks were most apparent in the region of the containment wall near the base where hoop tendons were not located (see Fig. 2). Constraint provided by the massive base mat as the containment was being post-tensioned probably contributed to cracking in this region. Concrete shrinkage also may

\footnotetext{
- According to the Trojan Final Safety Analysis Report, a few of tendon sheathings were injected with Visconorust 2090P materials and then the material was changed to Visconorust 2090P-2.
} 
have been a factor. Leakage of sheathing filler from the tendon conduits probably initiated when there was a breakdown in the seal (taped joint) between adjacent tendon sheaths (Fig. 4) due to the build-up of excessive pressure. Also, there is the possibility that the tendon sheathing could have been damaged during installation or construction. Although the exact cause of excessive pressure was not identified, possible sources could have been the result of either overpressurization or overfilling when the sheathing filler was initially installed or reinjected, hydrostatic pressure of the tendon sheathing filler, the effects of thermal gradients due to diurnal temperature change, or a combination of these potential causes. At injection the sheathing filler is generally heated to 71$88^{\circ} \mathrm{C}$ and at the Trojan Plant the filler was injected at about $689 \mathrm{kPa}(100 \mathrm{psi})$ measured at the anchorage inlet at the minimum injection temperature. As the sheathing filler cools after injection, it contracts leaving space for future expansion. Since it is thixotropic as a result of being composed of soft wax crystals that are very easily sheared, the tendon sheathing filler can flow easily. Also, some oil possibly may have separated from the product to exacerbate the problem. In order to study the migration of the tendon sheathing filler and its possible effects on the containment concrete, several concrete cores were obtained at different locations in the Trojan Plant containment exterior wall where tendon sheathing filler material had been observed.

\subsection{SAMPLING LOCATIONS}

Locations for obtaining concrete core samples were selected during a visit to the Trojan Nuclear Power Plant by NRC and ORNL personnel on August 7, 1996 (24). These locations are noted as "W," "X," "Y," and " $Z$ " in Fig. 5 which presents a plan view of the Trojan containment. The locations represent sites where corrosion inhibitor is visible on the containment surface and were selected on the basis of accessibility for coring and to provide specimens from areas of the containment that had slightly different diurnal effects due to exposure to the sun. Redundancy also was included in the selection of coring sites. Figure 6 shows leakage of tendon sheathing filler that has occurred at locations "W," "X," "Y," and " $\mathrm{Z}$ " prior to conduction of nondestructive examinations and coring. Additional locations where leakage of tendon sheathing filler was observed and their relative position in the containment are presented in Fig. 7.

\subsection{NONDESTRUCTIVE EXAMINATIONS}

A limited number of nondestructive examinations were performed prior to coring operations using the standard method for obtaining rebound number of hardened concrete (25). The purpose of these examinations was to evaluate the potential of this method to both detect the presence of tendon sheathing filler in concrete and its effect on the mechanical strength of the concrete, if any.

Prior to obtaining the rebound numbers, a grid was marked on the exterior concrete surface at each of the four sampling locations. Each grid was located so that it was aligned with the longitudinal direction of the containment wall (i.e., crack direction) and centrally located horizontally (i.e., hoop direction of containment) over the apparent primary crack from which the tendon sheathing filler was leaking. Figure 8 presents the grid that was used for location " $X$ ". Each subsection of the grid (e.g., A-B:1-2) represents an area $30.5 \mathrm{~cm}$ (12 in.) square.

After marking the grid at a location, rebound number measurements were obtained using the procedure described in Appendix B. A total of ten rebound number measurements were made in each subsection of the grid to provide a total of 300 measurements. The rebound hammer was impacted normal to the containment wall as shown in Fig. 9. If the rebound hammer measurements were obtained in an area where it was obvious that tendon sheathing filler was present, a note was made on the data sheet. Generally, in subsections where tendon sheathing filler was present on the concrete surface, six readings were obtained outside the stained region and 
four readings were obtained directly over the stained region. This procedure was then repeated at the other three locations.

\subsection{CONCRETE CORING AND SHIPPING}

After completion of the nondestructive examinations, a covermeter survey was conducted at each of the four sampling locations in an attempt to indicate steel reinforcement locations and orientations in the $\mathrm{X}-\mathrm{Y}$ plane of the containment wall. Appendix $\mathrm{C}$ presents the procedure that was used for conducting the covermeter survey and Fig. 10 shows a covermeter survey being conducted. Indicated locations of the longitudinal and circumferential reinforcement were marked with crayon on the containment wall.

Following the covermeter survey, concrete coring was initiated in accordance with guidance provided in ASTM C-42 (26). Initially a 152-mm (6-in.) diameter (nominal) core bit was utilized and locations were selected on the basis of the covermeter survey results. Figure 11 presents the equipment used to core the concrete. Unfortunately the effectiveness of the covermeter in locating the mild steel reinforcement was compromised because of the large amount of steel reinforcement contained in the containment wall (Fig. 12) and the depth of concrete cover over the reinforcement (i.e., $\geq 50.8 \mathrm{~mm}$ ). After several attempts at obtaining a concrete core that did not contain either mild steel reinforcement or other embedments (e.g., form tie-related materials), the size of the core bit was reduced to $127-\mathrm{mm}$ (5-in.) diameter (nominal). ${ }^{* *}$ Also, subsequent coring locations were selected using a combination of covermeter results and results of previous coring operations at the location (i.e, when the core bit encountered an embedment the coring process was halted, the concrete core removed, and the embedment orientation noted and marked on the containment wall). After obtaining a concrete core from the containment wall suitable for testing, the specimen was marked according to location from which it was obtained and its relative position in the coring sequence at the location (e.g., W-10). Figures 13-16 show the positions from which cores were obtained at locations " $W$ ", " $X$ ", "Y", and " $Z$ ", respectively. Specimen identification and type of loading performed on the core (i.e., splitting-tensile or compression) are also shown in the figures. Positions where attempts at obtaining a core sample were unsuccessful are also shown in the figures. Upon completion of all coring operations, the cores were sealed in plastic bags that were then placed into plywood boxes and shipped to ORNL for examination and testing.

\subsection{SPECIMEN PREPARATION}

A total of 54 concrete core specimens ( 40 uncracked and 14 cracked), primarily $127-\mathrm{mm}$ (5-in.) in diameter (nominal), were received from the Trojan Plant. After taking photographs of the specimens (Figs. 17-20), each specimen was sawn to obtain a test article that had relatively smooth ends that were perpendicular to the longitudinal axis (Fig. 21). Depending on the location from which a specimen was obtained (e.g., area with or without tendon sheathing filler present) and somewhat on the length of the core provided, a specimen was allocated either for compressive loading, splitting-tensile loading, or examination for tendon sheathing filler migration. Twenty-

\footnotetext{
'At each location except location " $Z$ " the presence of tendon sheathing filler was primarily in the form of concrete surface staining. However, at location " $Z$ " the leakage and thickness of tendon sheathing filler present on the concrete surface appeared to be greater than at the other three locations. In order to indicate the effect of a finite layer of tendon sheathing filler on the rebound number results, two sets of readings were taken. The initial set of readings was taken with the tendon sheathing filler in the "as-found" condition. The rebound number measurements were then repeated after the finite layer of tendon sheathing filler had been scraped from the concrete surface.

" Although it would have been easier to obtain concrete cores without steel embedments using a smaller diameter core bit, Reference 26 notes that the diameter of the test specimens should preferably be a least three times the nominal maximum size of coarse aggregate used in construction. A 38.1-mm (1.5-in.) maximum nominal size of coarse aggregate was used at the Trojan Plant so the preferable minimum core diameter was $114-\mathrm{mm}$ ( $4.5 \mathrm{in}$.).
} 
four of the specimens were used for compressive strength testing, twelve for splitting-tensile strength testing, and nine to determine the extent of tendon sheathing filler migration. Five specimens containing cracks were loaded in compression to failure to determine the effect of the presence of a crack with tendon sheathing filler on the fracture mode. The remaining four specimens were not suitable for testing either due to the presence of embedded steel reinforcement or being of inadequate length (i.e., X-2, X-7, Y-1, and Y-14). Specimens loaded in compression were capped with a high-strength capping compound prior to testing to provide parallel and plane ends (Fig. 22).

\subsection{SPECIMEN TESTING}

\subsubsection{Uncracked Specimens}

\subsubsection{Compressive strength testing}

Compressive strength tests were conducted in accordance with ASTM C-39 (27). The test procedure used to determine the compressive strength of each specimen consisted of (1) measuring the length and diameter at several locations to obtain average values, (2) centering the longitudinal axis of the capped specimen on the lower bearing platen of the testing machine, (3) checking alignment so that the axis of the specimen coincided with the center of thrust of the spherically-seated upper platen, (4) loading the specimen in compression, and (5) recording the maximum load that the specimen was able to withstand. Figure 23(a) presents a test specimen positioned in the testing machine just prior to testing. The compressive strength was determined from

$$
C=4 \mathrm{P} /\left(\pi \mathrm{D}^{2}\right)
$$

where

$$
\begin{aligned}
& \mathrm{C}=\text { compressive strength, psi }(\mathrm{kPa}) \\
& \mathrm{P}=\text { maximum applied load indicated by testing machine, } \mathrm{lbf}(\mathrm{kN}) \text {, and } \\
& \mathrm{D}=\text { diameter, in. }(\mathrm{mm}) .
\end{aligned}
$$

If the specimen length to diameter ratio (L/D) was less than 2.0 , the compressive strength value obtained from Eqn. (3.1) was adjusted by multiplying the result by the appropriate correction factor obtained from Ref. 27.

\subsubsection{Splitting-tensile strength testing}

Splitting-tensile tests were conducted in accordance with ASTM C-496 (28) to determine the splitting-tensile strength of uncracked specimens. The test procedure consisted of (1) measuring the length and diameter at several locations to obtain average values, (2) marking diametrical lines on the specimen that were in the same axial plane, (3) centering a masonite bearing strip on the lower bearing block, (4) placing the specimen longitudinally on the masonite strip and aligning it so that the ends of the diametrical lines were vertical and aligned over the strip, (5) placing a second masonite strip on top of the specimen and aligning the specimen so that the ends of the diametrical lines were vertical and their plane of projection intersected the center of the upper bearing plate, (6) loading the specimen in compression, and (7) recording the maximum load that the specimen was able to withstand. Figure 24(a) presents a test specimen positioned in the test fixture just prior to testing. The splitting-tensile strength was determined from

$$
\mathrm{T}=2 \mathrm{P} /(\pi \mathrm{DL})
$$

where 


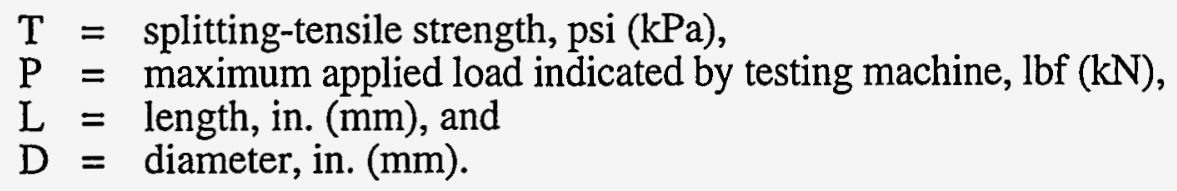

\subsubsection{Cracked Specimens}

Five of the fourteen specimens obtained from locations directly over a vertical concrete crack containing tendon sheathing filler were loaded in compression (i.e., specimens $\mathrm{W}-1, \mathrm{~W}-2$, $\mathrm{Z}-1, \mathrm{Z}-2$, and Z-3). The purpose of this loading was to determine the combined effect of the crack and tendon sheathing filler on the fracture mode of concrete tested in uniaxial compression. The crack contained in these specimens essentially formed a vertical diametrical plane that was approximately oriented in the direction of the specimen longitudinal axis (i.e., loading axis). The specimens were tested by loading in compression until fracture occurred. The fracture mode was then noted. Figure 23(b) presents a cracked test specimen positioned in the testing machine just prior to loading.

The remaining nine specimens obtained from locations directly over a vertical concrete crack that contained tendon sheathing filler (e.g., specimens $X-1$ and $X-5$ in Fig. 14) were examined to determine the extent of tendon sheathing filler migration into the concrete. In order to do this the specimens were first split diametrically perpendicular to the existing crack plane. This was accomplished using essentially the same procedure as for the splitting-tensile strength tests. Prior to loading, each specimen was positioned in the test fixture so that the crack containing the tendon sheathing filler was aligned essentially perpendicular to the loading axis as shown in Fig. 24(b). The specimens were then loaded in compression until fracture occurred. At conclusion of each test, the fracture surface was examined visually to determine the extent of tendon sheathing filler migration into the concrete. An indicator containing a number of phenolphthaleins indicating different $\mathrm{pH}$-values was then sprayed onto the fracture surface as an optical aid. Fracture surfaces of the concrete that were uncontaminated by the tendon sheathing filler turned purple in color ( $\mathrm{pH} \geq 11$ ) after spraying whereas the locations containing tendon sheathing filler did not experience this color change. 



\section{TEST RESULTS}

Three basic types of tests or examinations were conducted on the concrete cores obtained from the Trojan Plant containment: rebound number measurements, strength determinations (i.e., splitting-tensile and compressive), and visual examinations. The objectives of these examinations and tests were to indicate the extent of tendon sheathing filler migration into the concrete, and to determine its potential effects on concrete strength properties.

\subsection{REBOUND NUMBER MEASUREMENTS}

At least 300 rebound number determinations of the hardened concrete were obtained at each of the four locations selected for concrete coring. A total of 10 determinations were made in each of the 30 subsections of the grid at a location as noted in Section 3.3. An average rebound number was then calculated for each subsection, with readings that differed from the average of the 10 readings by more than 7 discarded. Figures $25-28$ present the rebound hammer results for locations "W", "X", "Y", and "Z", respectively. Contained in each of these figures is the overall average rebound number for each grid subsection, as well as an average rebound number for determinations that were made in areas where tendon sheathing filler or a concrete patch was present.

As noted in Figs. 25-28, the average rebound number from location to location in areas below the construction joint where tendon sheathing filler was not visible was relatively consistent (i.e., 52.1, 53.0, 52.8, and 52.3 at locations "W", "X", "Y", and "Z", respectively). Also, the range in average rebound numbers from subsection to subsection obtained at each location was relatively consistent (i.e., 7.5, 5.0, 6.9, and 6.8 at locations "W", " $\mathrm{X}$ ", "Y", and " $\mathrm{Z}$ ", respectively). These results indicate that the quality of the concrete was relatively consistent at each of the locations as well as from location to location. No quantitative results relative to the strength of the concrete could be derived because not enough concrete core samples were obtained to develop the required correlation curve between rebound number and concrete compressive strength.

The effect of the tendon sheathing filler on the rebound number results is also noted in Figs. 25-28. The average rebound number from location to location in areas below the construction joint where tendon sheathing filler was visible was relatively consistent (i.e., 50.2, $52.2,51.3$, and $48.0^{*}$ at locations " $\mathrm{W}$ ", "X", " $\mathrm{Y}$ ", and " $\mathrm{Z}$ ", respectively). Also, the range in average rebound numbers from subsection to subsection (i.e., 3.8, 1.1, 4.9, and 7.5 at locations "W", "X", "Y", and "Z", respectively) obtained at each location where tendon sheathing filler was present was somewhat lower than the corresponding range for areas where tendon sheathing filler was absent. However, the data sets from which these averages were determined was limited. In general, average rebound numbers obtained at each location from a subsection having areas where tendon sheathing filler was visible were consistently lower than corresponding values obtained from unaffected areas (i.e., 50.2 Vs $52.1,52.2$ Vs $53.0,51.3$ Vs 52.8 , and 48.0 Vs 52.3 at locations "W", "X", "Y", and "Z", respectively). Differences in average rebound numbers between areas exhibiting tendon sheathing filler and those unaffected were relatively small (i.e., generally less than two rebound numbers). Since these differences in rebound numbers are relatively small compared to the range of values that were obtained from subsection to subsection at each location, determination of the presence of tendon sheathing filler based on rebound hammer numbers alone would be difficult.

\footnotetext{
"As noted in Section 3.3, a second set of rebound numbers was obtained in areas at location " $\mathrm{Z}$ " where the tendon sheathing filler was present after the excess tendon sheathing filler had been scraped from the concrete surface. The average rebound number based on these results was 50.6. Also, the range in rebound numbers changed from 7.5 to 5.0 .
} 
As noted previously, a companion set of rebound numbers was obtained at location " $Z$ " after scraping the concrete with a shovel to remove excess material in order to indicate the effect on rebound number results of tendon sheathing filler thickness. Figure 29 presents the comparison of rebound number values before and after removal of excess tendon sheathing filler. The results show that the thickness of the tendon sheathing filler does affect the rebound number (i.e., the rebound number was reduced in magnitude by up to eight due to the presence of increased thickness of tendon sheathing filler). This result is expected because the test is based on the rebound distance of a spring-loaded hammer on the concrete surface. Reference 25 notes the importance of proper preparation of the concrete surface prior to conducting the test. The revised numbers also were more consistent with values obtained at other locations where tendon sheathing filler was present.

When conducting rebound number testing at location " $Y$ " it was observed that there were two areas of the grid where the concrete had been repaired by patching (i.e., subsections GH-12 and JK-12 in Fig. 27). A comparison of average rebound numbers obtained from repaired areas with those obtained from areas that had not required repair shows that the rebound numbers obtained for the repaired areas were lower. Also, the rebound numbers for the repaired areas generally were lower than those obtained in areas of the grid where tendon sheathing filler was present. The low results may indicate that either a material of lower hardness (e.g., quality) had been used for repair or there may have been some delamination of the repair from the host concrete, although there was no audible indication of a delamination present when the test was conducted.

\subsection{STRENGTH DETERMINATIONS}

Either compressive or splitting-tensile strength tests were conducted on uncracked concrete cores obtained from the Trojan Plant. Test results are provided for each of the four locations where concrete cores were removed from the containment. A search of the plant Final Safety Analysis Report indicated that both mixes E-1 and E-2 were used in the fabrication of the containment wall between elevations $44 \mathrm{ft}$ and $54 \mathrm{ft}$ where most of the concrete cores were obtained. Generally it appears as if mix E-1 (19.1 mm maximum size aggregate) was used in the lower part of the containment wall where the steel reinforcement was the most congested. However, this may not have always been true because specimens obtained at location "W" all appeared to contain the larger maximum size aggregate. Although each specimen was examined after testing and the apparent largest maximum size aggregate present noted, there still was some uncertainty associated with the mixes for a few specimens: Included with results provided below is an estimate of the concrete mix (i.e., E-1 or E-2 ) that was used in the part of the containment where the specimen was obtained.

\subsubsection{Compressive Strengths}

Twenty-four tests were conducted on uncracked specimens obtained from regions of the Trojan Plant containment where tendon sheathing filler was present. The primary purpose of these tests was to determine if the compressive strength of the concrete at the Trojan Plant had been affected by the presence of tendon sheathing filler in its vicinity. Table 1 presents a summary of the results obtained from the compressive strength tests. Contained in the table are the specimen dimensions, the maximum load that could be applied to the specimen, and the compressive strength values.

Compressive strength values obtained from specimens cast from mix E-2 ranged from $51.5 \mathrm{MPa}$ (7470 psi) to $65.8 \mathrm{MPa}(9550 \mathrm{psi})$, with an overall average of $59.4 \mathrm{MPa}(8610 \mathrm{psi})$. The average compressive strength was consistent from location to location, being $60.3 \mathrm{MPa}$ (8745 psi), 60.0 MPa (8705 psi), 60.3 MPa (8740 psi), and 57.0 MPa (8270 psi), at locations "W", "X", "Y", and " $Z$ ", respectively. Relative to the average compressive strength for mix E-2 at 
28-days age [42.3 $\mathrm{MPa}(6140 \mathrm{psi})$ ], the strength of the concrete at age 25.4 years had increased over $40 \%$. Compared to the 90-day reference average compressive strength $49.5 \mathrm{MPa}$ (7185 psi)], the average compressive strength of mix E-2 had increased about $20 \%$ at age 25.4 years. The increase in strength from 28-days age to 90-days age was about $17 \%$. Figure 30 shows that the change in compressive strength with age obtained from testing specimens from the Trojan Plant was consistent with that obtained from other U.S. nuclear power facilities.

\subsubsection{Splitting-Tensile Strengths}

Twelve tests were conducted on uncracked specimens obtained from regions of the Trojan Plant containment where tendon sheathing filler was present. The primary purpose of these tests was to determine if the splitting-tensile strength (and indirectly the shear strength) of the concrete at the Trojan Plant had been affected by the presence of tendon sheathing filler. Nine of these specimens were selected for splitting-tensile strength testing on the basis that their length-todiameter ratio was less than 1.3 and would require application of a significant correction factor (see Section 3.6.2) if they were tested to determine compressive strength. The three remaining specimens were selected to provide an indication of the splitting-tensile strength of the concrete using a more conventional size specimen (i.e., length-to-diameter ratio of $\sim 1.5$, or greater). Table 2 presents a summary of the results obtained from the splitting-tensile strength tests. Contained in the table are the specimen dimensions, the maximum load that could be applied to the specimen, and the splitting-tensile strength values.

Splitting-tensile strength values obtained from specimens cast from mix E-1 ranged from $2.85 \mathrm{MPa}$ (413 psi) to $4.49 \mathrm{MPa}$ (651 psi), whereas values obtained from specimens cast from mix E-2 ranged from 3.30 $\mathrm{MPa}(478 \mathrm{psi})$ to $4.55 \mathrm{MPa}(660 \mathrm{psi})$. Average values for mix E-1 results and mix E-2 results were comparable, being 3.67 $\mathrm{MPa}$ (532 psi) and 4.07 $\mathrm{MPa}$ (589 psi), respectively. Although the data are extremely limited and thus of no statistical significance, results from locations "W" ( 4 specimens) and " $Y$ " (two specimens), where mix E-2 was utilized, seem to indicate consistency in the concrete materials from location to location where the same mix was utilized [i.e., average splitting-tensile strengths at location " $\mathrm{W}$ " and "Y" were $3.99 \mathrm{MPa}$ (579 psi) and 4.14 $\mathrm{MPa}$ (600 psi), respectively] . Only one location, "X", had results for more than one specimen from mix E-1, so no inference can be derived relative to the consistency of this mix from location to location. Although no historical splitting-tensile strength data are available to indicate the change in splitting-tensile strength with time, the results obtained from mix E-2 specimens are typical of what would be expected based on prior rèsearch investigating the relationship between splitting-tensile strength and compressive strength (29).

\subsection{Visual Examinations}

As noted in the previous chapter, fourteen of the concrete cores from the Trojan Plant were obtained from locations directly over concrete cracks that contained tendon sheathing filler. Five of the specimens were loaded to fracture using the procedure described in Section 3.6.1.1. The nine remaining specimens were loaded to fracture (i.e., split) using the procedure described in Section 3.6.1.2. Tables 3 and 4 identify the specimens that were tested using the splitting-tension and compression procedures, respectively. For completeness, the specimen dimensions and maximum applied loads also are provided in the tables; however, valid strength values can not be determined for these specimens because of the presence of the crack and tendon sheathing filler.

After fracturing the five specimens by means of loading in uniaxial compression, the mode of fracture was examined. Figure 31 presents photos of specimens W-1 and W-2 before and after loading in compression. Similarly, Fig. 32 presents photos before and after compressive loading of specimens Z-1, Z-2, and Z-3. Comparison of results presented in Figs. 31 and 32 with a typical "cone or hourglass" fracture of concrete tested in compression (shown in Fig. 33) indicates that the specimens containing a crack with tendon sheathing filler tended to exhibit a 
preferential fracture related to the presence of the crack. Depending on the positioning of the crack, the fracture mode tended to shift toward shear, columnar, or a combination of these modes.

After fracturing the remaining nine specimens by means of the splitting-tension procedure, the separated surfaces were examined to determine the extent of migration of the tendon sheathing filler into the concrete (i.e., perpendicular to the initial crack). Following initial visual examinations, an indicator containing a number of phenolphthaleins indicating different $\mathrm{pH}$-values was sprayed onto the fracture surfaces as an optical aid. Fracture surfaces of the concrete that were uncontaminated by the tendon sheathing filler turned purple in color after spraying (i.e., $\mathrm{pH} \geq 11$ ) whereas the locations containing tendon sheathing filler did not experience this color change. Figures 34 and 35 present examples of fracture surfaces after loading to failure using the splittingtensile procedure. Visual examinations of each of the specimens listed in Table 4, both before and after application of the optical aid, indicated that the tendon sheathing filler did not penetrate the concrete to any perceptible depth. There was no apparent difference in the observed tendon sheathing filler presence due to either location (i.e., " $\mathrm{X}$ ", "Y", or " $\mathrm{Z}$ "), or elevation in the containment (e.g., specimen X-1 versus specimen X-6). These results indicate that the primary path of migration of the tendon sheathing filler was essentially confined to the cracks that formed over the vertical prestressing tendon. As noted in Fig. 3, there also was some migration of tendon sheathing filler through horizontal cracks that formed due to effects such as concrete shrinkage. Since the tendon sheathing filler is thixotropic as a result of being composed of soft wax crystals that are very easily sheared, the tendon sheathing filler can flow easily and thus confined itself to the cracks in the concrete where the resistance to flow was lowest. As noted by Trojan Plant personnel, the leakage of tendon sheathing filler appeared to increase after the containment posttensioning system had been detensioned. 


\section{SUMMARY, CONCLUSIONS, AND OBSERVATIONS}

\section{$5.1 \quad$ SUMMARY}

Tendon sheathing filler in the form of streaks has been observed on the outer surfaces of several post-tensioned concrete containment structures of U.S. commercial nuclear power plants. This investigation was conducted to provide an indication if migration of the tendon sheathing filler through the concrete has an effect on the concrete properties that could affect the containment structural capacity. Pertinent literature were reviewed relative to the effect of tendon sheathing filler intrusion on concrete mechanical properties. Also, a limited nondestructive examination was conducted and concrete core samples were obtained from the Trojan Nuclear Plant and tested to determine the extent of tendon sheathing filler migration into the concrete, and the concrete tensile and compressive strengths.

\subsection{CONCLUSIONS}

Based on results of this limited study several general conclusions can be derived:

- $\quad$ Review of the Final Safety Analysis Reports of six plants that had experienced leakage of tendon sheathing filler onto the concrete surface indicates that all these plants initially used early formulations of the tendon sheathing filler. These early formulations have a lower congealing point and a greater tendency for oil separation than the current generation product. In at least one plant where the older tendon sheathing filler had been replaced with the current generation product the leakage has ceased. No known incidences of leakage of tendon sheathing filler have been identified where the current formulation of tendon sheathing filler has been utilized. These results indicate that the older plants that have used the initial formulations of the tendon sheathing filler have a greater potential for leakage.

- Although a review of literature identified several articles on the effects of organicbased materials on concrete, these studies generally involved the use of crude or lubricating oils that are known to cause damage to concrete, particularly at elevated temperature. However, these materials have significantly different characteristics relative to the materials that are used as tendon sheathing fillers (e.g., sheathing fillers contain microcrystalline waxes plus additives). The only identified study that specifically addressed the leakage of tendon sheathing filler into the concrete at a nuclear power plant containment was conducted about 20 years ago to investigate staining of the outer containment surface at the San Onofre Nuclear Generating Station. The study concluded that the presence of sheathing filler in the radial concrete cracks did not compromise the structural integrity of the containment and the sheathing filler was non-reactive with the concrete. As a result of this investigation, the tendon sheathing filler being used was replaced with a current generation tendon sheathing filler (e.g., higher congealing point, higher viscosity, and lower tendency for oil separation). No new exterior surface leakage has been reported since the product change. No known studies have been identified that specifically address the interaction of tendon sheathing filler with concrete or the potential migration of tendon sheathing filler through concrete.

- Nondestructive examinations conducted in the form of rebound hammer number determinations indicate that the quality of the concrete was relatively consistent at each of the four locations investigated at the Trojan Plant. Also, the concrete quality was consistent from location to location. No quantitative results relative to the strength of the concrete could be derived from the rebound numbers because insufficient concrete core samples had been obtained to develop the required 
correlation curve between rebound number and concrete compressive strength. Differences in average rebound numbers between areas that had experienced leakage of tendon sheathing filler and those unaffected were relatively small, especially when compared to the range of values that were obtained from subsection to subsection at each location. Determination of the presence of tendon sheathing filler based on rebound hammer number results does not appear to be feasible. The only significant difference in rebound numbers between areas with and without tendon sheathing filler was obtained where there was a relatively thick layer of tendon sheathing filler on the concrete surface. Visual inspections are most effective for detection of the presence of tendon sheathing filler.

- Examination of concrete core samples removed from the containment at the Trojan Plant indicated that the appearance of tendon sheathing filler on the concrete surface was due to leakage of the filler from the conduits and its subsequent migration to the concrete surface through cracks. Migration of the tendon sheathing filler was confined to the crack and there was no perceptible movement into the concrete. Also, there were no visible indications of chemical interactions between the tendon sheathing filler and the concrete (i.e., absence of concrete spalling and pattern cracking). These results also indicate that there should be no migration of the tendon sheathing filler along the interface between the concrete and mild steel reinforcement unless the interface region has been degraded due to the presence of a crack or corrosion products.

- Results of compressive strength tests performed on several uncracked concrete cores obtained from regions of the containment near observable tendon sheathing filler leakage indicated that the concrete quality was consistent in the containment and that the concrete compressive strength had increased over $40 \%$ in 25.4 years relative to the average compressive strength at 28-days age. This increase in compressive strength with age was consistent with that observed from specimens obtained from several other U.S. nuclear power facilities.

\subsection{OBSERVATIONS}

As results presented are only for one plant, additional plants that had experienced leakage of tendon sheathing filler could be examined. These examinations could be conducted to demonstrate that the migration of the tendon sheathing filler was always through cracks that are present and that no perceptible movement of the tendon sheathing filler into the concrete has occurred (i.e., primarily an aesthetic or maintenance, rather than a potential structural problem). A limited number of small cores could be taken in the cover concrete over areas where tendon sheathing filler is present to investigate the extent of tendon sheathing filler migration into the concrete. These areas would be repaired after coring. Also, the plants could be compared to determine if there are any trends as to why certain plants had experienced leakage of tendon sheathing filler and others did not (e.g., Is it due to the plant design, technique for coupling tendon conduits, or use of certain tendon sheathing fillers?). These results could provide additional data to further demonstrate that tendon sheathing filler does not migrate into the concrete to affect its properties.

Specific evaluation of the effect of the cracks with (or without) tendon sheathing filler on the structural performance of the Trojan Plant containment under postulated accident conditions was beyond the scope of this limited study. Also, no attempt was made in this study to investigate the potential impact of the presence of tendon sheathing filler on the bond between the concrete and steel reinforcement, or to correlate results to shear behavior. A factor that may tend to mitigate the potential significance of a crack with tendon sheathing filler on a containment structural response is the large quantity of steel reinforcement present in the containment (see Fig. 12). 


\section{REFERENCES}

1. H. Ashar, D. J. Naus and C. P. Tan, "Prestressed Concrete in U. S. Nuclear Power plants: Part 1," Concrete International 16(5), pp. 30 - 34, American Concrete Institute, Detroit, Michigan (May 1994).

2. H. Ashar, C. P. Tan and D. J. Naus "Prestressed Concrete in U. S. Nuclear Power plants: Part 2," Concrete International 16(6), pp. 58 - 61, American Concrete Institute, Detroit, Michigan (June 1994).

3. J. Dougan, "Evaluation of In-Service Inspections of Greased Prestressing Tendons," NUREG/CR-2719 (ORNL/TM-8278), Oak Ridge National Laboratory, Oak Ridge, Tennessee (September 1980).

4. D. J. Naus, Concrete Component Aging and Its Significance Relative to Life Extension of Nuclear Power Plants, NUREG/CR-4652 (ORNL/TM-10059), Martin Marietta Energy Systems, Inc., Oak Ridge National Laboratory (September 1986).

5. D. J. Naus, C. B. Oland and B. R. Ellingwood, Report on Aging of Nuclear Power Plant Reinforced Concrete Structures, NUREG/CR-6424 (ORNL/TM-13148)), Lockheed Martin Energy Research Corp., Oak Ridge National Laboratory, Oak Ridge, Tenn. (March 1996).

6. "Inservice Inspection of Ungrouted Tendons in Prestressed Concrete Containment Structures," Regulatory Guide 1.35 (Rev. 3), Office of Standards Development, U.S. Nuclear Regulatory Commission, Washington, D.C. (July 1990).

7. H. Ashar and G. Bagchi, Assessment of Inservice Conditions of Safety-Related Nuclear Plant Structures, NUREG-1522, Office of Nuclear Reactor Regulation, U.S. Nuclear Regulatory Commission, Washington, D.C. (June 1995).

8. "VISCONORUST 2090P-4 Casing Filler," Technical Specifications, Viscosity Oil Company, Willowbrook, Illinois (August 19, 1996).

9. D. J. Naus, An Evaluation of the Effectiveness of Selected Corrosion Inhibitors for Protection of Prestressing Steels in PCPVs, ORNL/TM-6479, Oak Ridge National Laboratory, Oak Ridge, Tenn. (March 1979).

10. L. T. Phan and N. J. Carino, Effects of Tendon Grease Leakage on the Integrity of Prestressed Concrete Containment, Interagency Agreement No. NRC-03-93-038, National Institute of Standards and Technology, Gaithersburg, Maryland (March 1993).

11. ACI Committee 515, "A Guide to the Use of Waterproofing, Dampproofing, Protective, and Decorative Barrier Systems for Concrete," Part 5, ACI Manual of Concrete Practice, American Concrete Institute, Farmington Hills, Michigan (1985).

12. M. McVay, J. Rish III, C. Sakezles, S. Mohseen, and C. Beatty, Cements Resistant to Synthetic Oil, Hydraulic Fluid, and Elevated Temperature Environments, ACI Materials Journal 92(2), pp. 155-163, American Concrete Institute, Farmington Hills, Michigan (March-April 1995).

13. F. G. Murphy, A Survey of Literature on the Effect of Contamination (Other than Rust) on the Bond Strength of Reinforcement, Technical Note 86, Construction Industry Research and Information Association, London, England (November 1977). 
14. D. L. Houghton, San Onofre Nuclear Generating Station Unit 2 Containment - Report on Exterior Dome Surface Leakage of Sheathing Filler Material, Bechtel Power Corporation, San Francisco, California (1978).

15. O. A. Onabolu, "Some Properties of Crude-Oil Soaked Concrete - I. Exposure at Ambient Temperature," ACI Materials Journal 86(2), pp. 150-158, American Concrete Institute, Farmington Hills, Michigan (March-April 1989).

16. O. A. Onabolu, "Some Properties of Crude-Oil Soaked Concrete - II. Exposure at Elevated Temperatures," ACI Materials Journal 86(3), pp. 205-213, American Concrete Institute, Farmington Hills, Michigan (May-June 1989).

17. M. McVay, L. D. Smithson and C. W. Mazione, "Chemical Damage to Airfield Concrete Aprons from Heat and Oils," ACI Materials Journal 90(3), pp. 253-258, American Concrete Institute, Farmington Hills, Michigan (May-June 1993).

18. M. McVay, C. W. Mazione and J. Murfee, Damage to Aircraft Parking Ramps from Jet Oils and Auxiliary Power Units, paper prepared for presentation at Annual Meeting of the Transportation Research Board, Washington, D.C. (January 1993).

19. M. A. Matti, "Effect of Oil Soaking on the Dynamic Modulus of Concrete," International Journal of Cement Composites and Lightweight Concrete 5(4), pp. 277-282 (November 1983).

20. F. I. Faiyadh, "Bond Characteristics of Oil Saturated Concrete," International Journal of Cement Composites and Lightweight Concrete 7(2), pp. 115-131 (May 1985).

21. "Uncoated Stress-Relieved Steel Wire for Prestressed Concrete," ASTM A 421, Annual Book of ASTM Standards, American Society for Testing and Materials, West Conshohocken, Pennsylvania (1989).

22. "Standard Specification for Steel, Sheet, Carbon, Cold-Rolled, Commercial Quality," ASTM A 366, Annual Book of ASTM Standards, American Society for Testing and Materials, West Conshohocken, Pennsylvania (1989).

23. "Deformed and Billet-Steel Bars for Concrete Reinforcement," ASTM A 615, Annual Book of ASTM Standards, American Society for Testing and Materials, West Conshohocken, Pennsylvania (1989).

24. C. B. Oland, Report of Trip to Trojan Nuclear Plant, Oak Ridge National Laboratory, Oak Ridge, Tennessee (August 15, 1996).

25. "Standard Test Method for Rebound Number of Hardened Concrete," ASTM C 805, Annual Book of ASTM Standards, American Society for Testing and Materials, West Conshohocken, Pennsylvania (1989).

26. "Standard Test Method for Obtaining and Drilling Cores and Sawed Beams of Concrete," ASTM C 42, Annual Book of ASTM Standards, American Society for Testing and Materials, West Conshohocken, Pennsylvania (1989).

27. "Standard Test Method for Compressive Strength of Cylindrical Concrete Specimens," ASTM C 39, Annual Book of ASTM Standards, American Society for Testing and Materials, West Conshohocken, Pennsylvania (1989). 
28. "Standard Test Method for Splitting Tensile Strength of Cylindrical Concrete Specimens," ASTM C 496, Annual Book of ASTM Standards, American Society for Testing and Materials, West Conshohocken, Pennsylvania (1989).

29. P. K. Mehta, Concrete - Structure, Properties, and Materials, Prentice-Hall, Inc., Englewood Cliffs, New Jersey (1986). 

Table 1

Compressive Strength Results

(Uncracked Specimens)

\begin{tabular}{|c|c|c|c|c|c|}
\hline $\begin{array}{l}\text { Specimen } \\
\text { Number }\end{array}$ & $\begin{array}{l}\text { Concrete } \\
\text { Mix* }^{*}\end{array}$ & $\begin{array}{l}\text { Average } \\
\text { Length, } \\
\text { mm }\end{array}$ & $\begin{array}{c}\text { Average } \\
\text { Diameter, } \\
\text { mm }\end{array}$ & $\begin{array}{l}\text { Maximum } \\
\text { Applied } \\
\text { Load, } \\
\text { kN }\end{array}$ & $\begin{array}{c}\text { Compressive } \\
\text { Strength,** } \\
\mathrm{MPa}\end{array}$ \\
\hline $\begin{array}{l}W-3 \\
W-4 \\
W-7 \\
W-9 \\
W-10\end{array}$ & $\begin{array}{l}\text { E-2 } \\
\text { E-2 } \\
\text { E-2 } \\
\text { E-2 } \\
\text { E-2 }\end{array}$ & $\begin{array}{l}245.1 \\
250.8 \\
257.6 \\
254.8 \\
257.6\end{array}$ & $\begin{array}{l}118.7 \\
118.6 \\
118.7 \\
118.8 \\
118.8\end{array}$ & $\begin{array}{l}677.2 \\
650.5 \\
658.3 \\
671.6 \\
678.3\end{array}$ & $\begin{array}{l}61.2 \\
58.9 \\
59.5 \\
60.6 \\
61.2\end{array}$ \\
\hline $\begin{array}{l}X-8 \\
X-9 \\
X-11 \\
X-12 \\
X-13 \\
X-14 \\
X-15 \\
X-16\end{array}$ & $\begin{array}{l}\text { E-2 } \\
\text { E-2 } \\
\text { E-2 } \\
\text { E-2 } \\
\text { E-2 } \\
\text { E-2 } \\
\text { E-2 } \\
\text { E-2 }\end{array}$ & $\begin{array}{l}257.8 \\
244.7 \\
223.9 \\
216.5 \\
257.4 \\
255.1 \\
258.4 \\
214.6\end{array}$ & $\begin{array}{l}118.4 \\
118.4 \\
118.3 \\
118.5 \\
118.4 \\
118.5 \\
118.6 \\
118.7\end{array}$ & $\begin{array}{l}591.6 \\
683.9 \\
656.1 \\
712.2 \\
640.5 \\
632.6 \\
678.3 \\
725.0\end{array}$ & $\begin{array}{l}53.8^{\circ} \\
62.1^{\wedge} \\
59.2^{\wedge} \\
63.7^{\wedge} \\
58.2^{\prime} \\
57.3^{\prime} \\
61.4^{\wedge} \\
64.5^{\wedge}\end{array}$ \\
\hline $\begin{array}{l}Y-8 \\
Y-10 \\
Y-12 \\
Y-13 \\
Y-15\end{array}$ & $\begin{array}{l}\text { E-2 } \\
\text { E-2 } \\
\text { E-2 } \\
\text { E-2 } \\
\text { E-2 }\end{array}$ & $\begin{array}{l}250.8 \\
306.5 \\
247.1 \\
231.5 \\
254.8\end{array}$ & $\begin{array}{l}119.0 \\
143.9 \\
119.0 \\
118.9 \\
119.3\end{array}$ & $\begin{array}{r}642.5 \\
1070.9 \\
650.5 \\
698.3 \\
632.7\end{array}$ & $\begin{array}{l}57.8 \\
65.8 \\
58.5 \\
62.6^{\wedge} \\
56.6\end{array}$ \\
\hline $\begin{array}{l}Z-4 \\
Z-7 \\
Z-8 \\
Z-9 \\
Z-10 \\
Z-11\end{array}$ & $\begin{array}{l}\text { E-2 } \\
\text { E-2 } \\
\text { E-2 } \\
\text { E-2 } \\
\text { E-2 } \\
\text { E-2 }\end{array}$ & $\begin{array}{l}243.8 \\
252.1 \\
253.2 \\
254.2 \\
253.8 \\
255.3\end{array}$ & $\begin{array}{l}118.5 \\
118.8 \\
118.8 \\
118.8 \\
118.8 \\
118.7\end{array}$ & $\begin{array}{l}666.1 \\
668.3 \\
643.8 \\
570.5 \\
660.5 \\
577.4\end{array}$ & $\begin{array}{l}60.4 \\
60.3 \\
58.1 \\
51.5 \\
59.6 \\
52.1\end{array}$ \\
\hline
\end{tabular}

* See Table A.1.

** Compressive strength values for cylinders having a length-to-diameter ratio of less than 2.0 were adjusted according to information in Ref. (27). The maximum adjustment was $1.4 \%$ for Specimen X-12. Specimens whose compressive strengths were adjusted downward are denoted by $\wedge$. 
Table 2

Splitting-Tensile Strength Results

(Uncracked Specimens)

\begin{tabular}{lccccc}
\hline $\begin{array}{l}\text { Specimen } \\
\text { Number }\end{array}$ & $\begin{array}{c}\text { Concrete } \\
\text { Mix* }\end{array}$ & $\begin{array}{c}\text { Average } \\
\text { Length, }\end{array}$ & $\begin{array}{c}\text { Average } \\
\text { Diameter, }\end{array}$ & $\begin{array}{c}\text { Maximum } \\
\text { Applied } \\
\text { Load, } \\
\mathrm{kN}\end{array}$ & $\begin{array}{c}\text { Splitting-Tensile } \\
\text { Strength, }\end{array}$ \\
\hline W-5 & E-2 & 146.4 & 118.6 & 99.0 & $\mathrm{MPa}$ \\
W-6 & E-2 & 109.2 & 118.6 & 86.3 & 3.63 \\
W-8 & E-2 & 251.1 & 118.7 & 202.2 & 4.24 \\
W-11 & E-2 & 174.0 & 118.8 & 123.2 & 4.32 \\
X-3 & E-1 & 121.9 & 118.3 & 83.0 & 3.80 \\
X-4 & E-1 & 115.9 & 118.4 & 96.7 & 3.66 \\
X-10 & E-2 & 136.5 & 118.3 & 83.6 & 3.49 \\
& & & & & \\
Y-6 & E-1 & 113.7 & 118.9 & 60.5 & 2.85 \\
Y-9 & E-2 & 177.8 & 143.8 & 182.8 & 4.55 \\
Y-11 & E-2 & 142.6 & 143.9 & 119.7 & 3.72 \\
Z-5 & E-2 & 142.2 & 118.8 & 119.0 & 4.48 \\
Z-6 & E-2 & 228.6 & 118.8 & 193.9 & 4.55 \\
\hline
\end{tabular}

* See Table A.1. 
Table 3

Dimensions and Maximum Applied Loads for Cracked Specimens

Loaded to Fracture Using Compression Test Procedure

\begin{tabular}{ccccc}
\hline $\begin{array}{c}\text { Specimen } \\
\text { Number }\end{array}$ & $\begin{array}{c}\text { Concrete } \\
\text { Mix* }\end{array}$ & $\begin{array}{c}\text { Average } \\
\text { Length, } \\
\mathrm{mm}\end{array}$ & $\begin{array}{c}\text { Average } \\
\text { Diameter, }\end{array}$ & $\begin{array}{c}\text { Maximum } \\
\text { Applied } \\
\text { Load, } \\
\mathrm{kN}\end{array}$ \\
\hline W-1 & E-2 & 208.7 & 118.6 & 561.0 \\
W-2 & E-2 & 215.9 & 118.6 & 568.2 \\
Z-1 & E-1 & 220.6 & 118.4 & 715.0 \\
Z-2 & E-1 & 205.5 & 118.5 & 689.4 \\
Z-3 & E-1 & 185.4 & 118.6 & 814.0 \\
\hline
\end{tabular}

* See Table A.1.

Table 4

Dimensions and Maximum Applied Loads for Cracked Specimens

Loaded to Fracture Using Splitting-Tensile Test Procedure

\begin{tabular}{ccccc}
\hline $\begin{array}{c}\text { Specimen } \\
\text { Number }\end{array}$ & $\begin{array}{c}\text { Concrete } \\
\text { Mix* }\end{array}$ & $\begin{array}{c}\text { Average } \\
\text { Length, } \\
\mathrm{mm}\end{array}$ & $\begin{array}{c}\text { Average } \\
\text { Diameter, }\end{array}$ & $\begin{array}{c}\text { Maximum } \\
\text { Applied } \\
\text { Load, } \\
\mathrm{kN}\end{array}$ \\
\hline X-1 & E-1 & 231.1 & 118.6 & 111.0 \\
X-5 & E-1 & 222.3 & 118.4 & 131.0 \\
X-6 & E-1 & 231.8 & 118.4 & 115.4 \\
Y-2 & E-1 & 208.3 & 118.9 & 113.0 \\
Y-3 & E-1 & 207.3 & 118.9 & 134.1 \\
Y-4 & E-1 & 192.7 & 118.9 & 125.2 \\
Y-5 & E-1 & 204.8 & 119.0 & 101.4 \\
Y-7 & E-1 & 204.8 & 119.0 & 126.8 \\
Z-12 & E-1 & 154.9 & 144.3 & 102.3 \\
\hline
\end{tabular}

* See Table A.1. 



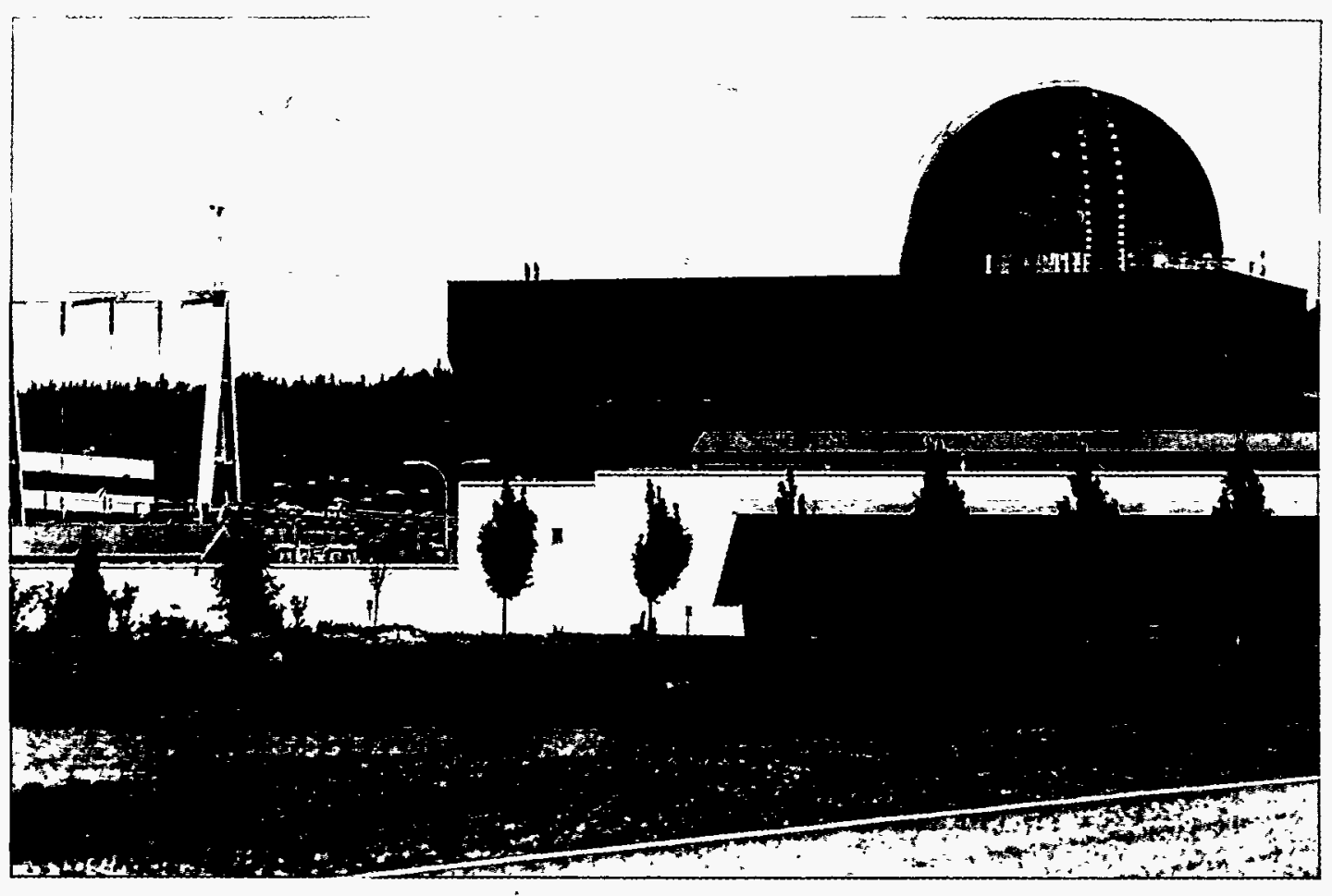

Figure 1. Trojan Nuclear Plant. 


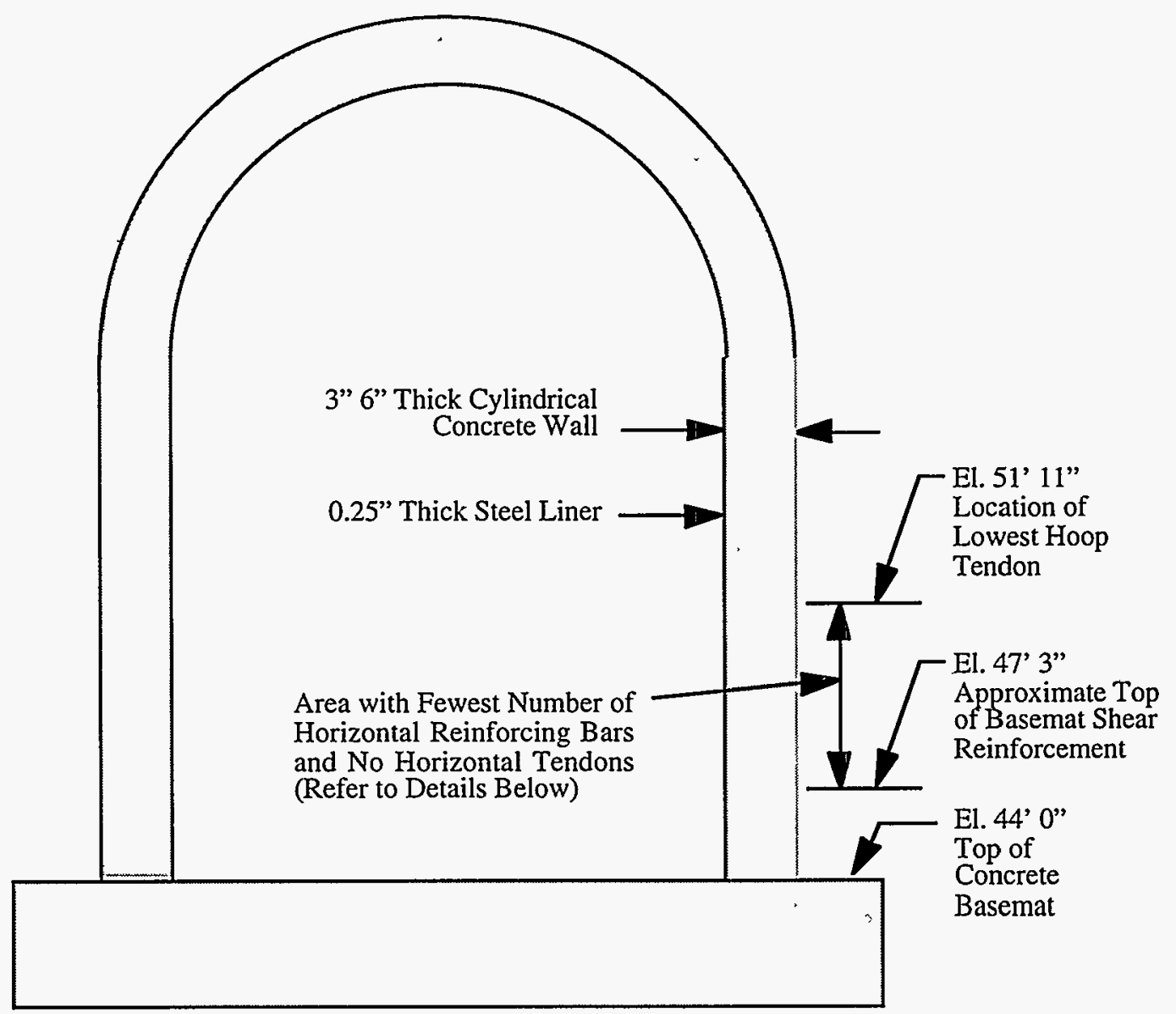

Reinforcing Bar Details (Outside Face of Containment Wall)

Hoop Bars:

\#11 bars @7.5" up to El. 52' 4", then \#11 bars@15"up to El.55'6"

Vertical Bars:

\#18 bars@18" up to El.64'0"

Horizontal Tie Bars:

\#7 bars, 2" cover (min.)

vertical spacing varies
Post-Tensioning Tendon Details

Hoop Tendons

Vertical spacing alternates between

1' 1" and 2' 2" starting at El. 51' 11 "

Distance from outside containment surface to center line of hoop tendon sheath is 12 "'

Vertical Tendons

3' 0" horizontal spacing (Approx.) Distance from outside containment surface to center line of vertical tendon sheath is 17.25 "

Figure 2. Elevation view of Trojan containment presenting steel reinforcement information. 


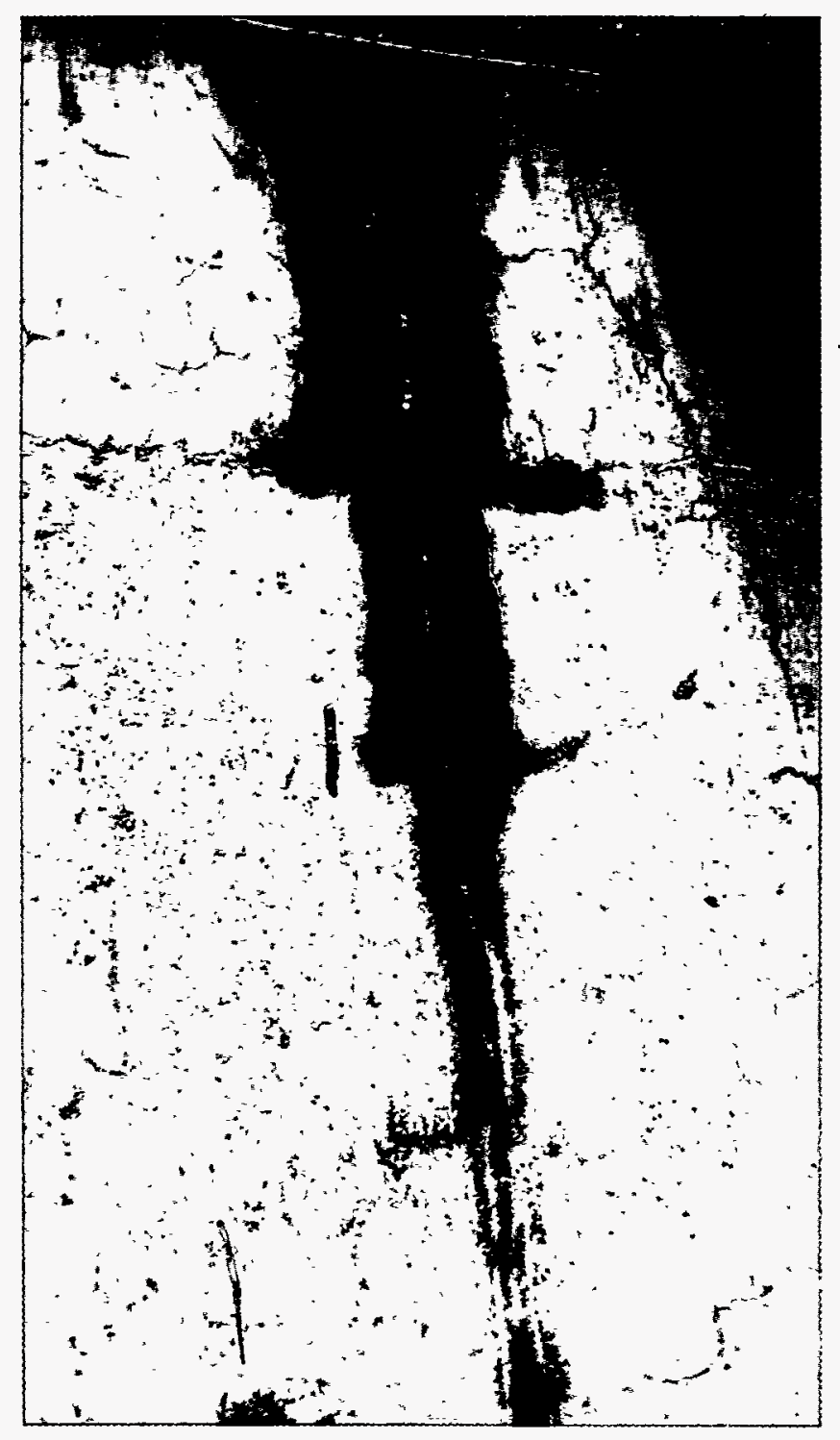

Figure 3. Example of staining of outer containment surface due to leakage of tendon sheathing filler. 


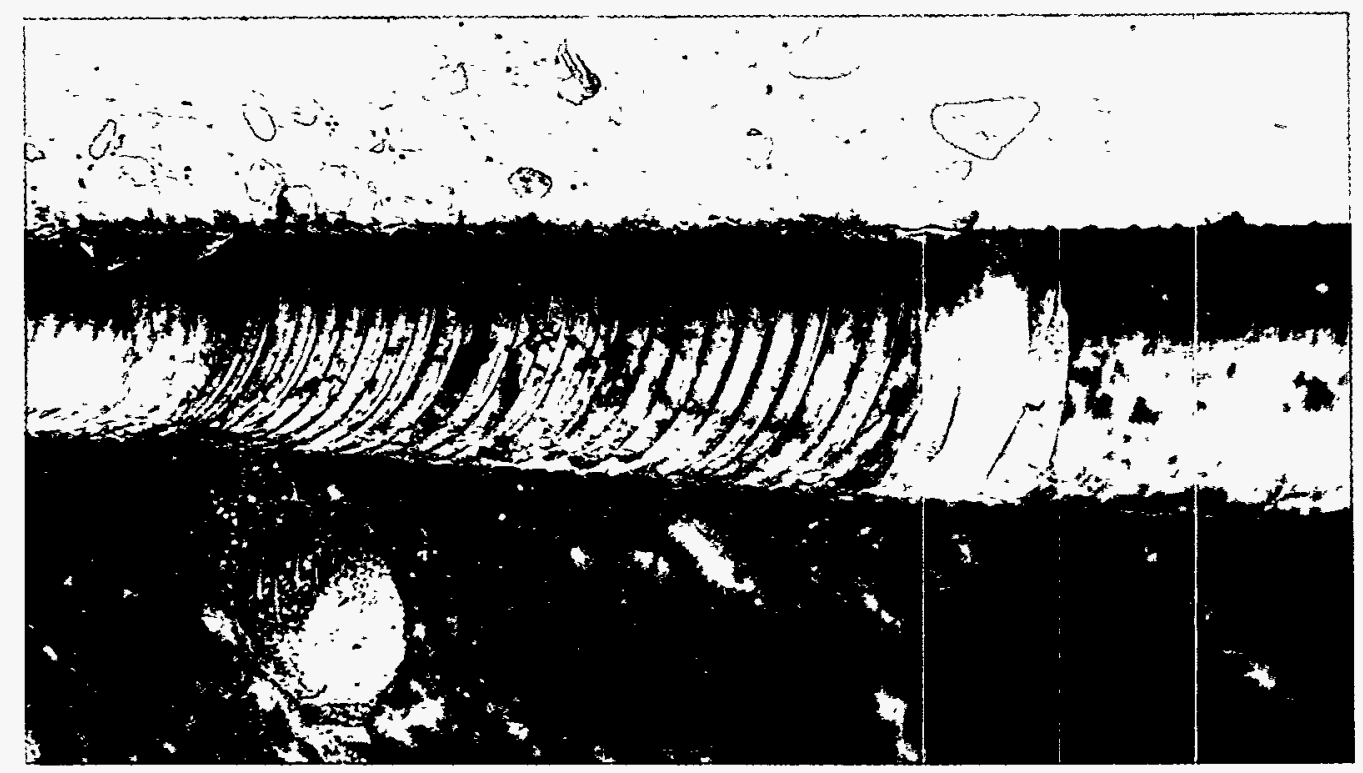

Figure 4. Coupling of tendon sheaths at Trojan Plant. 


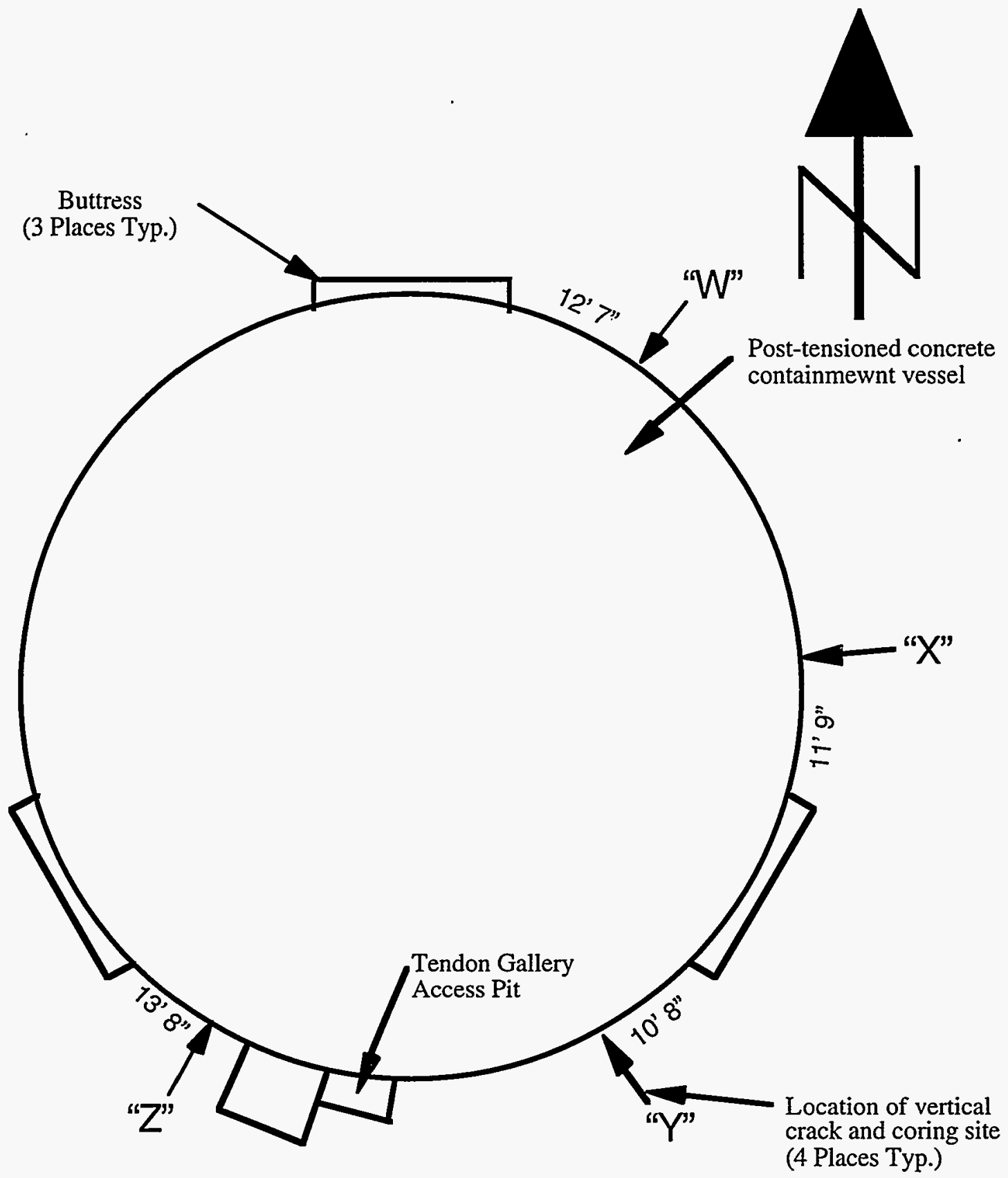

Note: Dimensions shown were measured along the outside surface of the containment vessel from the nearest buttress or the tendon gallery access pit.

Figure 5. Plan view of Trojan containment showing coring locations. 


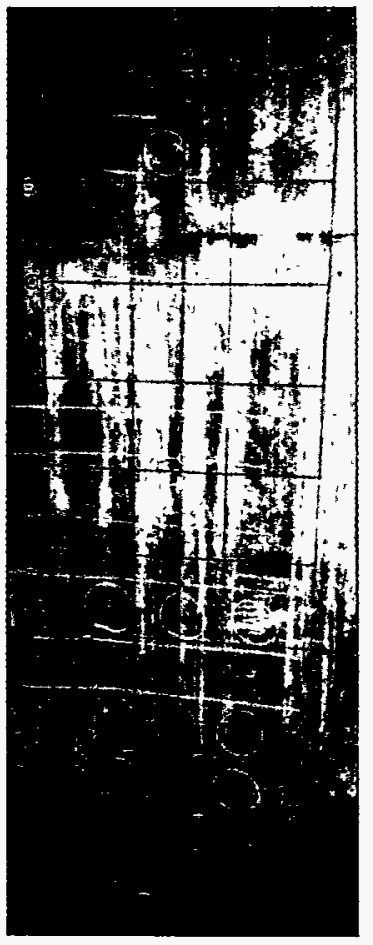

Location "W"

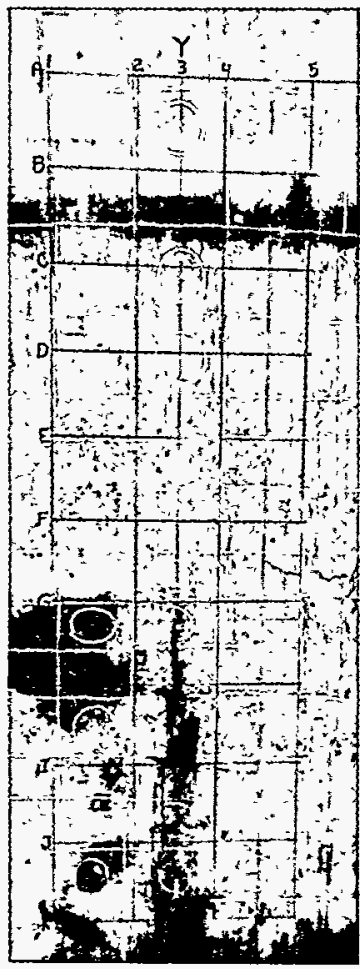

Location "Y"

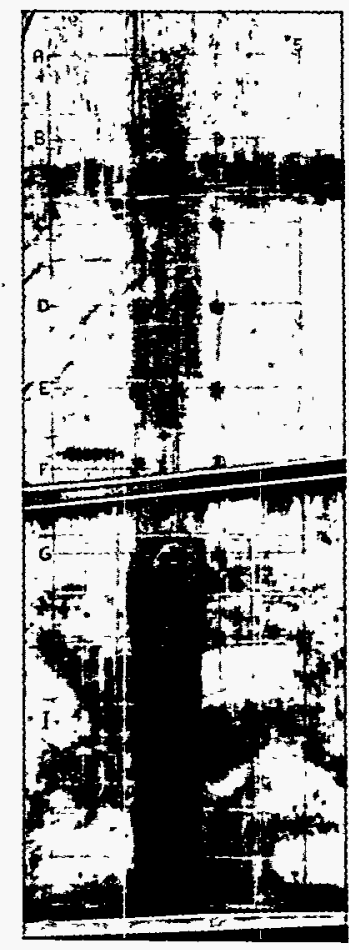

Location " $\mathrm{X}$ "

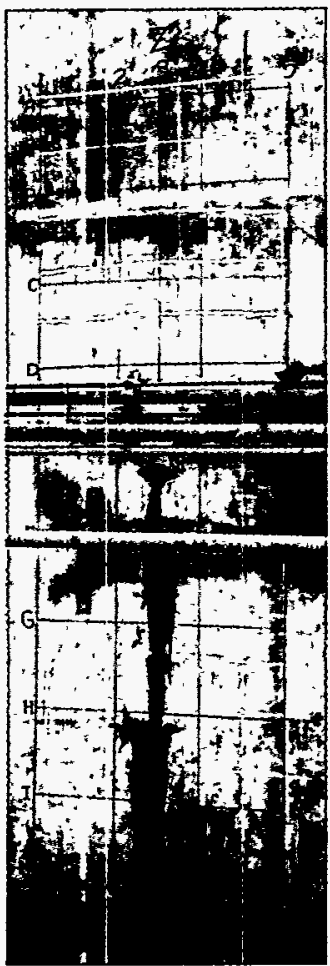

Location " $Z$ "

Figure 6. Leakage of tendon sheathing filler at sites selected for examination. 


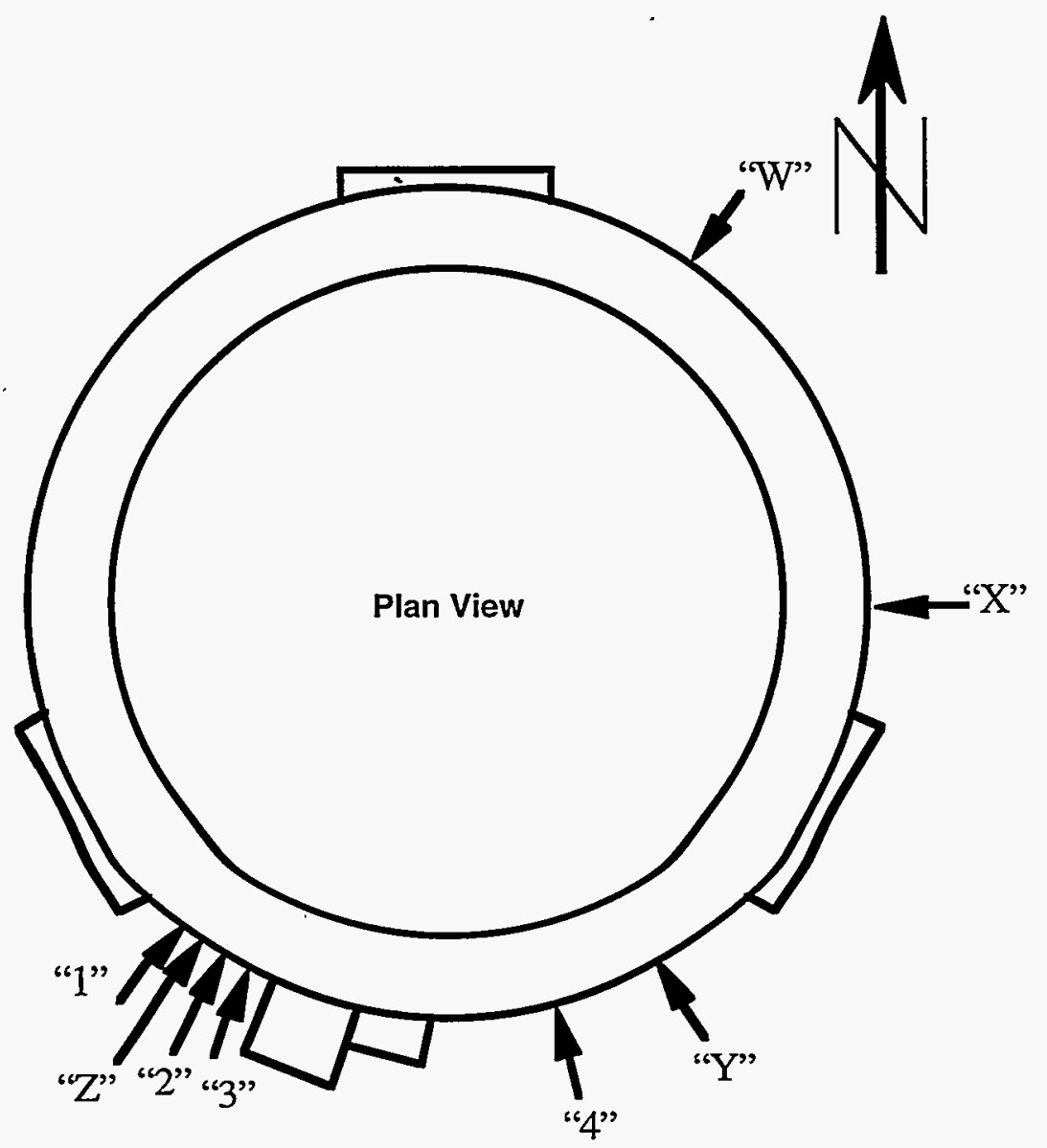

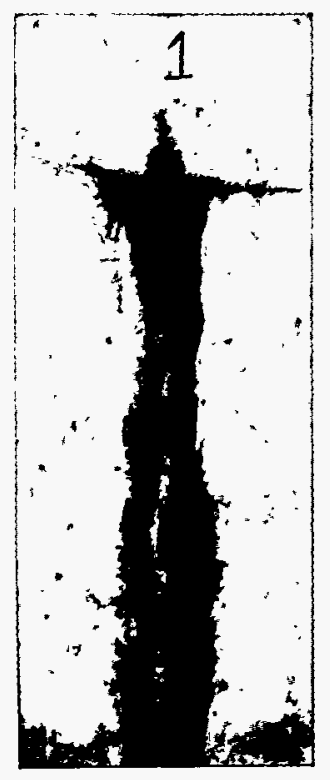

Location " 1 "

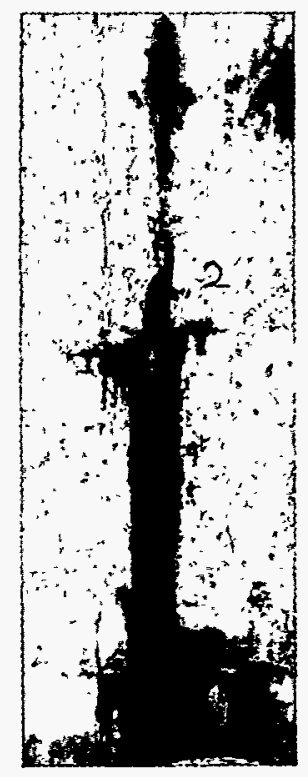

Location " 2 "

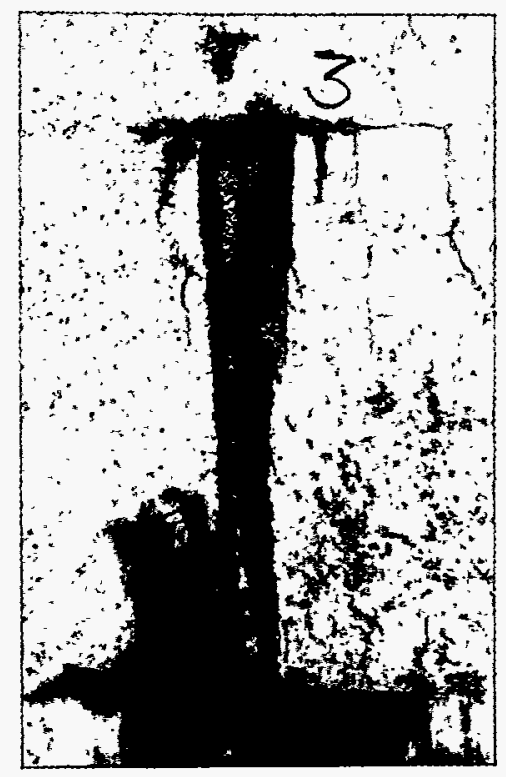

Location " 3 "

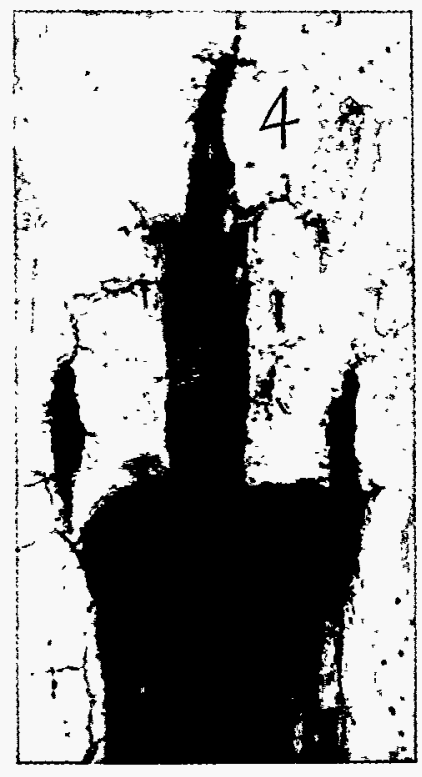

Location " 4 "

Figure 7. Additional locations where leakage of tendon sheathing filler was observed. 


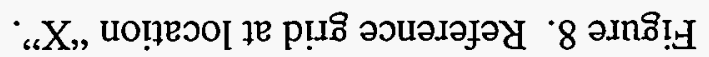

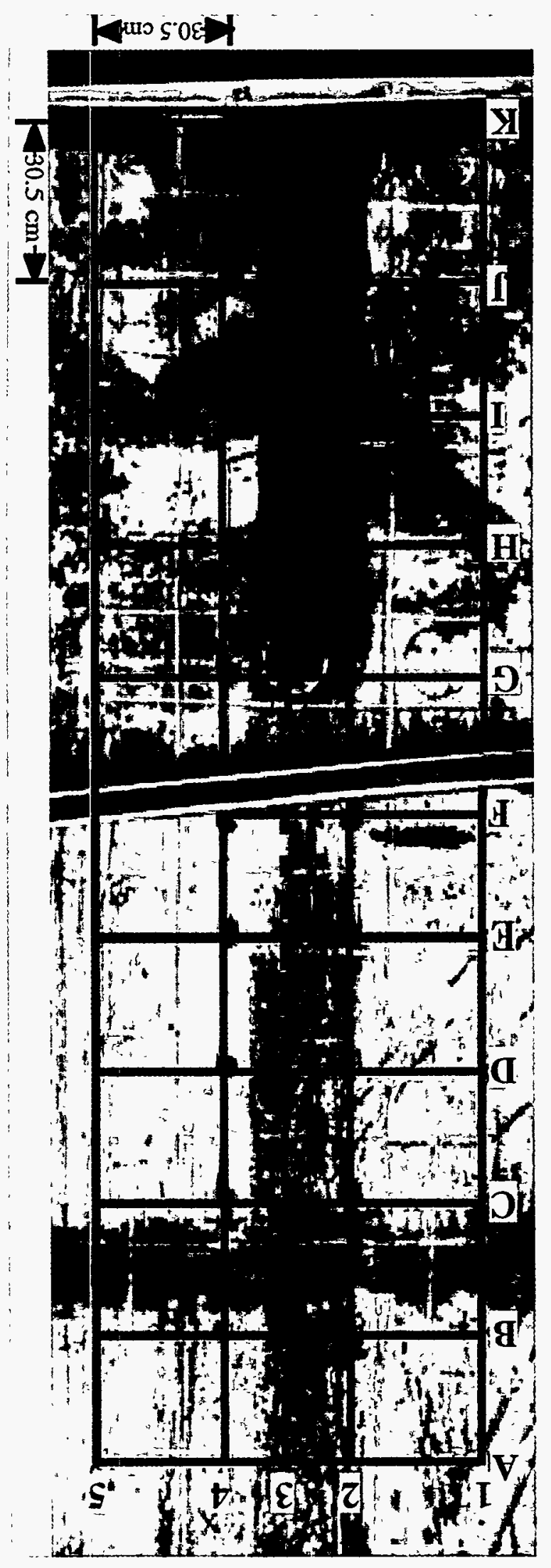




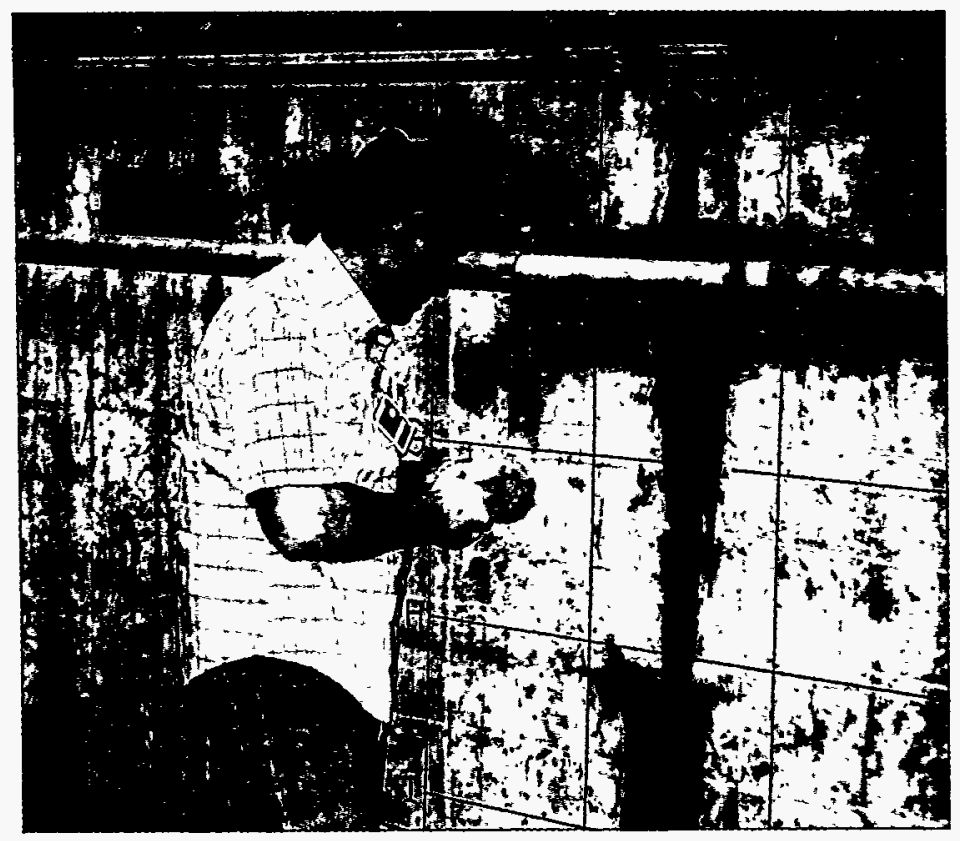

Figure 9. Obtaining rebound number of hardened concrete.

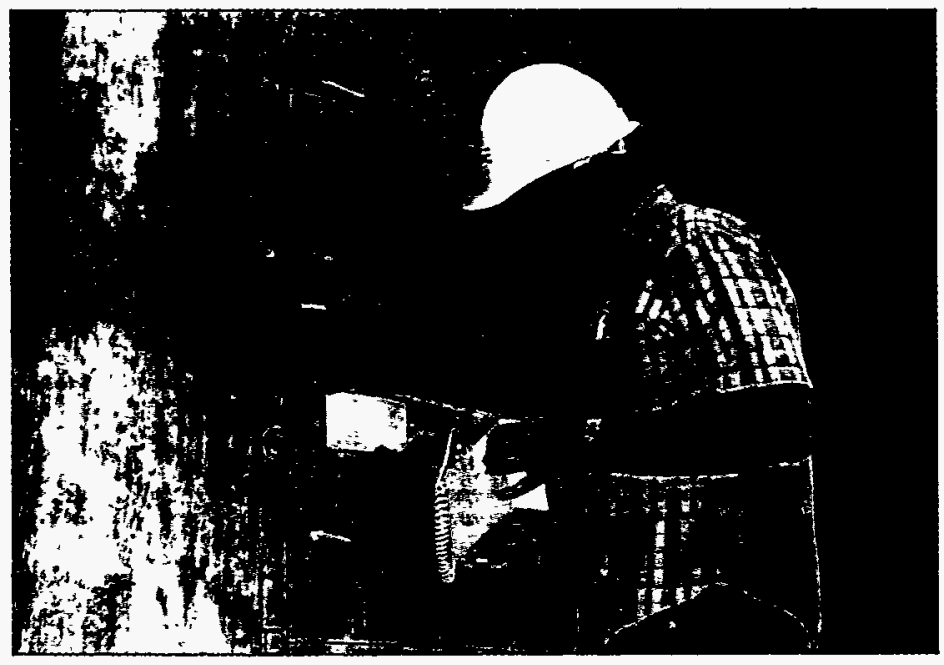

Figure 10. Use of covermeter to locate embedded steel 


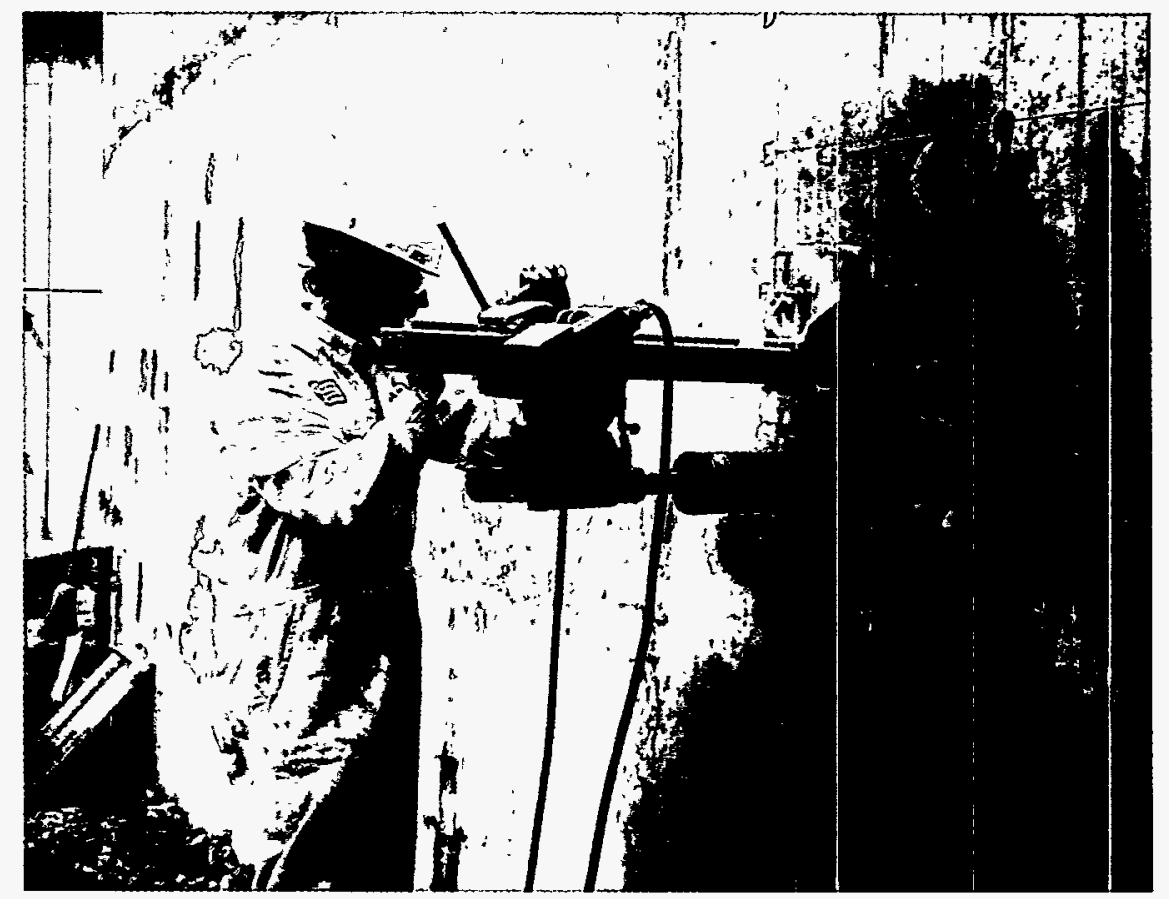

Figure 11. Coring to obtain test articles. 


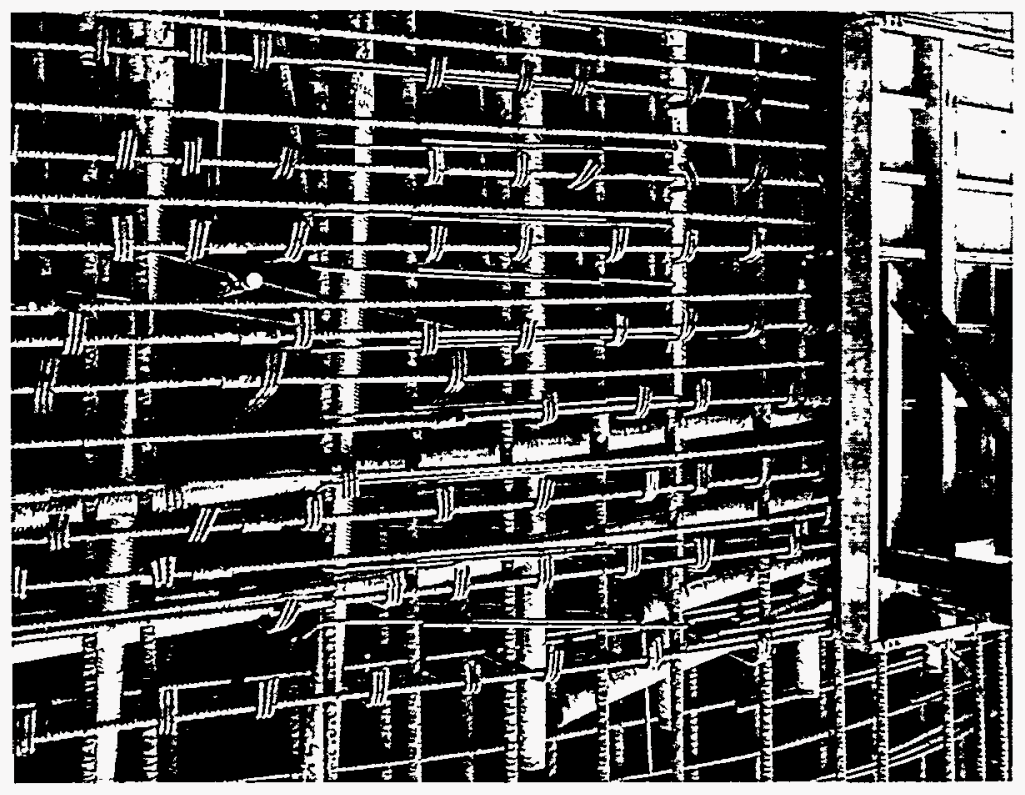

a. Typical rebar, ties and tendon sheathing arrangement for containment wall structure.

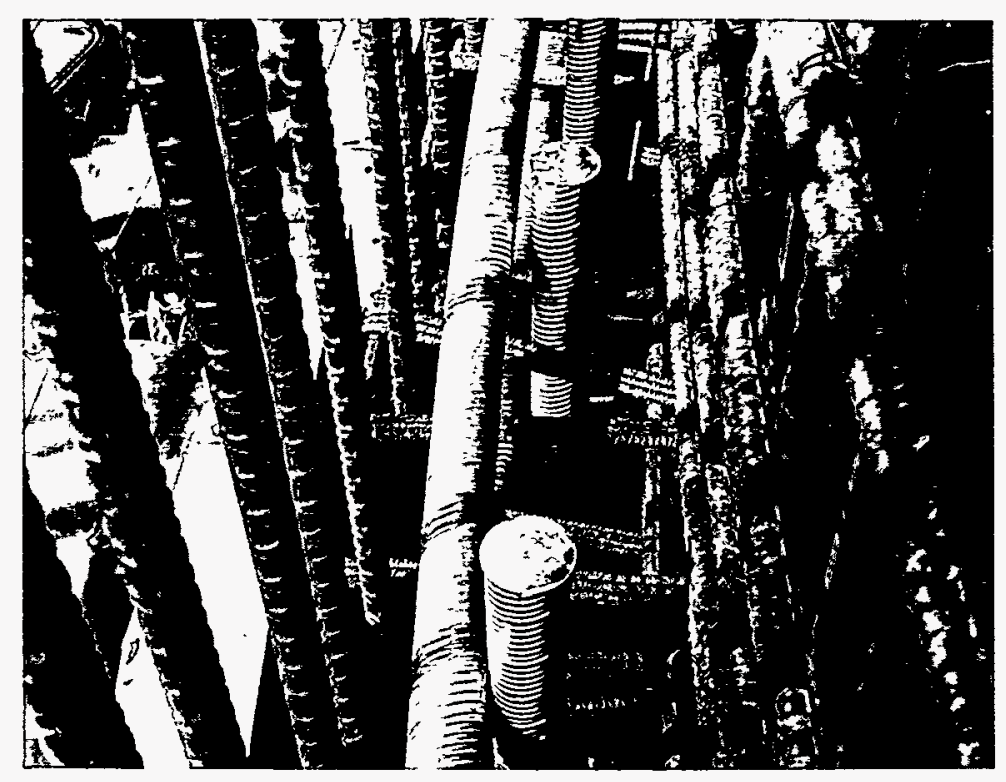

b. Typical rebar, ties and tendon sheathing arrangement between perimeters of containment wall structure.

Figure 12. Typical steel reinforcement and tendon sheathing arrangement of Trojan Plant containment wall structure. 


\section{Location "W"}
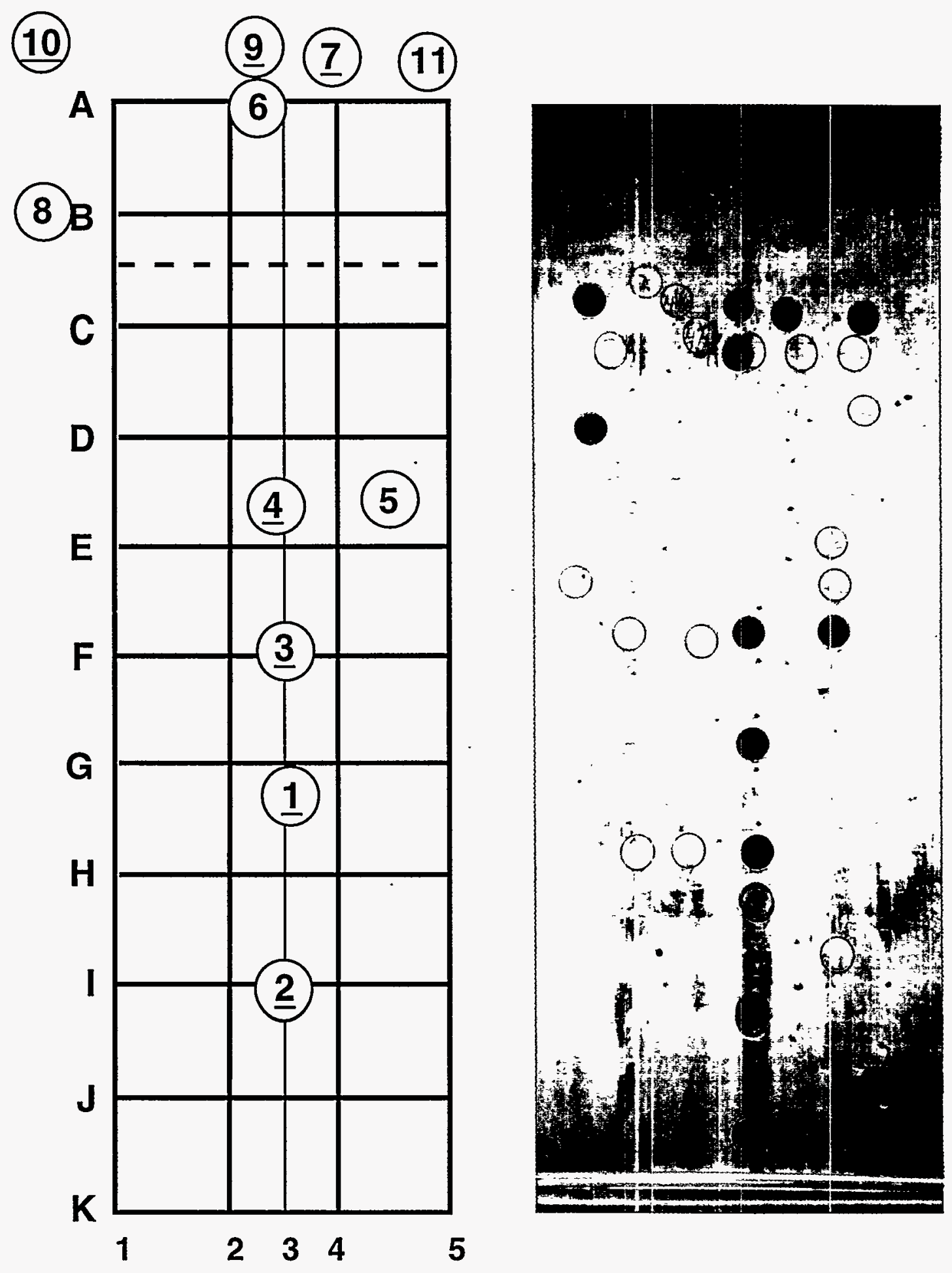

Cores with underlined numbers were loaded in compression.

Figure 13. Grid placement and coring positions for location "W". 


\section{Location " $X$ "}
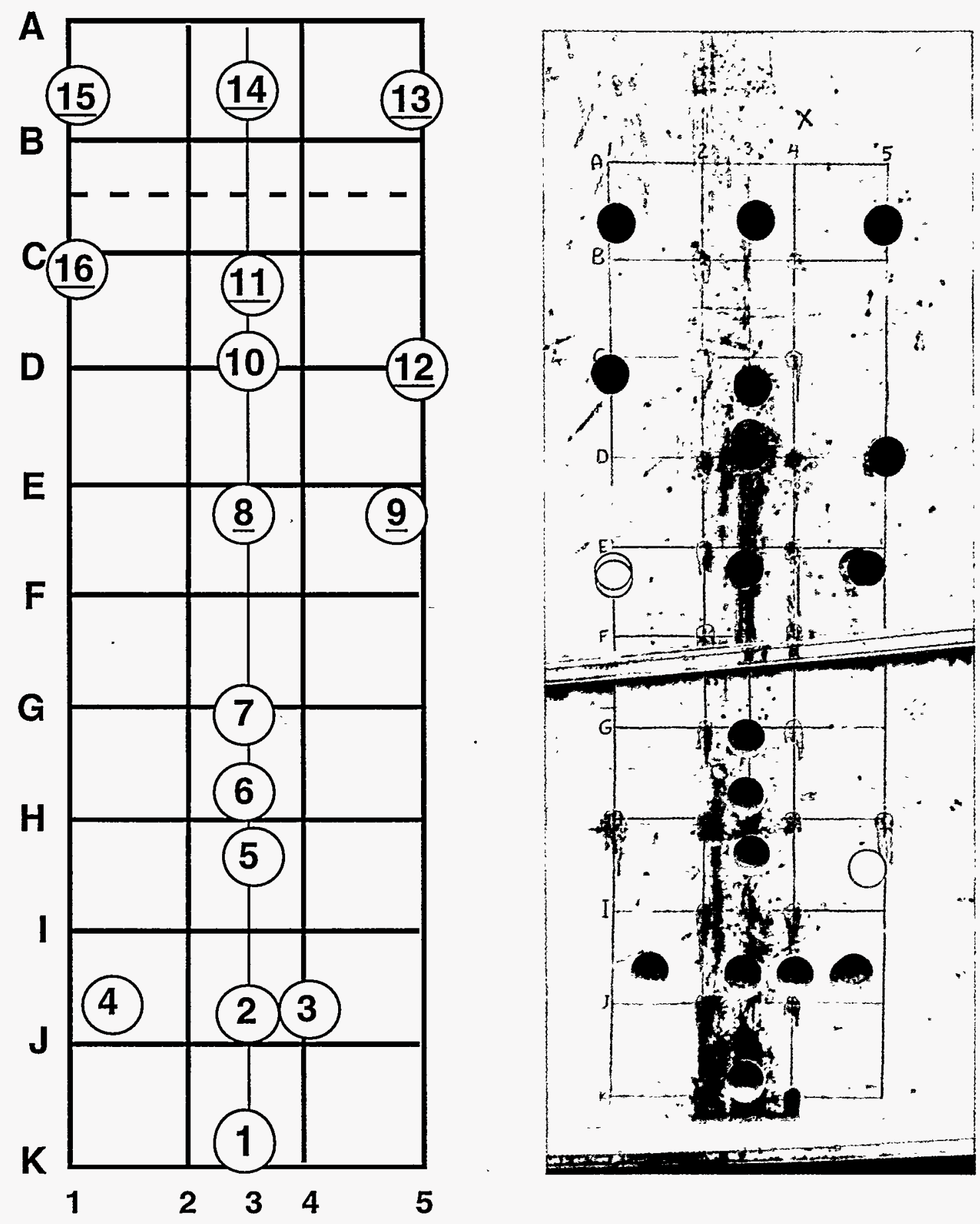

Cores with underlined numbers were loaded in compression.

Figure.14. Grid placement and coring positions for location " $\mathrm{X}$ ". 


\section{Location "Y"}
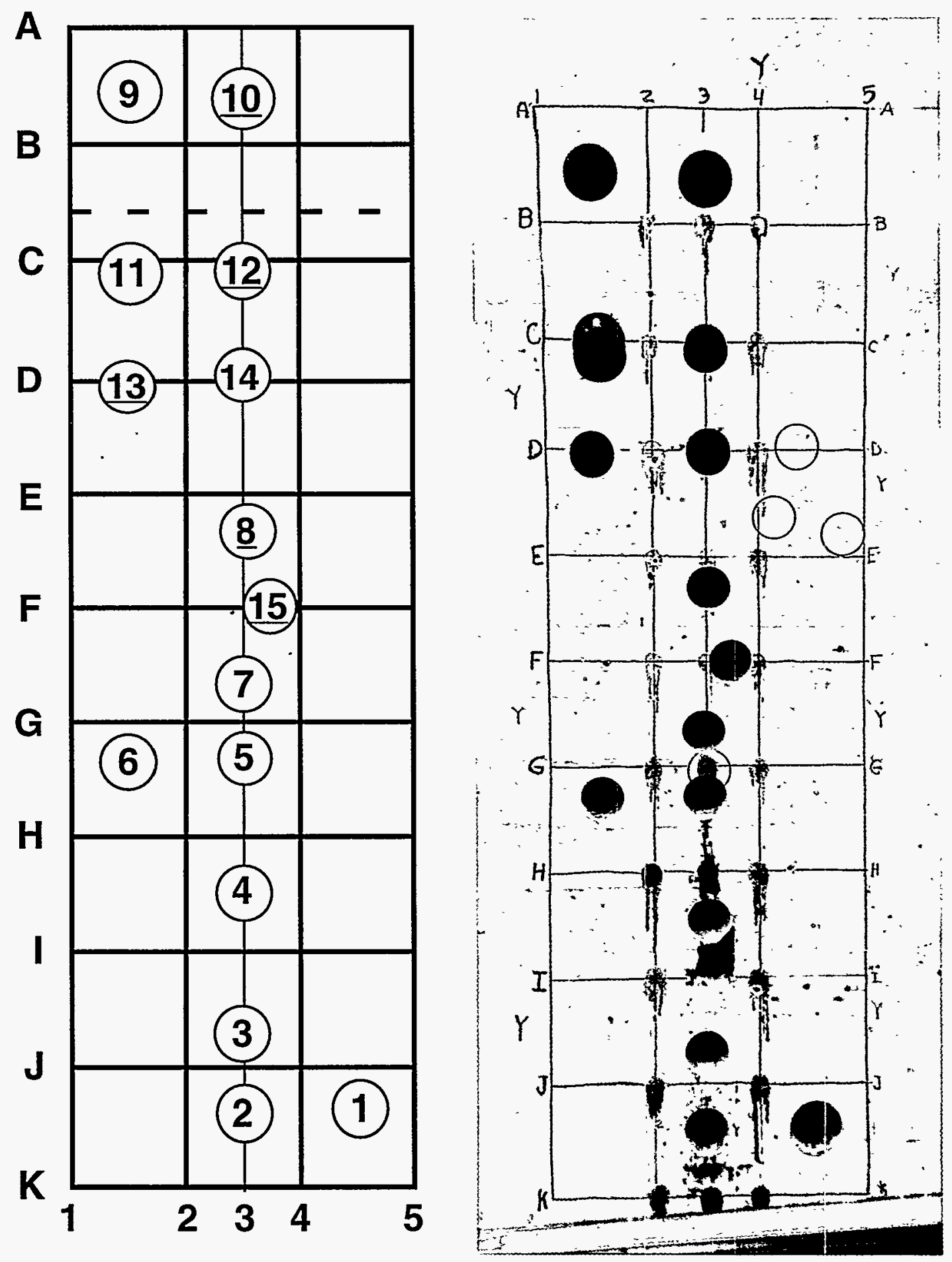

Cores with underlined numbers were loaded in compression.

Figure 15. Grid placement and coring positions for location "Y". 


\section{Location " $Z$ "}

(7)
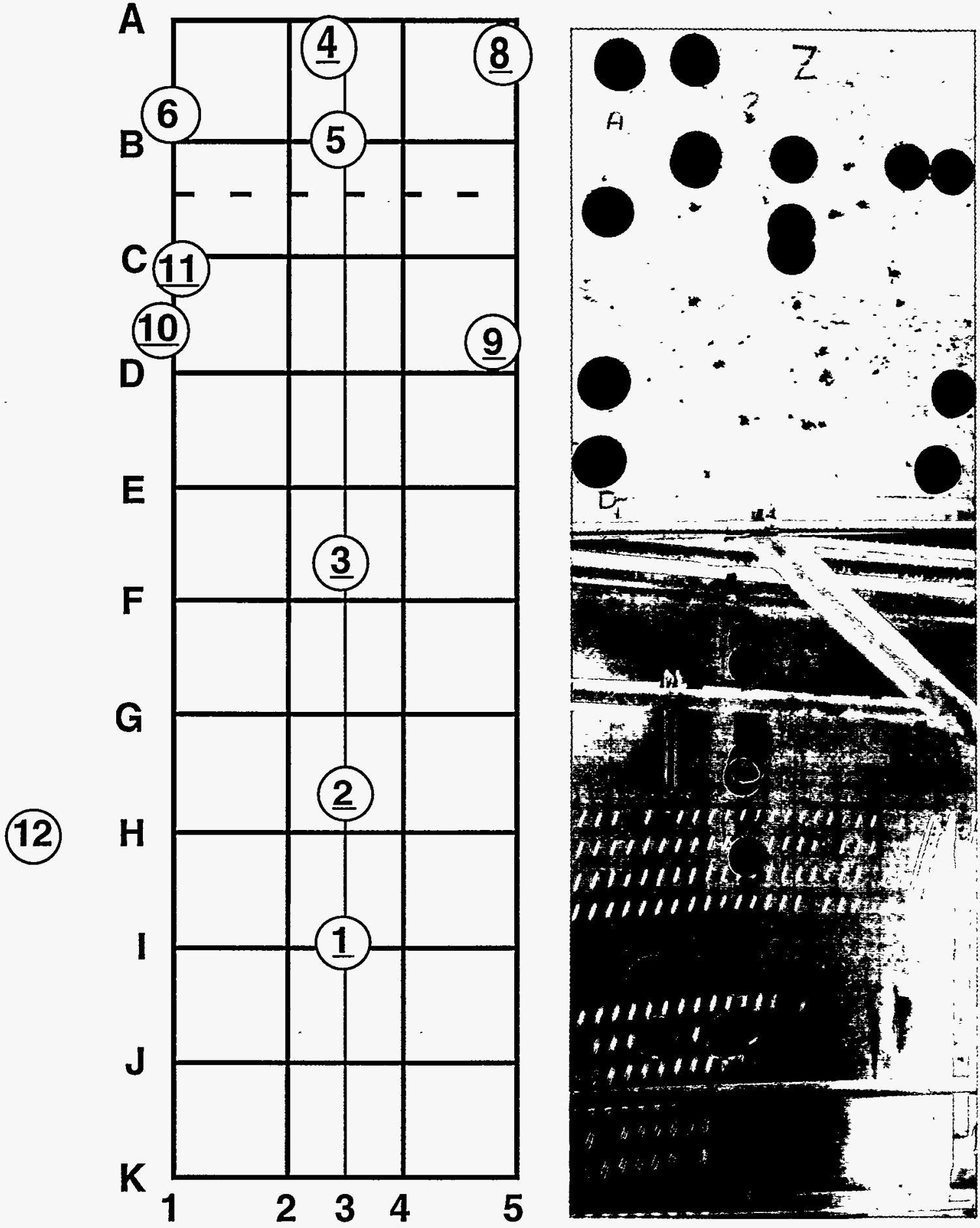

Cores with underlined numbers were loaded in compression.

Figure 16. Grid placement and coring location for location " $\mathrm{Z}$ ". 

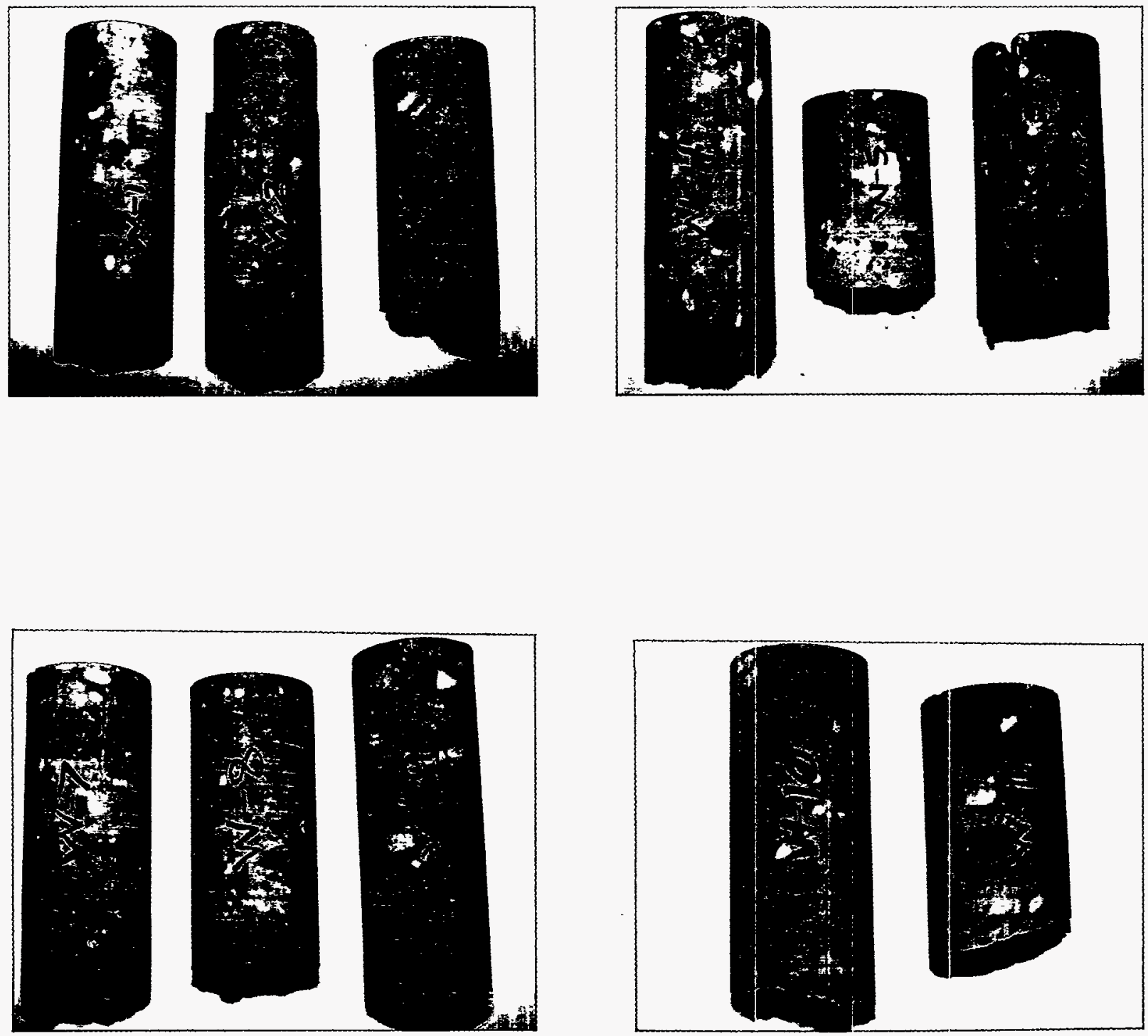

Figure 17. Concrete cores from location "W". 

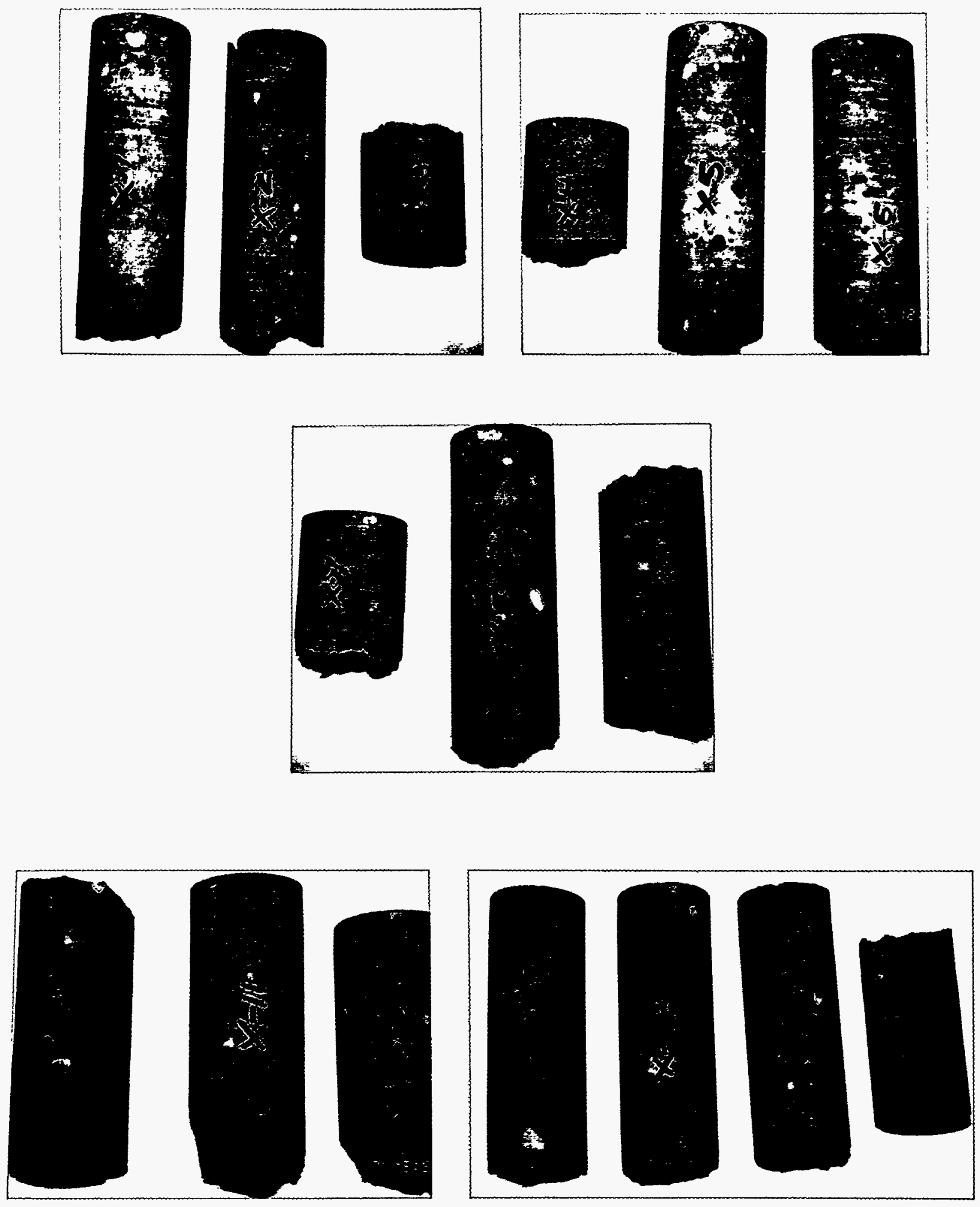

Figure 18. Concrete cores obtained from location " $\mathrm{X}$ ". 

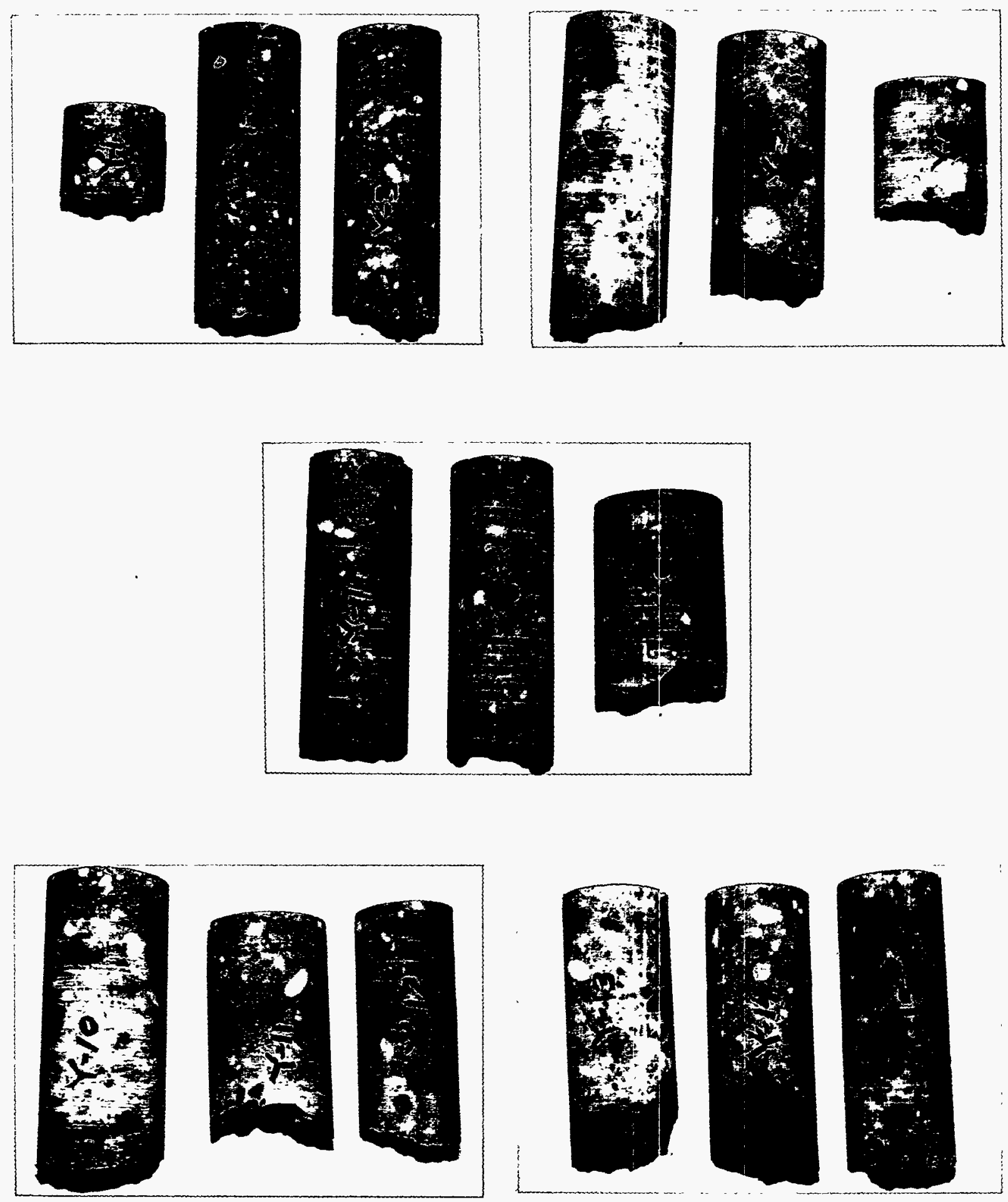

Figure 19. Concrete cores obtained from location "Y". 

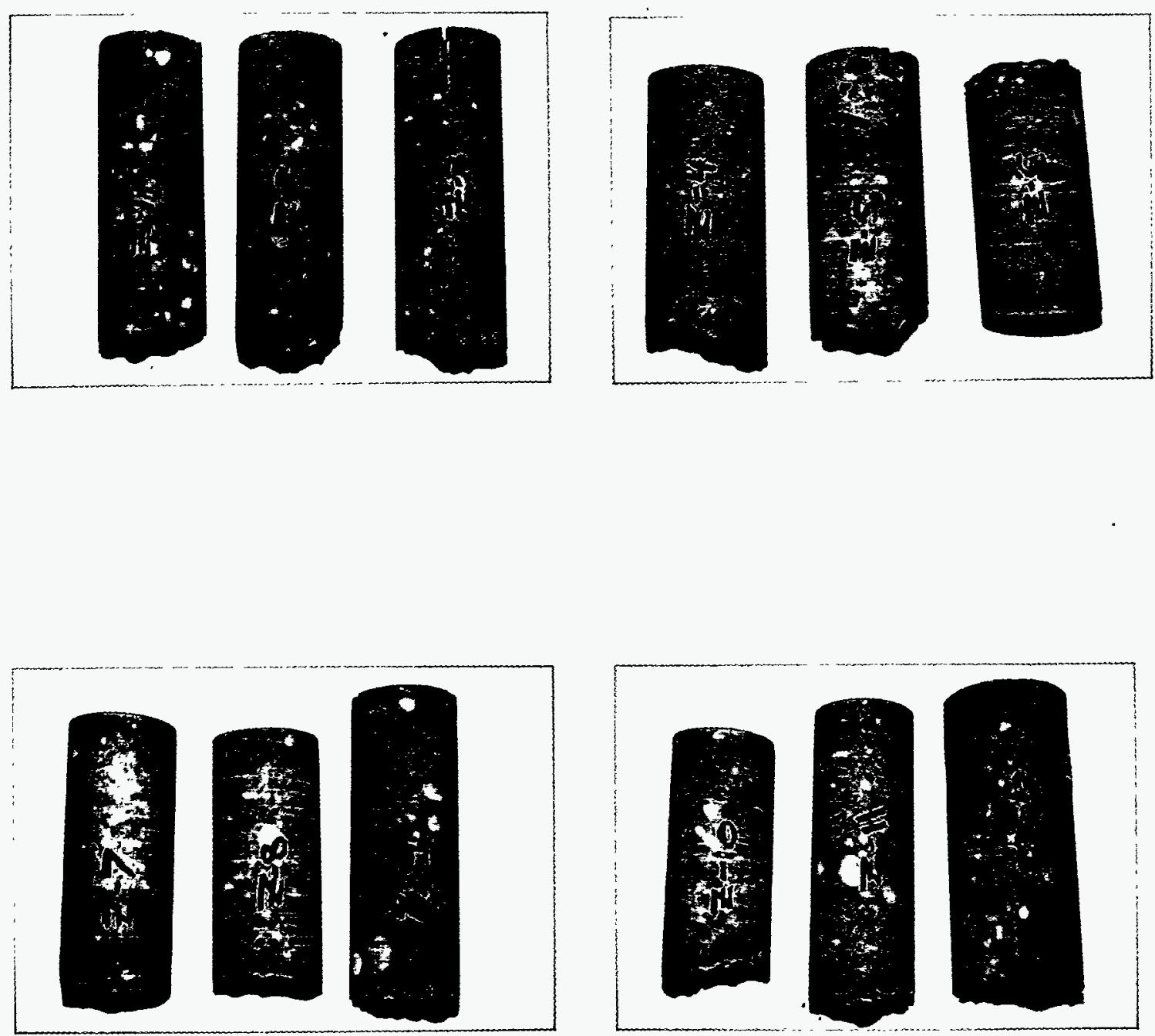

Figure 20. Concrete cores obtained from location " $Z$ ". 


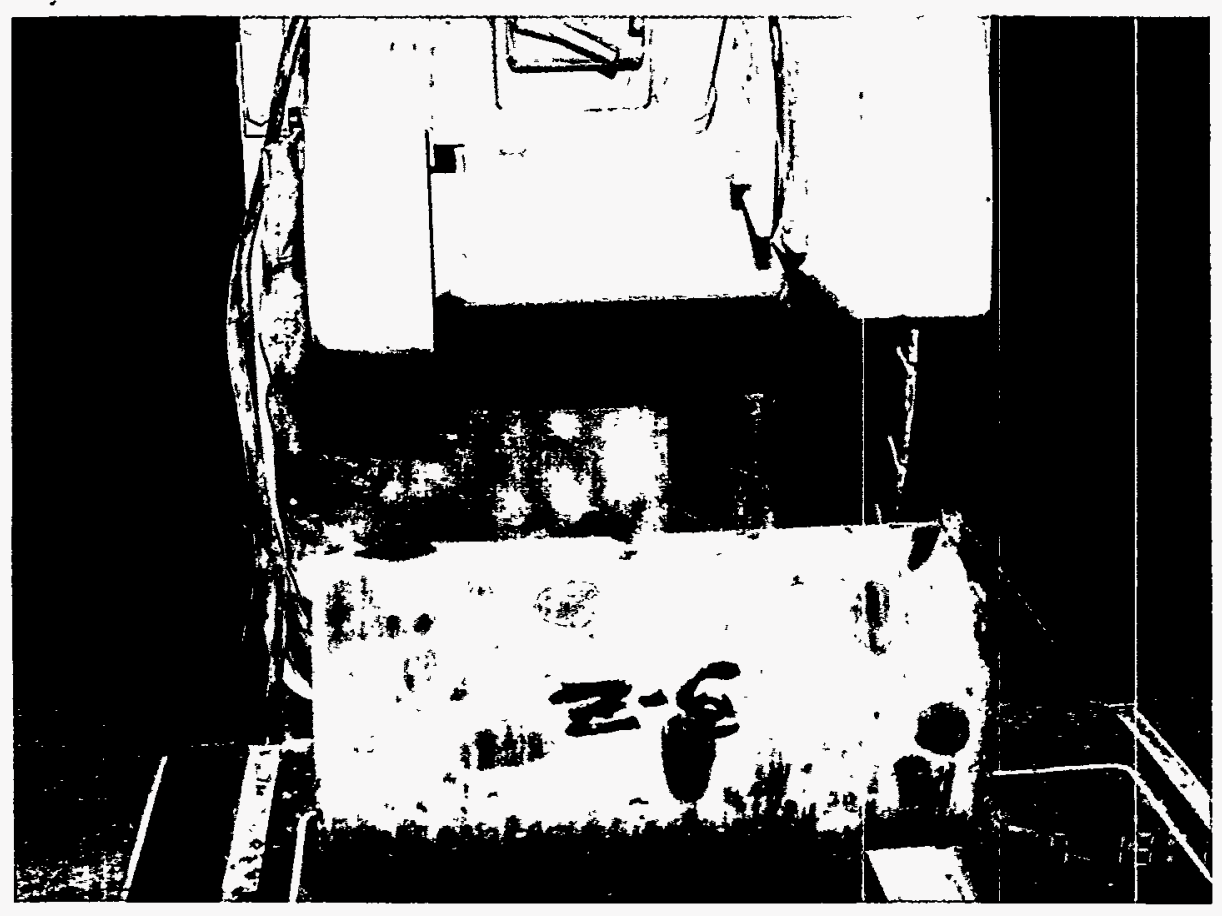

Figure 21. Sawing of specimen to obtain a test article that had relatively smooth ends that were perpendicular to the longitudinal axis.

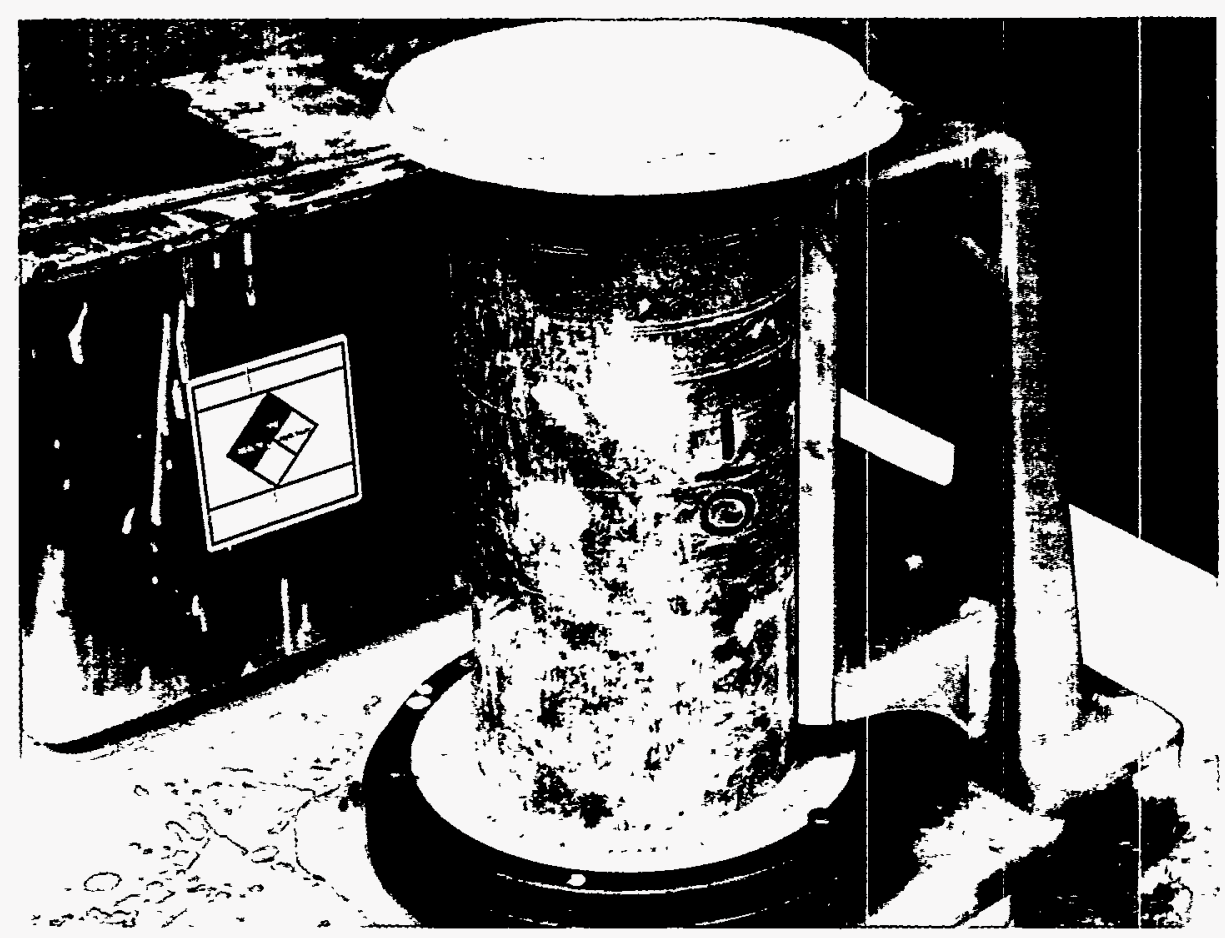

Figure 22. Test fixture for capping specimen ends prior to loading in compression. 


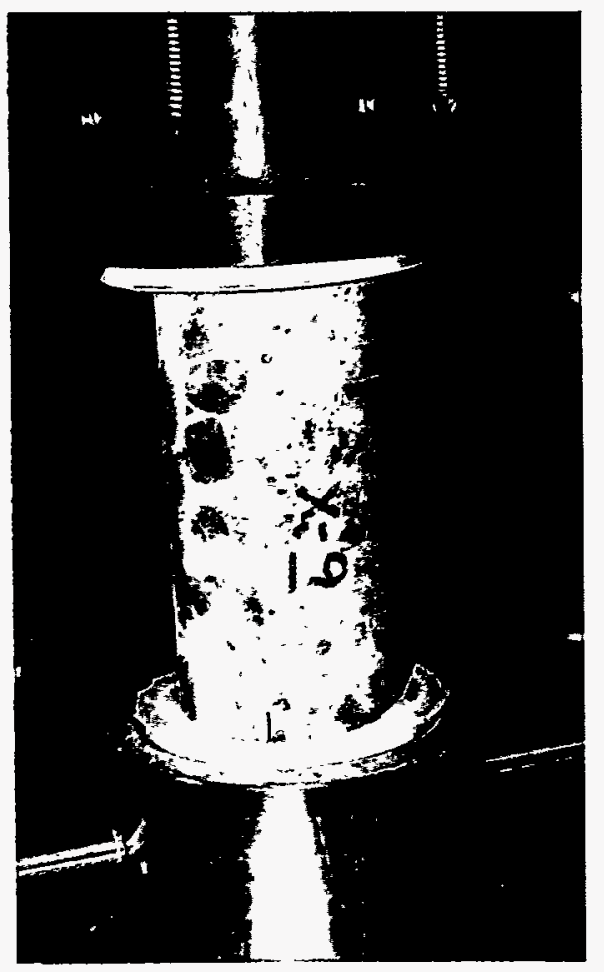

a. Uncracked specimen.

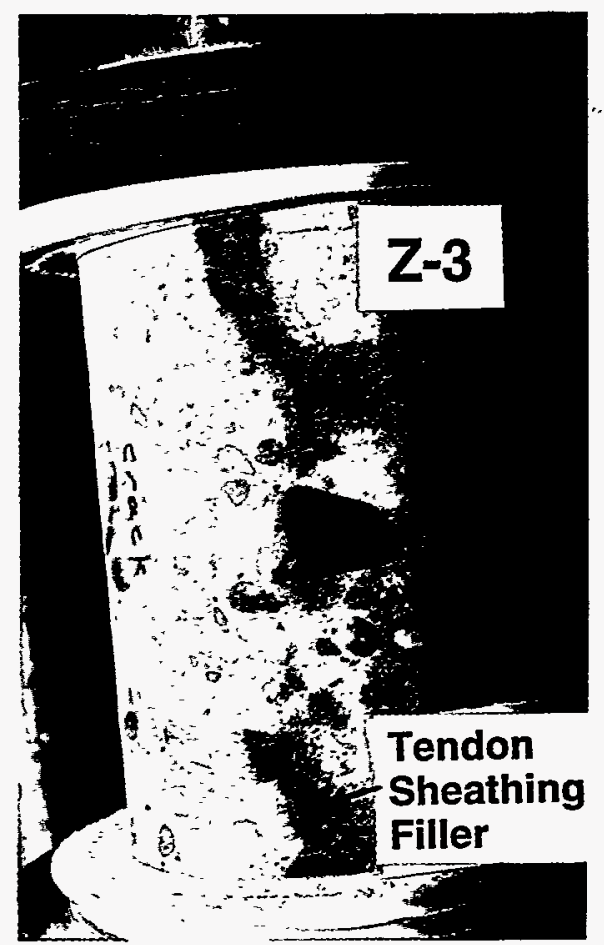

b. Specimen containing crack and tendon sheathing filler.

Figure 23. Test setup for compression procedure. 


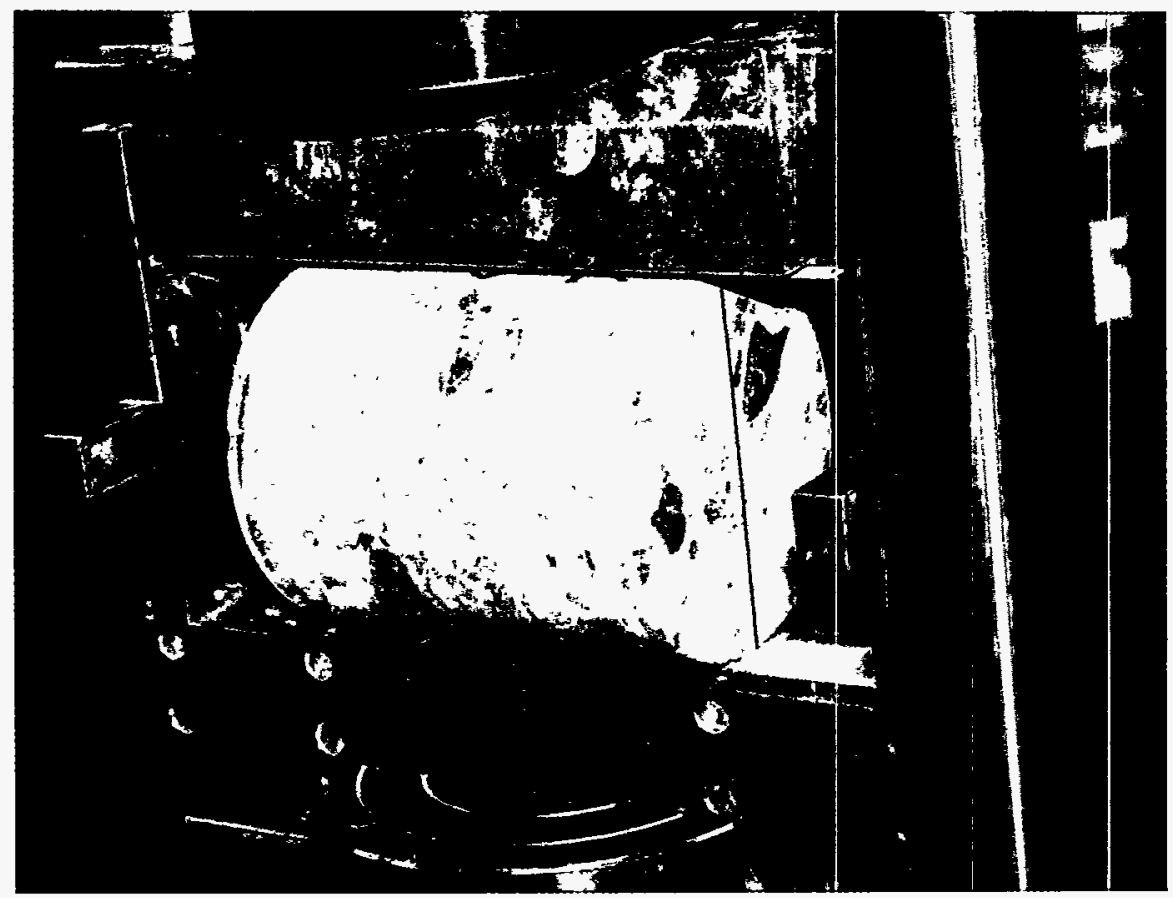

a. Uncracked specimen.

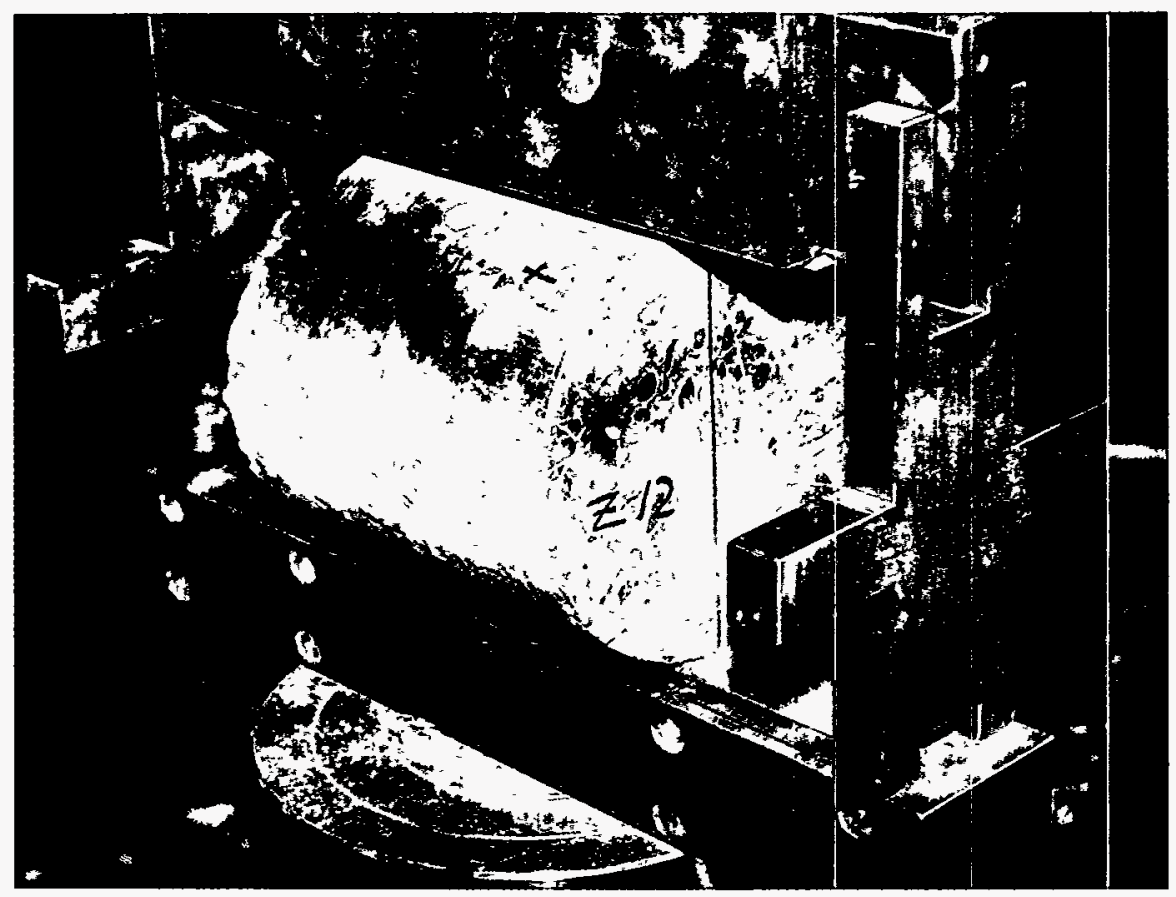

b. Specimen containing crack with tendon sheathing filler.

Figure 24. Test setup for splitting-tensile procedure. 


\section{Location "W"}
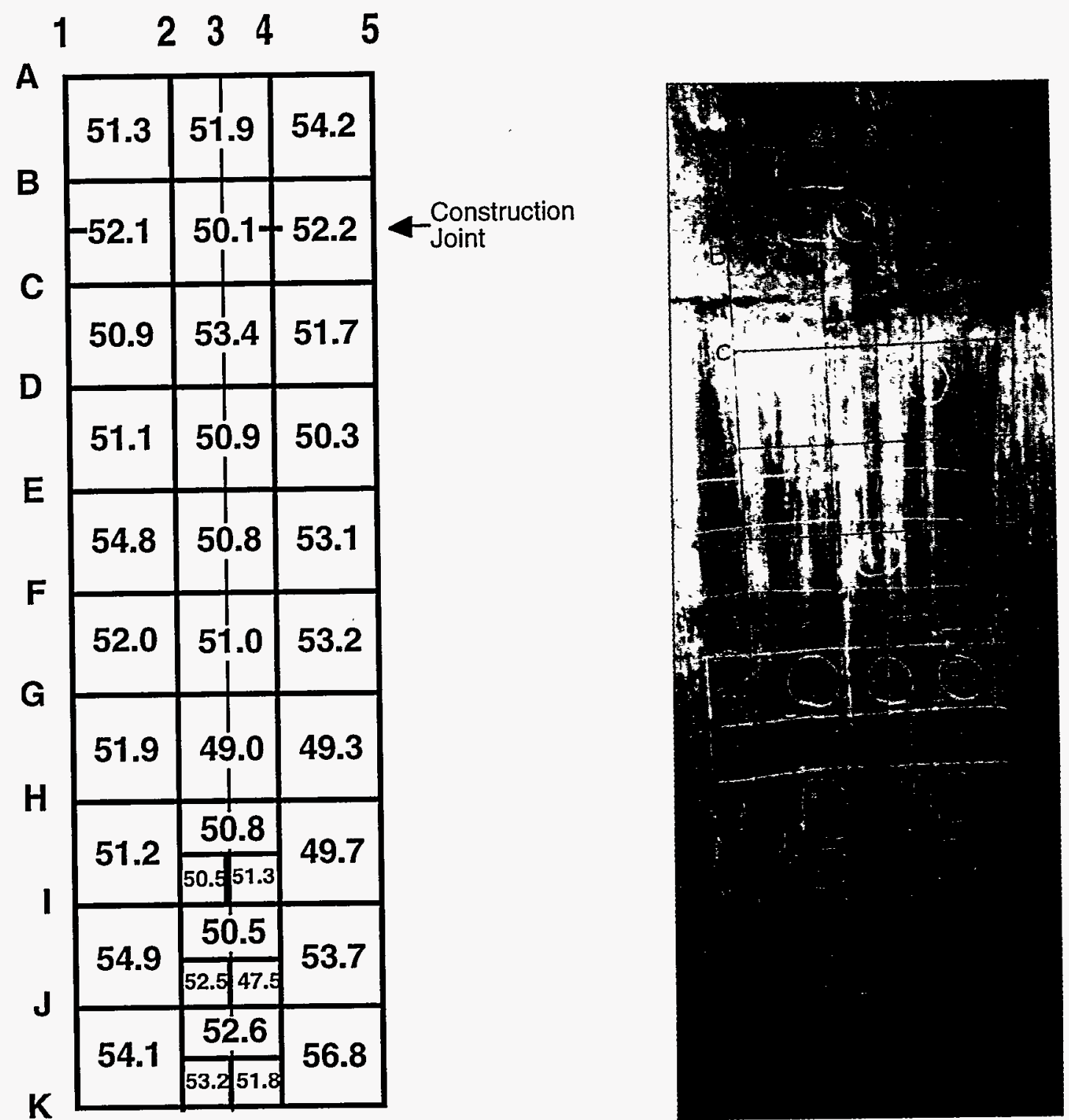

Key:

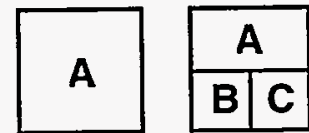

$A=$ Subsection average value overall

$B=$ Average value w/o tendon sheathing filler

$\mathrm{C}=$ Average value $\mathrm{w} /$ tendon sheathing filler

Figure 25. Rebound hammer results for location "W". 


\section{Location " $X$ "}
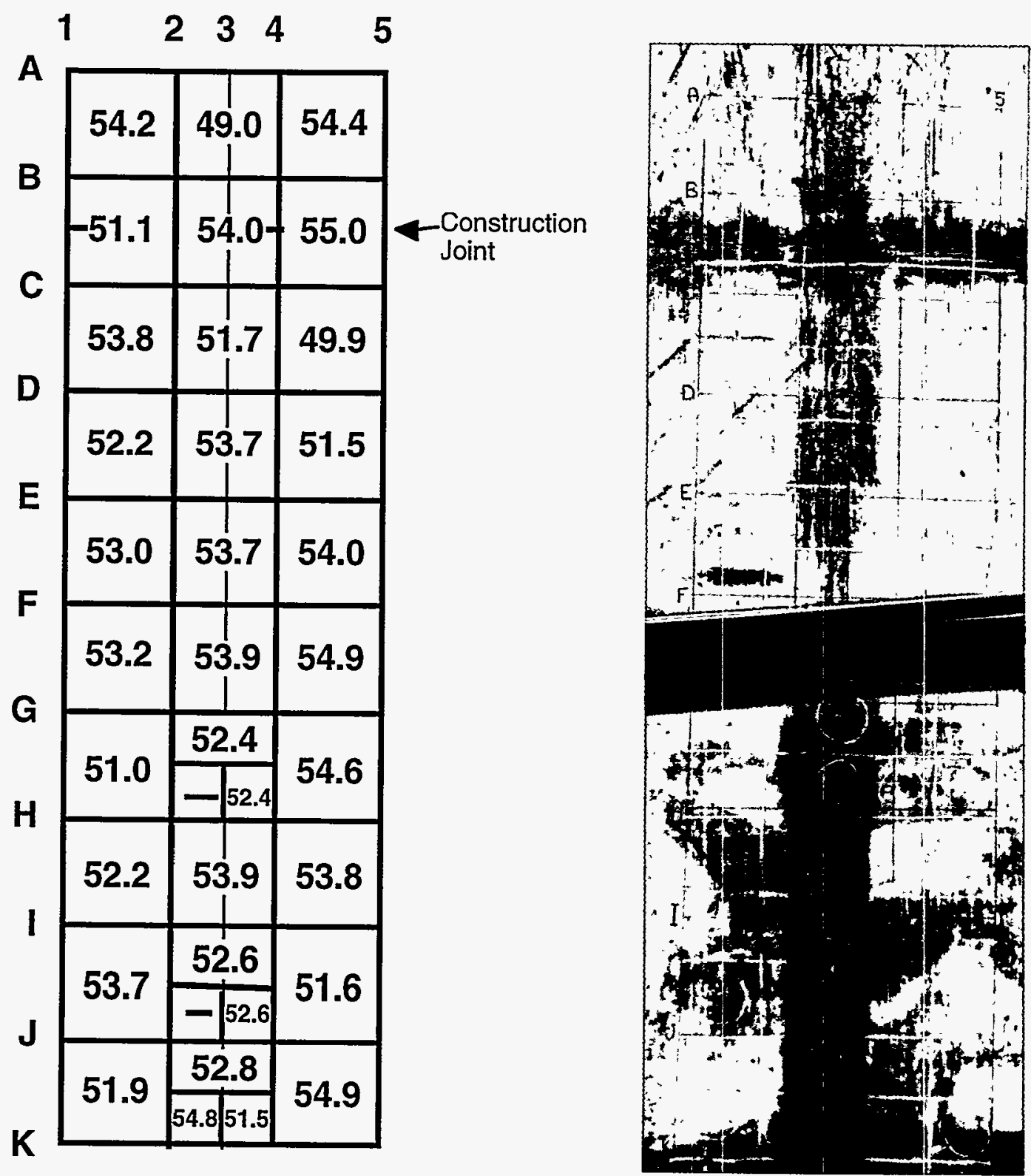

Key:

\section{A}

\begin{tabular}{|l|l|}
\hline \multicolumn{2}{|c|}{$A$} \\
\hline$B$ & $C$ \\
\hline
\end{tabular}

$A=$ Subsection average value overall

$B=$ Average value w/o tendon sheathing filler

$\mathrm{C}=$ Average value $\mathrm{w} /$ tendon sheathing filler

Figure 26. Rebound hammer results for location " $\mathrm{X}$ ". 


\section{Location "Y"}
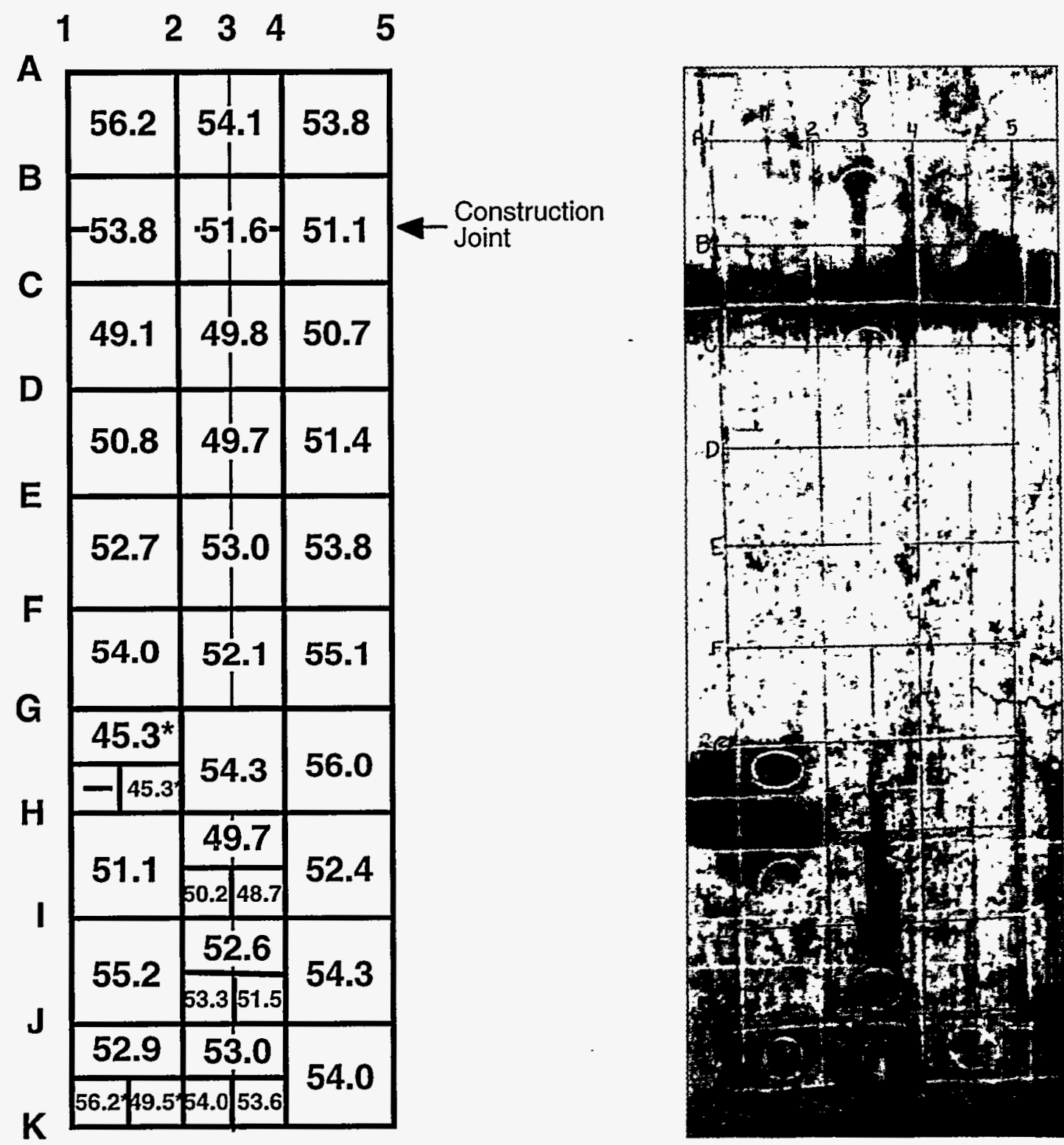

Key:

A

\begin{tabular}{|l|l|}
\hline \multicolumn{2}{|c|}{$A$} \\
\hline$B$ & $C$ \\
\hline
\end{tabular}

$A=$ Subsection average value overall

$B=$ Average value w/o tendon sheathing filler

$C=$ Average value $w /$ tendon sheathing filler

Figure 27. Rebound hammer results for location "Y". 


\section{Location " $Z$ "}
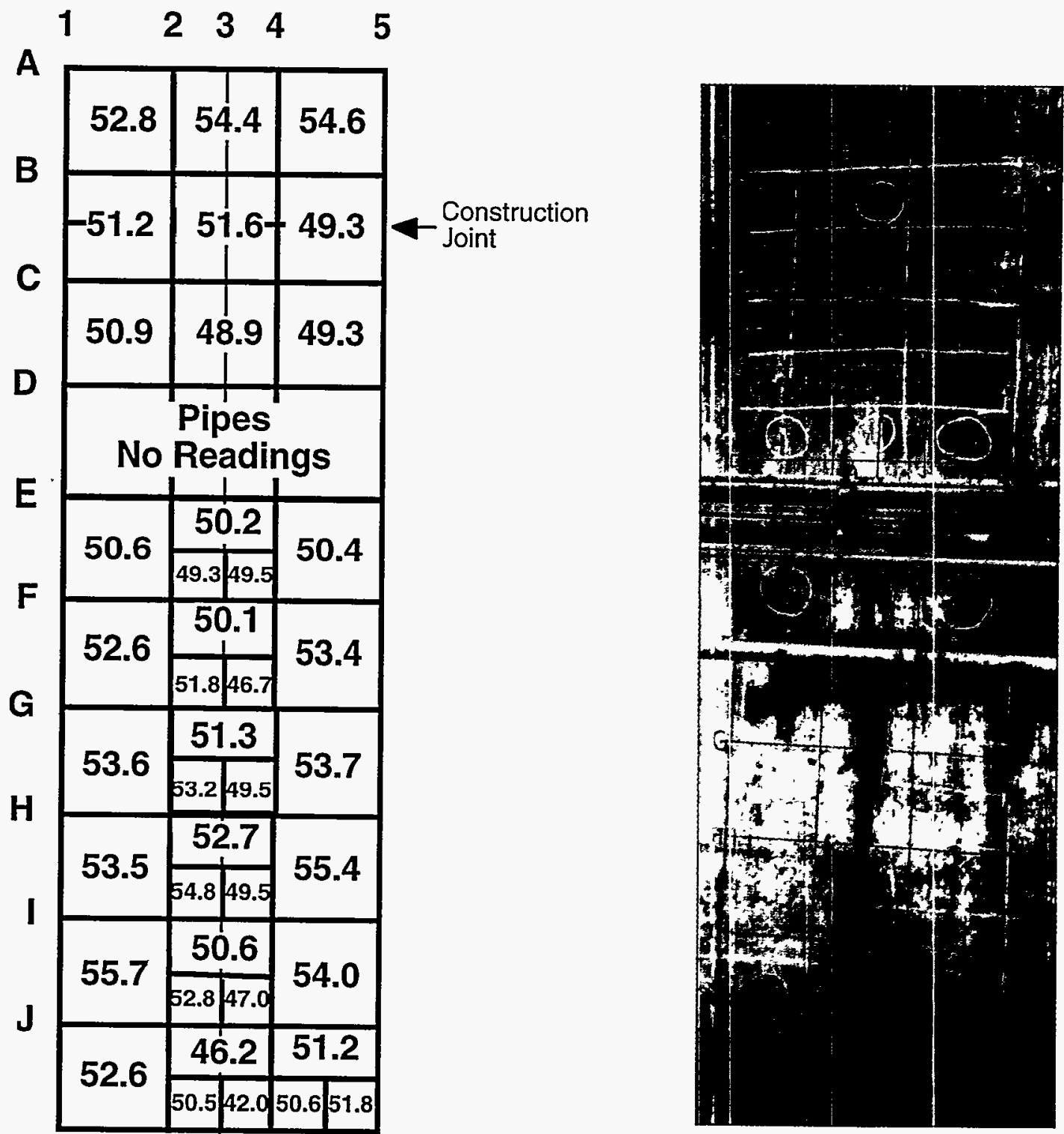

Key:

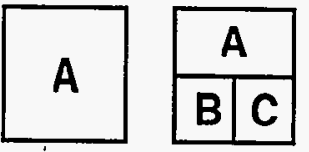

$A=$ Subsection average value overall

$B=$ Average value w/o tendon sheathing filler

$C=$ Average value $\mathrm{w} /$ tendon sheathing filler

Figure 28. Rebound hammer results for location "Z". 


\section{Location "Z"}
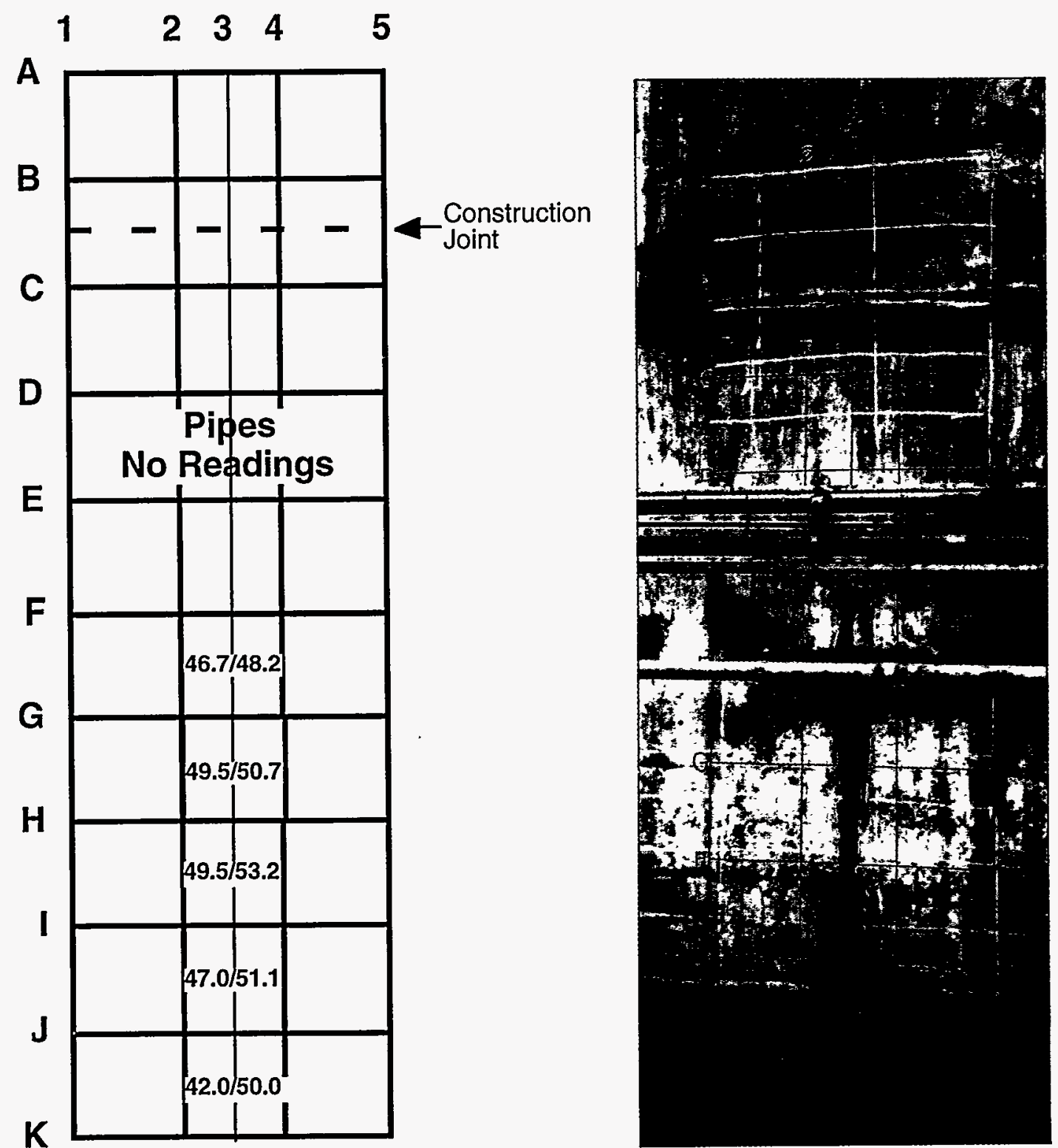

Key:

$A / B$

$A=$ value $w /$ tendon sheathing filler as found

$B=$ value after removing surface tendon sheathing filler

Figure 29. Effect of tendon sheathing filler on rebound number readings. 


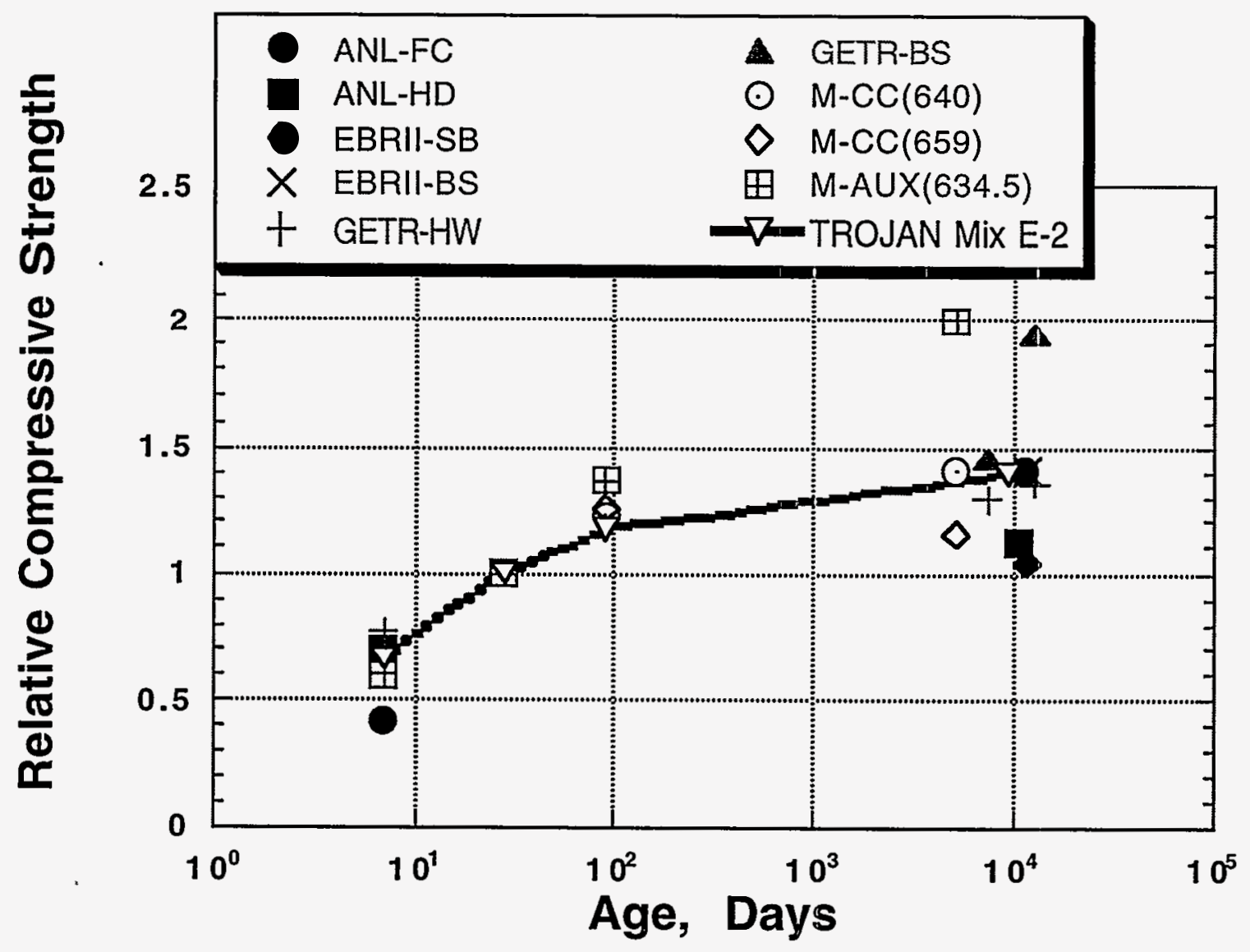

Figure 30. Comparison of Trojan Plant compressive strength data with that obtained from other nuclear power facilities. 


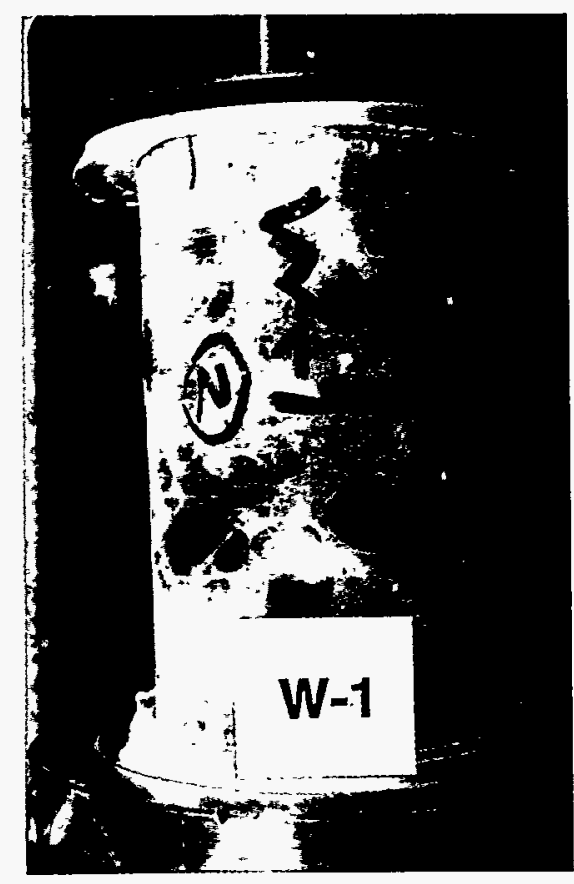

Before Testing

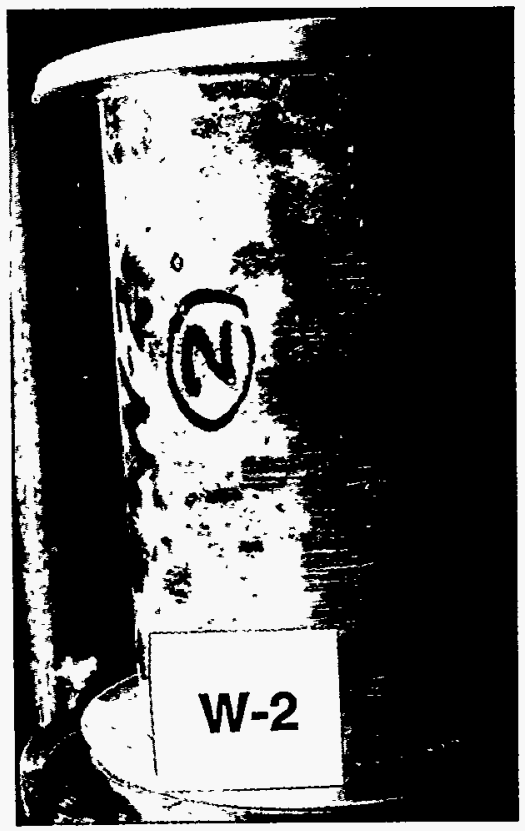

Before Testing

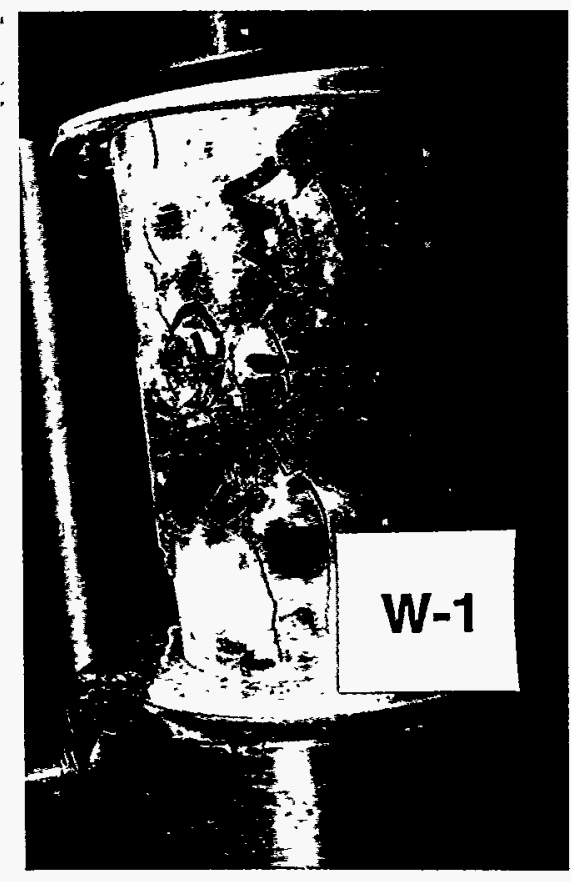

After Testing

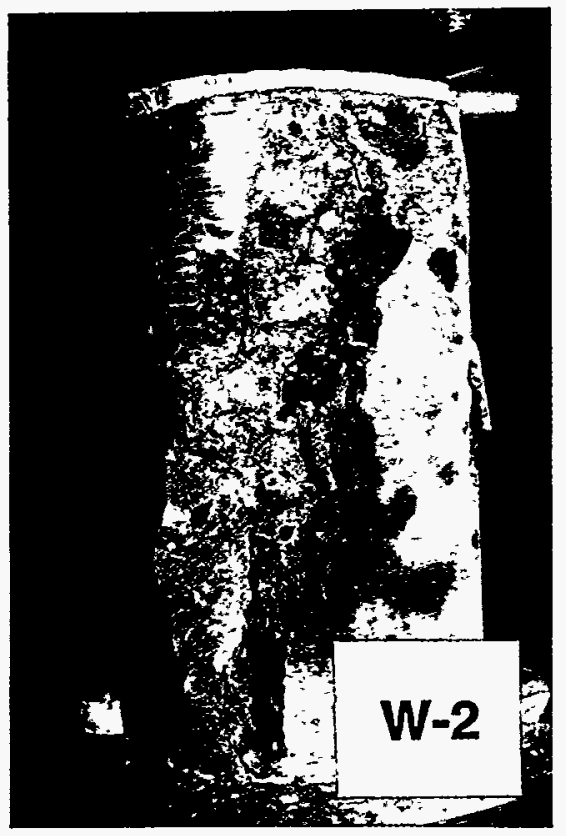

After Testing

Figure 31. Specimens W-1 and W-2 before and after application of compression procedure. 

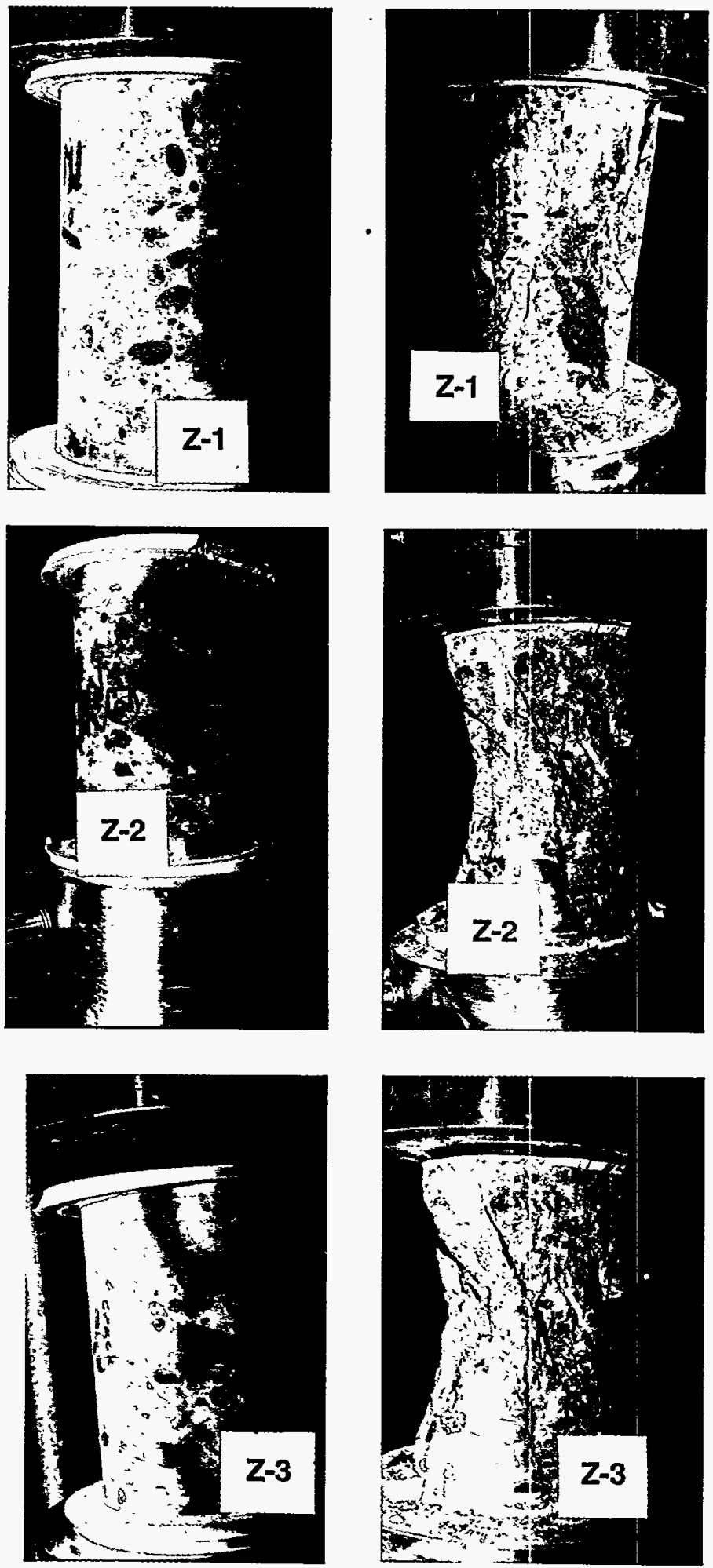

Before Test

After Test

Figure 32. Specimens $Z-1, Z-2$, and Z-3 before and after application of compression procedure. 


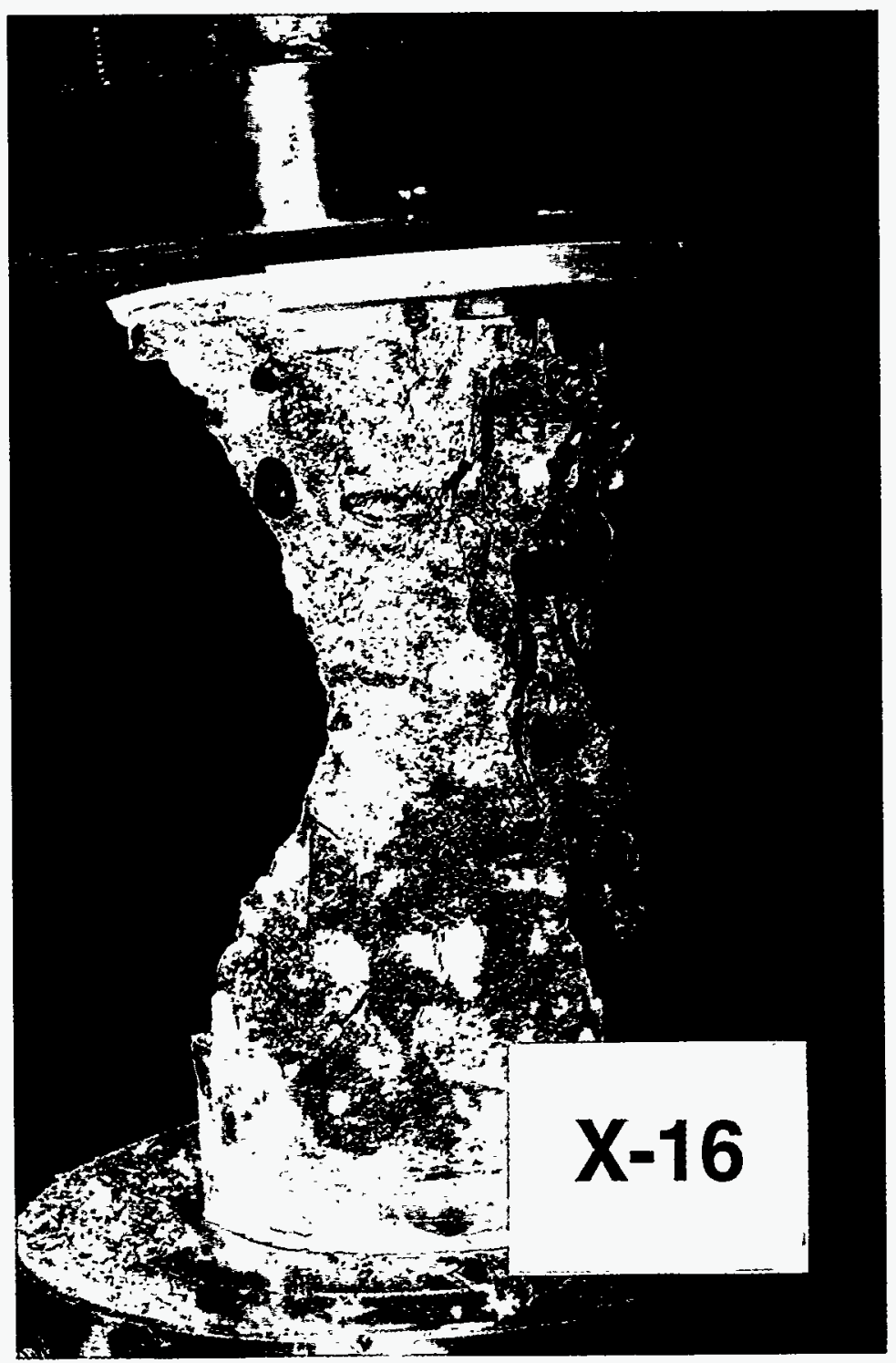

Figure 33. Typical "cone or hourglass" fracture for concrete tested in compression. 


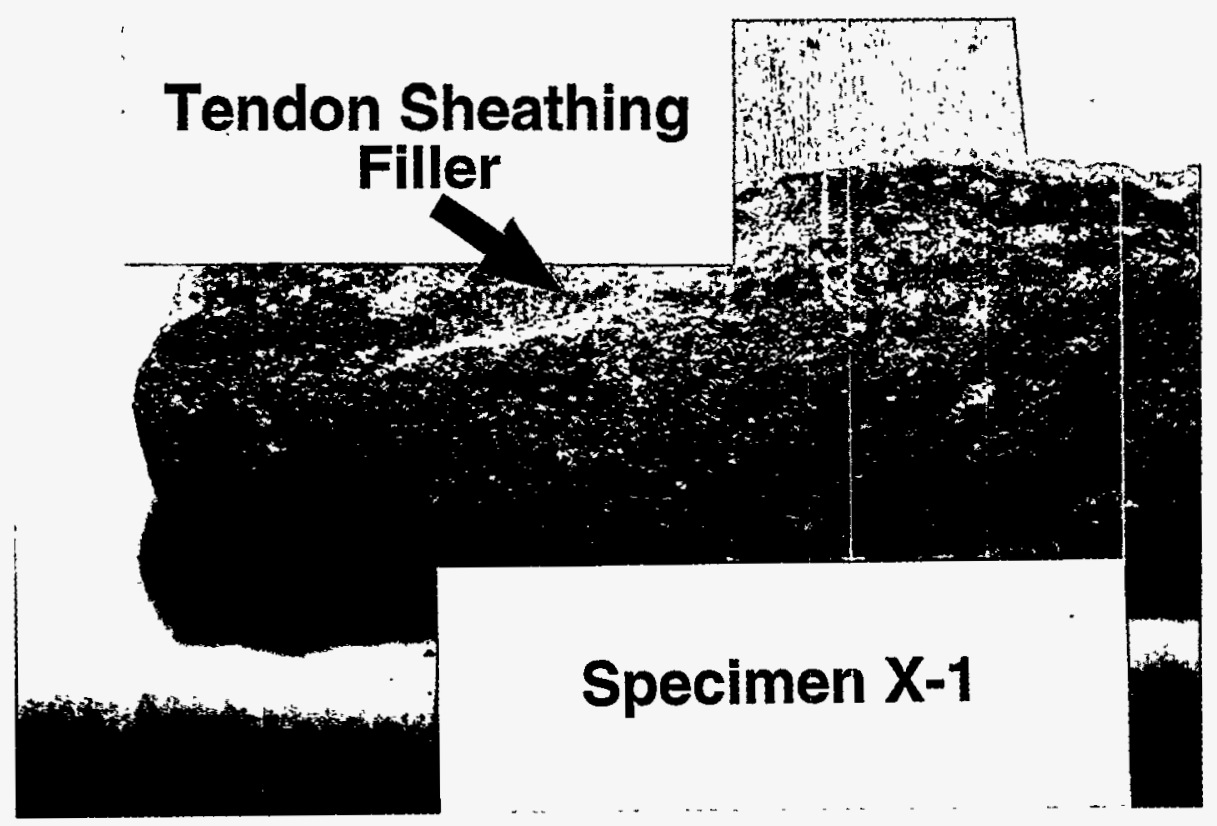

Figure 34. Fracture surface after application of splitting-tensile procedure.

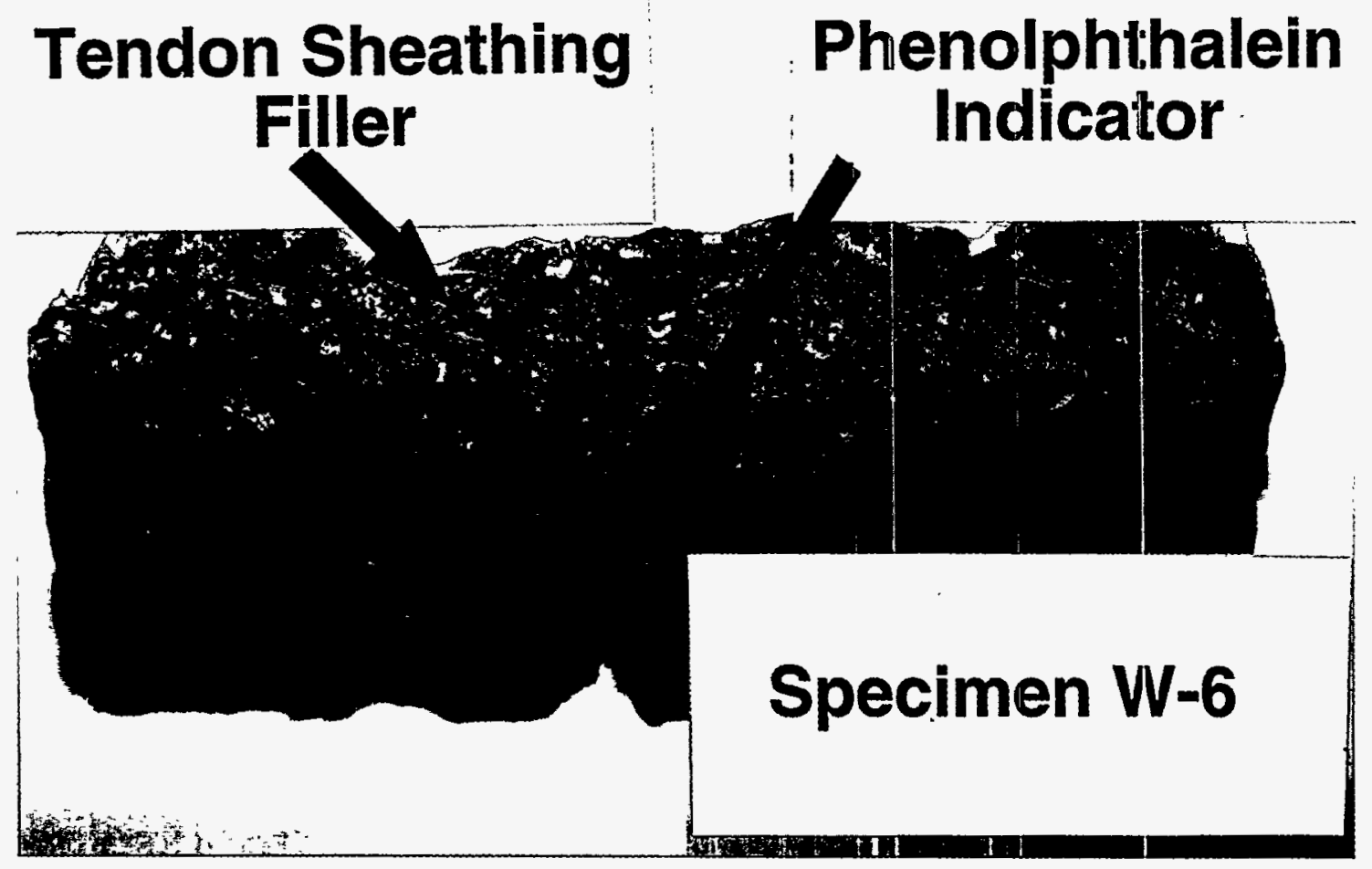

Figure 35. Fracture surface after application of phenolphthalein indicator. 


\section{APPENDIX A CONCRETE MATERIALS}

\subsection{GENERAL}

All concrete work at the Trojan Nuclear Power Plant was conducted in accordance with procedures provided in ACI 318-63, "Building Code Requirements for Reinforced Concrete, " and ACI 301, "Specifications for Structural Concrete for Buildings."

\subsection{MATERIALS}

Type II low-alkali Portland cement conforming to ASTM C-150, "Standard Specification for Portland Cement," was utilized. Admixtures were utilized to improve the quality and workability of the concrete during placement (i.e., water reducing-retarding and air-entraining agent). The water-reducing admixture conformed to the basic requirements provided in ASTM C494, "Specifications for Chemical Admixtures for Concrete." The air-entraining admixture conformed to the basic requirements provided in ASTM C-260, "Specifications for Air-Entraining Admixtures for Concrete." Fly ash was used to provide about $12 \%$ of the total weight of cementitious materials (i.e., fly ash replaced about $15 \%$ of the cement, by weight). The fly ash conformed to the basic requirements of ASTM C-618, "Tentative Specification for Fly Ash and Raw or Calcined Natural Pozzolans for Use in Portland Cement Concrete." Coarse aggregate materials were obtained from a local source (i.e., Willamette River Deposit) and conformed to the basic requirements in ASTM C-33, "Standard Specifications for Concrete Aggregates." Two maximum size coarse aggregates were used, either $19.1 \mathrm{~mm}$ (0.75 in.) or $38.1 \mathrm{~mm}$ (1.5 in.). Water for mixing the concrete was obtained from the Columbia River and was tested in accordance with American Association of State Highway and Transportation Officials T-26-51, "Quality of Water to be Used in Concrete." Ice used in some of the mixes to help control the concrete temperature was produced using water from the Portland municipal supply.

\subsection{DESIGNS}

Concrete mixes were designed in accordance with ACI Standard 613, "Recommended Practice for Selecting Proportions for Concrete." Concrete mix designs ranging in compressive strength from 13.8 to $41.4 \mathrm{MPa}(2,000$ to $6,000 \mathrm{psi})$ were used in construction of the Trojan Plant. For each nominal concrete strength a $19.1 \mathrm{~mm}(0.75 \mathrm{in}$.$) and 38.1 \mathrm{~mm}$ (1.5 in.) maximum size aggregate mix were developed (ten total mixes). Only mixes meeting the design requirements specified for the concrete were used.

Construction of the containment wall used a $41.4 \mathrm{MPa}(6,000 \mathrm{psi})$ concrete mix design and thus this is the only concrete of interest in the present study. Table A.1 presents the mix designs for the $19.1 \mathrm{~mm}(0.75 \mathrm{in}$.) and $38.1 \mathrm{~mm}$ (1.5 in.) maximum size aggregate concrete mixes (i.e., concrete mixes E-1 and E-2, respectively) that were used to fabricate the containment wall in the region where the concrete core samples were obtained (i.e., between approximate elevations $44 \mathrm{ft}$ and $57 \mathrm{ft}$ ). Average numbers are presented for each of the concrete mixes because the differences from mix to mix were small and it can not be determined from information available exactly which mix was used at each location around the perimeter of the containment. Although differences in batch quantities between Mixes E-2 used in the construction of the containment wall between elevation $44 \mathrm{ft}$ and $54 \mathrm{ft}$, and between elevation $54 \mathrm{ft}$ and $64 \mathrm{ft}$ were small, separate mixes are provided in the table for completeness. 


\subsection{PLASTIC AND HARDENED CONCRETE PROPERTIES}

During concrete mixing, samples were taken at the batch plant from each pour, or every $76 \mathrm{~m}^{3}\left(100 \mathrm{yd}^{3}\right)$, in accordance with ASTM C-172, "Standard Method of Sampling Fresh Concrete." Periodic samples also were taken during placement to correlate results. From these samples six cylinders for compression testing were made in accordance with ASTM C-31, "Standard Method for Making and Curing Concrete Compression and Flexure Test specimens in the Field."

\subsection{Plastic Concrete Properties}

Air content, slump, and temperature measurements of the concrete were taken when the compressive strength cylinders were cast. Air content tests were performed in accordance with ASTM C-231, "Test for Air Content of Freshly Mixed Concrete by the Pressure Method," and ASTM C-173, "Test for Air Content of Freshly Mixed Concrete by the Volumetric Method." Slump tests were performed in accordance with ASTM C-143, "Standard Method of Test for Slump of Portland Cement Concrete." Table A.1 presents average values of the plastic concrete properties that were obtained.

\subsection{Hardened Concrete Properties}

From the six concrete cylinders cast from each pour or designated volume of concrete, two cylinders each were tested at ages of seven days, twenty-eight days, and ninety days. Compressive strength tests were conducted in accordance with ASTM C-39, "Method of Test for Compressive Strength of Molded Concrete Cylinders." Evaluation of compression tests was in accordance with ACI 214, "Recommended Practice for Evaluation of Strength Test Results of Concrete." Table A.2 presents average results of the compressive strength tests that were conducted on cylinder sets (at least two specimens tested for each result presented) for concrete materials that were used to fabricate the portion of the containment wall where concrete cores were obtained. Average results are presented as it can not be determined from information available exactly which mix was used at each location around the perimeter of the containment. 
Table A.1

Concrete Mix Designs and Plastic Concrete Properties Trojan Plant Concrete Mixes E-1 and E-2

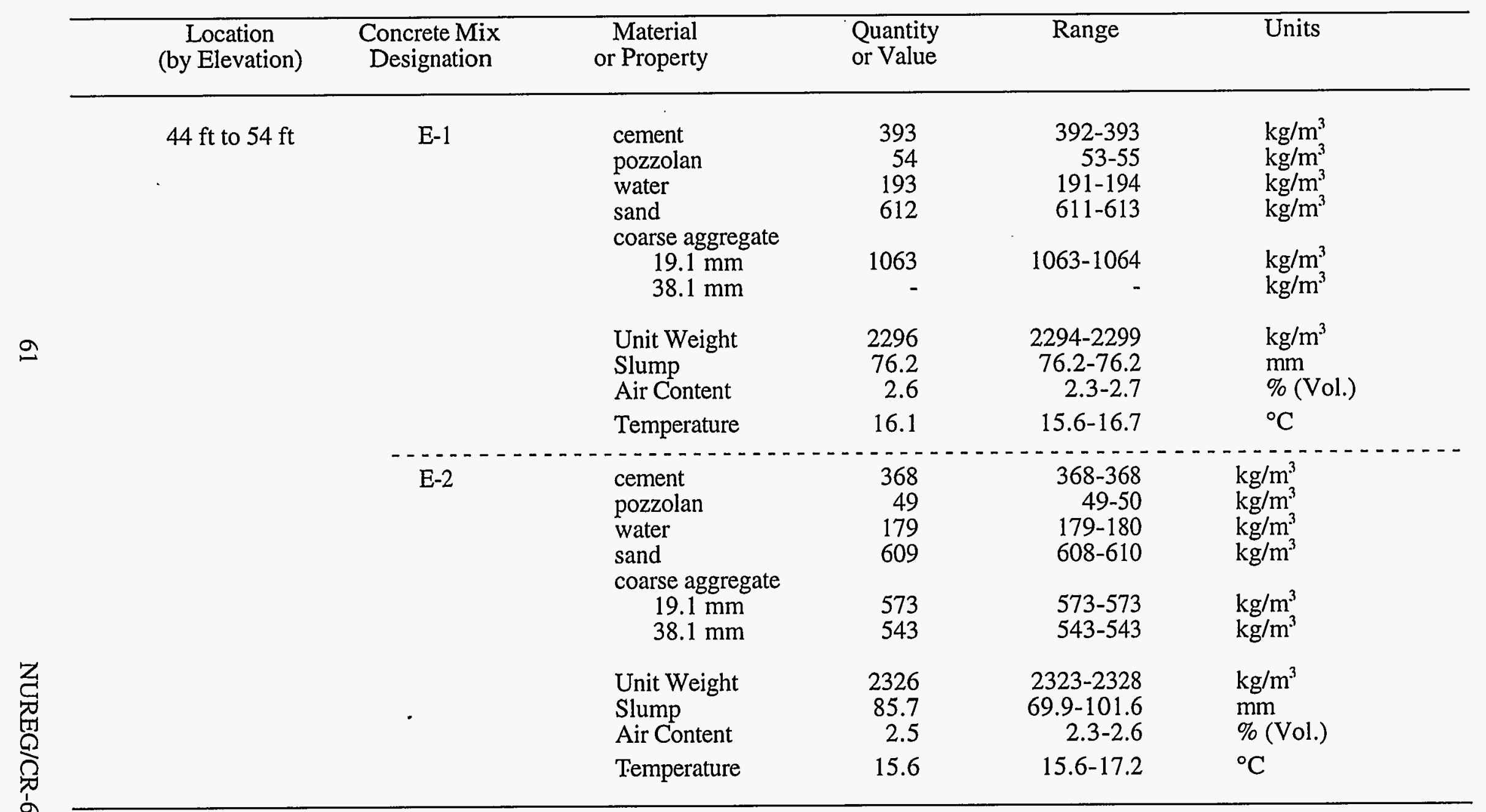


Table A.1(Cont.)

Concrete Mix Designs and Plastic Concrete Properties

Trojan Plant Concrete Mixes E-1 and E-2

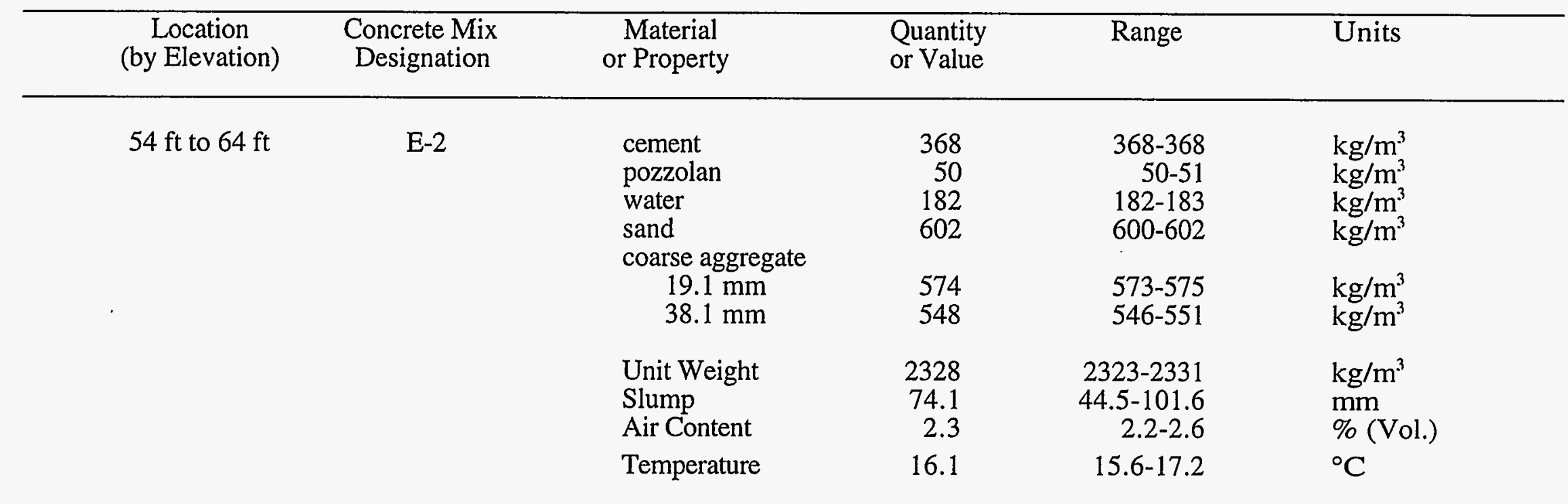


Table A. 2

Concrete Reference Compressive Strength Values

Trojan Plant Concrete Mixes E-1 and E-2

\begin{tabular}{|c|c|c|c|c|c|}
\hline \multirow{2}{*}{$\begin{array}{c}\text { Location } \\
\text { (by Elevation) }\end{array}$} & \multirow{2}{*}{$\begin{array}{c}\text { Concrete Mix } \\
\text { Designation }\end{array}$} & \multirow{2}{*}{$\begin{array}{l}\text { Cylinder } \\
\text { Set }\end{array}$} & \multicolumn{3}{|c|}{ Compressive Strength (MPa) } \\
\hline & & & 7-day & 28-day & 90-day \\
\hline $44 \mathrm{ft}$ to $54 \mathrm{ft}$ & E-1 & $\begin{array}{c}1 \\
2 \\
3 \\
\text { Average = }\end{array}$ & $\begin{array}{l}28.6 \\
27.4 \\
28.0\end{array}$ & $\begin{array}{l}49.5 \\
46.3 \\
43.4 \\
46.4\end{array}$ & $\begin{array}{l}52.8 \\
51.0 \\
51.9\end{array}$ \\
\hline & $\mathrm{E}-2$ & $\begin{array}{c}1 \\
2 \\
3 \\
4 \\
\text { Average }=\end{array}$ & $\begin{array}{r}26.4 \\
- \\
23.8 \\
25.8 \\
25.3\end{array}$ & $\begin{array}{l}42.9 \\
42.7 \\
38.2 \\
42.9 \\
41.7\end{array}$ & $\begin{array}{r}49.0 \\
50.2 \\
50.3 \\
49.8\end{array}$ \\
\hline $54 \mathrm{ft}$ to $64 \mathrm{ft}$ & $\mathrm{E}-2$ & $\begin{array}{l}1 \\
2 \\
3 \\
4 \\
5 \\
6 \\
7 \\
8 \\
9 \\
\text { Average }=\end{array}$ & $\begin{array}{r}26.4 \\
31.1 \\
28.5 \\
27.3 \\
30.2 \\
26.4 \\
31.1 \\
\frac{28.5}{28.7}\end{array}$ & $\begin{array}{l}39.4 \\
44.3 \\
43.9 \\
40.6 \\
42.4 \\
45.6 \\
39.4 \\
44.3 \\
43.9 \\
42.6\end{array}$ & $\begin{array}{r}48.6 \\
50.5 \\
48.6 \\
48.7 \\
51.3 \\
- \\
48.6 \\
50.5 \\
\frac{48.6}{49.4}\end{array}$ \\
\hline
\end{tabular}




\section{APPENDIX B REBOUND NUMBER FOR CONCRETE SURFACES}

\subsection{PURPOSE}

The purpose of this procedure is to establish requirements for determining the rebound number of concrete surfaces where concrete core samples will be removed from the containment wall of the Trojan Nuclear Plant. Rebound hammer testing provides a nondestructive means for assessing relative concrete quality or to monitor time-dependent changes. Results of rebound hammer testing will be used as part of an assessment of the impact of the leakage of corrosion inhibitor on the quality and strength of concrete. Another potential application is in the delineation of regions of a post-tensioned concrete containment where leakage of corrosion inhibitor into the concrete has occurred.

\subsection{SCOPE}

Rebound hammer testing of concrete surfaces is a nondestructive examination technique that encompasses two activities performed under the direction of a qualified inspector. These activities involve field testing and a laboratory investigation. Field testing is performed by obtaining rebound numbers at prescribed locations within the designated inspection (i.e., locations of the containment wall where core samples will be removed). Results from the field testing provide the basis for development of a contour map that shows the distribution and variation of rebound numbers within the designated inspection area. The laboratory investigation (not applicable to the present study) involves rebound hammer and compressive strength testing of cores removed from within the designated inspection area. Data from the laboratory investigation provide the basis for development of an empirical correlation between rebound number and compressive strength that can be used as the basis to indicate the concrete compressive strength at other locations in the same structure. As rebound numbers and compressive strength values are determined, the results are documented.

\subsection{REFERENCES}

B.1. ASTM C-805. "Standard Test Method for Rebound Number of Hardened Concrete," American Society of Testing and Materials, West Conshohocken, Pennsylvania.

B.2. Certification of Accuracy. Certification of Accuracy for Test Hammer (Soiltest Model CT-320A, Serial Number G96715), ELE International, Inc., P.O. Box 8004, Albrecht Drive, Lake Bluff, Illinois, September 9, 1996.

B.3. Manuale User Guide. "Manuale User Guide," Sclerometro Meccanico, Mechanical ConcreteTest Hammer. 


\subsection{EQUIPMENT}

Tools and equipment that may be required to obtain rebound numbers in accordance with this technical procedure are listed below.

1. Tape measure and ruler

2. Rebound hammer (Soiltest Model CT-320A, Serial Number G96715)

3. Calibration anvil (Soiltest Model CT-322, Serial Number 77)

4. Silicon carbide stone

5. Chalk line or string

6. Miscellaneous office supplies including paint markers

7. Safety glasses, ear plugs, protective gloves, and hard hats

\subsection{PROCEDURE}

The following procedure provides requirements for performing field testing of concrete within the designated inspection area. Requirements in this technical procedure are based on a standardized test method (Ref. B.1) and the use of a rebound hammer similar to the one shown in Fig. B.1.

Field testing involves obtaining rebound numbers of concrete surfaces at prescribed locations within the designated inspection area and documentation of the rebound numbers at corresponding locations on the field sketch master sheets. Requirements for determining rebound numbers, recording results, and noting observations are provided below.

1. Prior to rebound hammer testing, calibration of the rebound hammer (Soiltest Model CT-320A, Serial Number G96715) must be verified using the calibration anvil (Soiltest Model CT-322, Serial Number 77). To be considered within calibration and, therefore, acceptable, the average of 10 consecutive rebound numbers must be within the range $78 \pm 2$ as shown on the Certification of Accuracy (Ref. B.2).

2. Each test location surface shall have either a smooth-formed or trowelled finish. Heavily textured, soft, or surfaces with loose mortar shall be ground smooth with an abrasive silicon carbide stone prior to testing. Delaminated concrete and concrete adjacent to construction joints, large cracks, and spalls shall not be tested. Exact locations for rebound hammer testing shall be designated by the qualified inspector.

3. Testing at each location shall involve 10 readings. To obtain a reading, firmly hold the rebound hammer in a position that allows the plunger to strike perpendicularly to the surface being tested. Gradually increase the pressure on the plunger until the hammer impacts. After impact, press the button on the side of the device, read the indicated rebound number on the linear scale, and record the rebound number to two significant digits. Examine the impression made on the surface after impact and disregard the reading if the impact crushes or breaks through a near-surface void.

4. Discard readings differing from the average of 10 readings by more than seven units and determine the average of the remaining readings. If more than two readings differ from the average by seven units, disregard the entire set of readings.

5. Record the average rebound number to two significant digits on the appropriate field sketch master sheet and include one of the following letters to indicate plunger orientation during impact. Record a " $U$ " if the plunger was vertical and upward, a " $D$ " if the plunger was vertical and downward, or an " $H$ " if the plunger was horizontal. Rebound numbers that are obtained with the rebound hammer in the vertical position, either up or down, must be corrected to compensate for the effects of gravity. One approach for making this compensation is described in Ref. B.3.

6. Measure the distance of the inspection location from the nearest reference baseline and record the dimensions on the appropriate field sketch master sheets. 
7. After all locations within the designated inspection area have been tested and the rebound numbers recorded, verify the calibration of the rebound hammer using the calibration anvil as described above. If the rebound hammer is not within calibration, all recorded rebound numbers must be disregarded and the field testing must be repeated. 


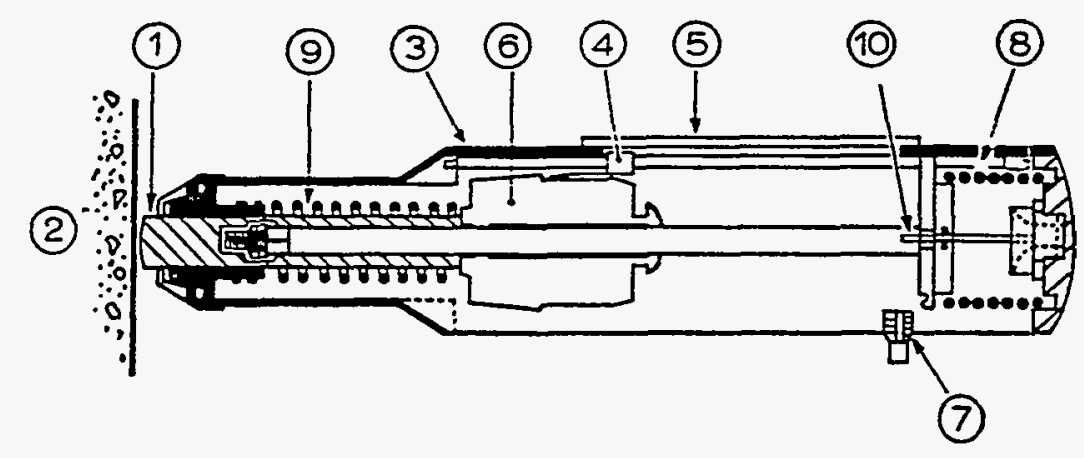

1. Plunger

2. Concrete

3. Tubular housing

4. Rider

5. Scale

6. Mass

7. Release button

8. Spring

9. Spring

10. Catch

Fig. B.1. Cutaway view of a rebound hammer. 


\section{APPENDIX C CONCRETE REINFORCING BAR SURVEY}

\subsection{PURPOSE}

The purpose of this procedure is to establish requirements for performing a survey of reinforcing bars embedded in the wall of the containment at the Trojan Nuclear Plant where concrete core samples will be removed. A reinforcing bar survey is a noninvasive technique for locating steel reinforcing bars embedded in concrete, determining the depth of concrete cover over the reinforcing bar, and identifying areas where the depth of concrete cover is less than a specified value. Results of the reinforcing bar survey will be used to assist in laying out the grid for removal of concrete core samples for testing.

\subsection{SCOPE}

A reinforcing bar survey conducted in accordance with this technical procedure involves a nondestructive examination technique based on eddy-current technology. The technique uses electronic equipment intended for use in locating reinforcing bars embedded in concrete, establishing the orientation of individual reinforcing bars, and measuring the depth of concrete cover. The equipment can also be used to perform an area cover survey in which accessible concrete surfaces within the designated inspection area are systematically searched to identify locations where the concrete cover is less than a specified value, but this is not part of the present investigation. Results of the reinforcing bar survey will be marked on the containment surface to indicate the locations and orientations of steel reinforcement.

\subsection{REFERENCES}

C.1. User Manual. Protovale CM5 CoverMaster, Protovale (Oxford) Ltd., England, October 1992, pp. 1-31.

C.2. User Manual. Protovale CM52 CoverMaster, Protovale (Oxford) Ltd., England, April 1995, pp. 1-4.

\subsection{EQUIPMENT}

Tools and equipment that may be required to perform a reinforcing bar survey in accordance with this technical procedure are listed below. Other equipment not listed may also be used when necessary to accomplish the overall objectives of this technical procedure.

1. Tape measure and ruler

2. CM52 CoverMaster, Protovale Oxford, Ltd.

3. Straight edge

4. Chalk line or string

5. Miscellaneous office supplies and chalk

6. Safety glasses, ear plugs, and protective gloves

\subsection{PROCEDURE}

The following procedure provides requirements for performing reinforcing bar location and orientation surveys in a localized area corresponding to the locations where concrete core 
samples will be removed. Equipment required to perform a reinforcing bar survey is described in References C. 1 and C.2 and shown in Figure C.1.

Before initiating a reinforcing bar survey, the inspector shall ensure that the battery that powers the CM52 CoverMaster has been sufficiently charged. Background information such as the specified reinforcing bar size, spacing, distribution, and cover at a particular location that may be useful to the inspectors in interpreting CM52 CoverMaster readings and making decisions about further actions required to successfully complete a reinforcing bar survey may be provided on applicable construction drawings. Setup and use of the CM52 CoverMaster in accordance with manufacturer recommendations is provided in the References C. 1 and C.2. Settings for the CM52 CoverMaster based on conventional reinforcing bar sizes used in the United States are provided in Table C.1. A cross reference for use in converting inch values to millimeters is provided in Table C.2. Use of available background information in setting up the CM52 CoverMaster to perform a reinforcing bar survey is encouraged, whenever possible.

\subsection{LOCATION AND ORIENTATION SURVEY}

Location and orientation surveys will be conducted in a localized area corresponding to the locations where concrete core samples will be removed. Survey objectives are to locate each reinforcing bar within the localized area of interest and determine the orientation of each bar. Although the search process may be iterative, the basic search technique shall be used to systematically perform the survey. The objective of the survey is to find each reinforcing bar and align the search head parallel to it, with its flat face over the bar.

1. Judge which way most of the reinforcing bars will run.

2. With the search unit head held parallel to the main run of bars, slowly scan the head sideways to locate those lengthwise bars (Figure C.1). The audible indicator will sound each time it passes over a bar.

3. Find the position of exact maximum signal by listening for the highest-pitched tone, looking for the maximum rightwards deflection of the analog meter, and looking for the highest reading on the digital display.

4. Each time the head passes over a bar, find the exact maximum and use chalk to mark each end of the centerline of the search head. The chalk marks should clearly show where each bar runs. Join up the chalk marks to indicate the positions of the bars.

5. Now turn the search head through 90 degrees to search for transverse bars (if any). Scan midway between the known positions of the lengthwise bars (Figure C.2). The levels of maximum signal will usually be different from those for the lengthwise bars because the transverse bars will be at a different depth and also possibly of a different diameter.

6. Carefully identify the locations of maximum signal, and mark and join up the positions of the transverse bars as before.

7. Turn the search unit head back to its original orientation and rescan the lengthwise bars to make sure that none of the signals were false indications from other bars.

8. If necessary, rescan the transverse bars as well. Keep repeating the process until all indications make sense, either as real signals or as probable false signals from other bars. 
Table C.1. CM52 CoverMaster settings forconventional reinforcing bar sizes used in the United States.

\begin{tabular}{|c|c|c|c|}
\hline \multirow{2}{*}{$\begin{array}{c}\text { Bar Size } \\
\text { Designation }\end{array}$} & \multicolumn{2}{|c|}{ Diameter } & \multirow{2}{*}{$\begin{array}{c}\text { CM52 CoverMaster } \\
\text { Setting }\end{array}$} \\
\cline { 2 - 3 } & in. & $\mathrm{mm}$ & 10 \\
\hline \hline 3 & 0.375 & 9.5 & 12 \\
\hline 4 & 0.500 & 12.7 & 16 \\
\hline 5 & 0.625 & 15.9 & 20 \\
\hline 6 & 0.750 & 19.1 & 20 \\
\hline 7 & 0.875 & 22.2 & 25 \\
\hline 8 & 1.000 & 25.4 & 25 \\
\hline 9 & 1.128 & 28.7 & 32 \\
\hline 10 & 1.270 & 32.3 & 32 \\
\hline 11 & 1.410 & 35.8 & \\
\hline
\end{tabular}

Table C.2. Cross reference for inches to millimeters.

\begin{tabular}{|c|c|c|}
\hline \multicolumn{2}{|c|}{ Inches } & mm \\
\hline \hline Fraction & Decimal & 3.2 \\
\hline $1 / 8$ & 0.125 & 6.3 \\
\hline $1 / 4$ & 0.250 & 9.5 \\
\hline $3 / 8$ & 0.375 & 12.7 \\
\hline $1 / 2$ & 0.500 & 15.9 \\
\hline $5 / 8$ & 0.625 & 19.0 \\
\hline $3 / 4$ & 0.750 & 22.2 \\
\hline $7 / 8$ & 0.875 & 25.4 \\
\hline 1 & 1.000 & 50.8 \\
\hline 2 & 2.000 & \\
\hline
\end{tabular}




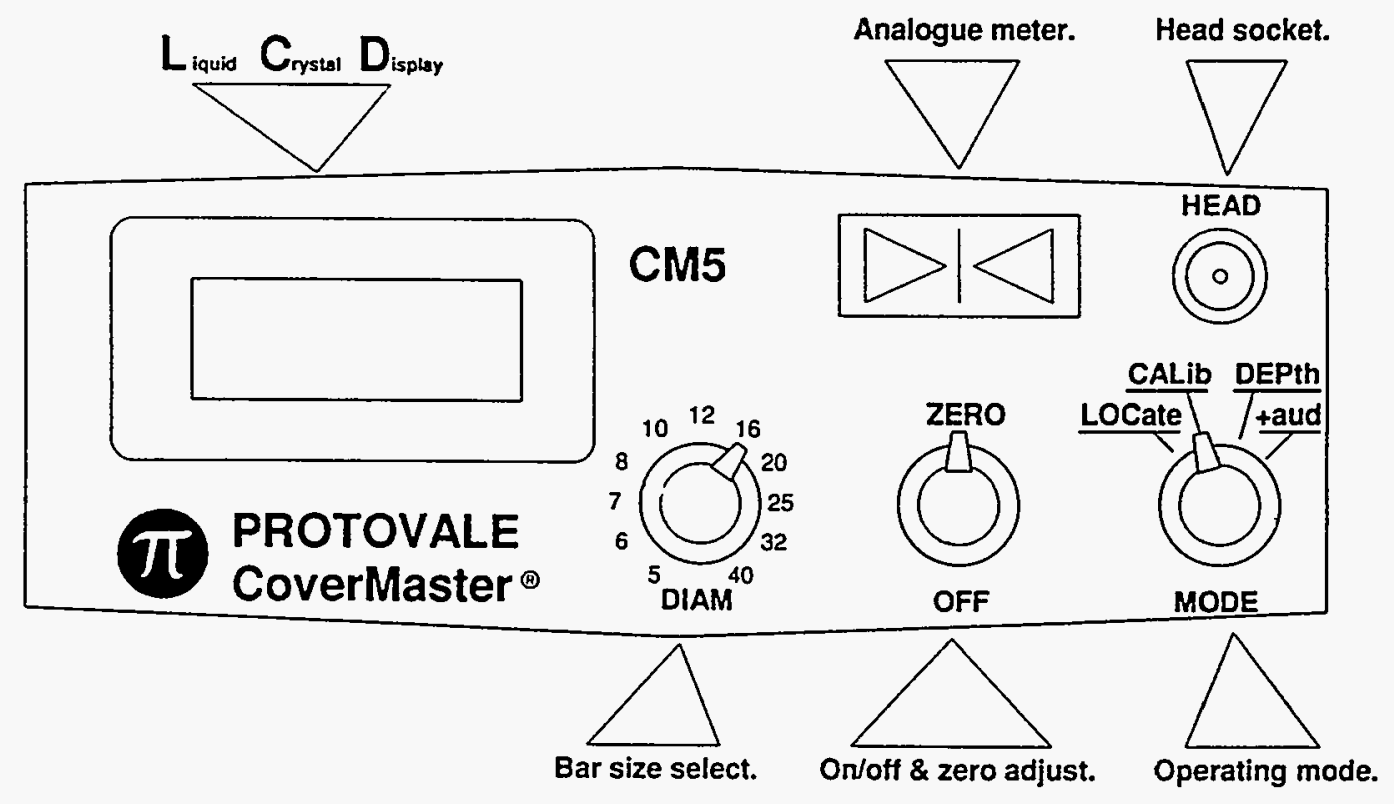

Figure C.1. Front panel of the CM5 CoverMaster.

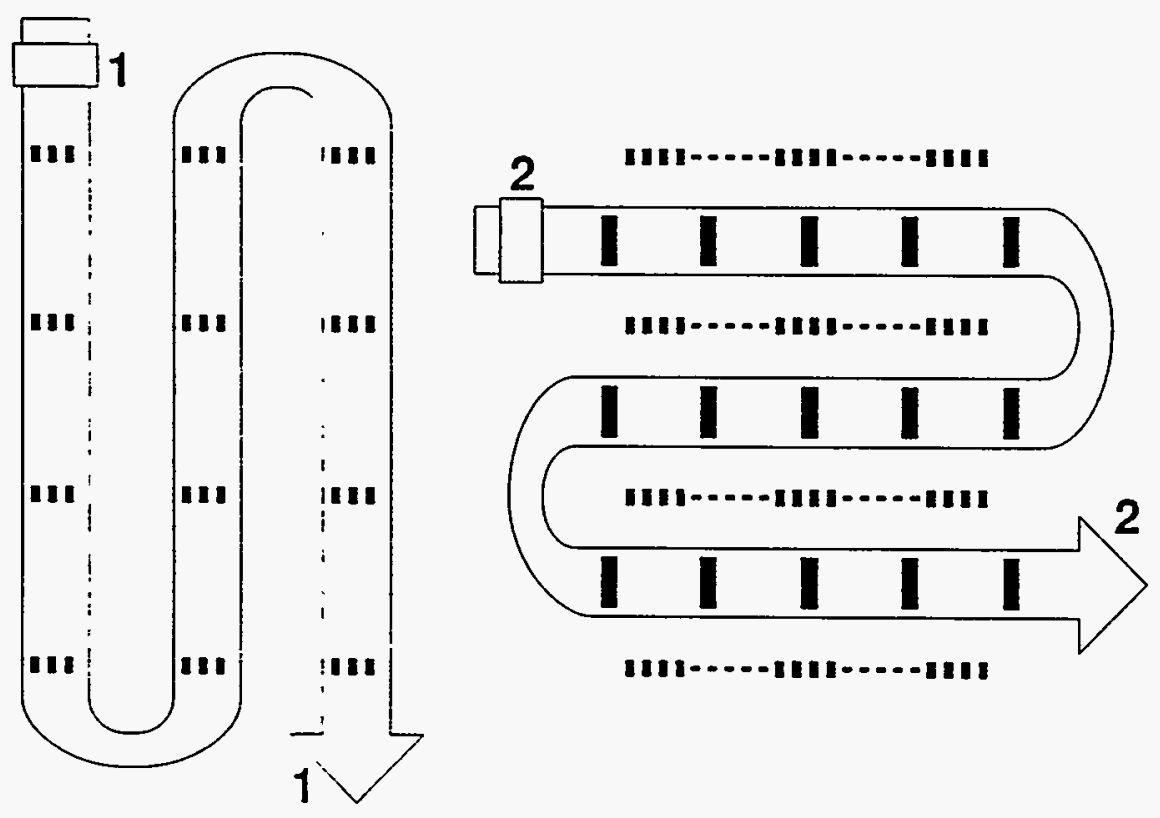

Figure C.2. Systematic location of reinforcing bars. 
NUREG/CR-6598

ORNL/TM-13554

Dist. Category RD, R9

\section{INTERNAL DISTRIBUTION}

1. W. G. Craddick

2. R. G. Gilliland

3-12. D. J. Naus

13-20. C. B. Oland

21. C. E. Pugh
22. ORNL Patent Section

23. Central Research Library

24. Document Reference Section

25-26. Laboratory Records

27. Laboratory Records, ORNL-RC

\section{EXTERNAL DISTRIBUTION}

28. H. G. Ashar, Division of Engineering, Office of Nuclear Reactor Regulation, U. S. Nuclear Regulatory Commission, Washington, DC 20555-0001

29. G. Bagchi, Division of Engineering, Office of Nuclear Reactor Regulation, U. S. Nuclear Regulatory Commission, Washington, DC 20555-0001

30. J. Carey, Electric Power Research Institute, 3412 Hillview Avenue, Palo Alto, CA 94304

31. K. N. Chao, Consumers Power Co., 1945 West Parnell Road, Jackson MI 49201

32. J. R. Clifton, National Institute of Standards and Technology, Building 226, Room B-348, Gaithersburg, MD 20899

33. Commander and Director, USAE Waterways Experiment Station, ATTN: CEWES-IM-MI-R, Alfreda S. Clark, CD Dept. I \#1072, 3909 Halls Ferry Road, Vicksburg, MS 39180-6199

34. J. F. Costello, Division of Engineering Technology, Office of Nuclear Regulatory Research, U. S. Nuclear Regulatory Commission, Washington, DC 20555-0001

35. K. Cozens, NEI, 1776 I Street, NW, Washington, DC 20006-3708

36. C. Cragg, Ontario Hydro, 700 University Avenue, Toronto, Ontario MSG IX6, Canada

37. J. W. Craig, Division of Engineering Technology, Office of Nuclear Regulatory Research, U. S. Nuclear Regulatory Commission, Washington, DC 20555-0001

38. D. R. Eggett, Commonwealth Edison, 1400 Opus Place, Suite 500, Downers Grove, IL 60515

39. B. Ellingwood, Professor of Civil Engineering, The Johns Hopkins University, 3400 North Charles St., Baltimore, MD 21218-2699

40. G. Frohnsdorff, National Institute of Standards and Technology, Building 226, Room B-368, Gaithersburg, MD 20899

41. W. L. Gamble, Professor of Civil Engineering, University of Illinois, 3122 Newmark Civil Engineering Laboratory, 205 N. Mathews, Urbana, IL 61801

42. H. L. Graves, III, Division of Engineering Technology, Office of Nuclear Regulatory Research, U. S. Nuclear Regulatory Commission, Washington, DC 20555-0001

43. F. E. Gregor, LCM Engineering, PLLC, 2103 Otter Court, Tarpon Springs, FL 34689

44. H. K. Hilsdorf, Institute für Massivbau und Baustofftechnologie, Universität Karlsruhe (TH), Arbeitlung Baustofftechbologie, Postfach 6380, 7500 Karlsruhe, Germany

45. R. J. Janowiak, Mechanical and Structural Engineering Department, COMED, 1400 Opus Place, Downers Grove, IL 60514

46. D. C. Jeng, Division of Engineering, Office of Nuclear Reactor Regulation, U. S. Nuclear Regulatory Commission, Washington, DC 20555-0001 
47. R. Judge, AEA Technology, Bldg. 329, Harwell, Didcot, Oxford, OX 11 ORA, United Kingdom

48. D. Kluge, Swiss Federal Nuclear Safety Inspectorate (HSK), CH-5303, Wurenlingen, Switzerland

49. P. Krauss, Wiss, Janney, Elstner Associates, Inc., 330 Pfingsten Road, Northbrook, IL 60062-2095

50. P-T. Kuo, Division of Reactor Program Management, Office of Nuclear Reactor Regulation, U. S. Nuclear Regulatory Commission, Washington, DC 20555-0001

51. T. C. Liu, Chief, Materials Engineering Section, Headquarters, U. S. Army Corps of Engineers, 20 Massachusetts Ave., NW, HQUSACE (CECW-EG), Washington, DC 20314

52. W. McCleese, U.S. Army Corps of Engineers, Waterways Experiment Station, (CEWES-SC-A), 3909 Halls Ferry Road, Vicksburg, MS 39180-6199

53. T. McNulty, Nuclear Safety Directorate, Health and Safety Executive, ONIT 2F, Room 402, St. Peters House, Balliol Road, Bootle, Merseyside L20 3LZ, United Kingdom.

54. P. K. Mukherjee, Ontario Hydro, Ontario Hydro Research Division, Civil Research Department, 800 Kipling Avenue, KR 163, Toronto, Ontario M8Z 5S4, Canada

55. A. J. Murphy, Division of Engineering Technology, Office of Nuclear Regulatory Research, U. S. Nuclear Regulatory Commission, Washington, DC 20555-0001

56. W. E. Norris, Division of Engineering Technology, Office of Nuclear Regulatory Research, U. S. Nuclear Regulatory Commission, Washington, DC 20555-0001

57. C. W. Novak, Viscosity Oil, 600-H Joliet Road, Willowbrook, IL 60521

58. J. Philip, Division of Regulatory Applications, Office of Nuclear Regulatory Research, U. S. Nuclear Regulatory Commission, Washington, DC 20555-0001

59. M. K. Ravindra, EQE International, 44 Montgomery Street, Suite 3200, San Francisco, CA 94104-4805

60. J. W. Reed, Jack R. Benjamin and Assoc., 444 Castro St., Suite 501, Mountain View, CA 94041

61. R. F. Sammataro, Proto-Power Corporation, 15 Thames Street, Groton, CT 06340

62. S. P. Shah, Center for ACBM, Northwestern University, 1800 Ridge Avenue, Evanston, IL 60208-4400

63. L. C. Shao, Division of Engineering Technology, Office of Nuclear Regulatory Research, U. S. Nuclear Regulatory Commission, Washington DC 20555-0001

64. R. E. Shewmaker, Office of Nuclear Materials Safety \& Safeguards, Low-Level Waste Management Branch, U. S. Nuclear Regulatory Commission, Washington, DC 20555-000 1

65. C. J. Sjöström, Head, Materials and Structures Division, The National Swedish Institute of Building Research, P. O. Box 88, S-801 29, Gälve, Sweden

66. M. Vagins, Division of Engineering Technology, Office of Nuclear Regulatory Research, U. S. Nuclear Regulatory Commission, Washington, DC 20555-0001

67. J. P. Vora, Division of Engineering Technology, Office of Nuclear Regulatory Research, U. S. Nuclear Regulatory Commission, Washington, DC 20555-0001

68. P. Zwicky, Basler \& Hofmann, Forchstrasse 395, CH-8029 Zurich, Switzerland

69. Office of Assistant Manager for Energy Research and Development, DOE-OR, Oak Ridge, TN 37831

70-71. Office of Scientific and Technical Information, P. O. Box 62, Oak Ridge, TN 37831 
BIBLIOGRAPHIC DATA SHEET

(Soe instructions on the reverse)

\section{TITLE AND SUBTITLE}

An Investigation of Tendon Sheating Filler Migration Into Concrete
(Assigned by NRC, Add Vol., Supp., Rev., and Addendum Numbers, if any.)
NUREG/CR-6598

ORNLTM-13554

\begin{tabular}{l|r} 
MONTH & YEAR \\
March & 1998
\end{tabular}

4. FIN OR GRANT NUMBER

W6536

6. TYPE OF REPORT

Technical

7. PERIOD COVERED (Inclusive Dates)

8. PERFORMING ORGANIZATION - NAME AND ADDRESS (f NRC, provide Division, Ofice or Region, U.S. Nuclear Regulatory Commission, and mailing address; if contractor, provido name and mailing eddress.)

Oak Ridge National Laboratory

Oak Ridge, TN 37831-8056

9. SPONSORING ORGANIZATION - NAME AND ADDRESS (f NRC, type "Same as above; if contractor, provide NRC Division, Office or Region, U.S. Nuclear Regulatory Commission, and malling address.)

\section{Division of Engineering Technology}

Office of Nuclear Regulatory Research

U.S. Nuclear Regulatory Commission

Washington, DC 20555-0001

10. SUPPLEMENTARY NOTES

J.F. Costello, NRC Project Manager

\section{ABSTRACT (200 words or fess)}

During some of the inspections at nuclear power plants with prestressed concrete containments, it was observed that the containments had experienced leakage of the tendon sheathing filler (i.e., streaks). The objective of this activity was to provide an indication of the extent of tendon sheathing filler leakage into the concrete and its affects on concrete properties. Literature was reviewed and concrete core samples were obtained from the Trojan Nuclear Plant and tested. The literature primarily addressed effects of crude or lubricating oils that are known to cause concrete damage. However, these materials have significantly different characteristics relative to the materials used as tendon sheathing fillers. Examination and testing of the concrete cores indicated that the appearance of tendon sheathing filler on the concrete surface was due to leakage from the conduits and its subsequent migration through cracks that were present. Migration of the tendon sheathing filler was confined to the cracks and there was no perceptible movement into the concrete. Results of compressive strength testing indicated that the concrete quality was consistent in the containment and that the strength had increased over $40 \%$ in 25.4 years relative to the average compressive strength at 28-days age.

Prestressed Concrete Containment

Rebound Number

Spliting-Tensile Strength

Steel Reinforcement

Tendon

Tendon Sheathing

Visual Examination
Grease Leakage

Inspection

Post-Tensioning System

Compressive strength
Concrete
Concrete coring
Concrete Mix Design
Covermeter Survey
Grease Leakage
Inspection
Post-Tensioning System

\begin{tabular}{|c|}
\hline $\begin{array}{l}\text { 13. AVAILABILTTY STATEMENT } \\
\text { unlimited }\end{array}$ \\
\hline 14. SECURTY CLASSIFICATION \\
\hline (This Page) \\
\hline unclassified \\
\hline (This Report) \\
\hline unclassified \\
\hline 15. NUMBER OF PAGES \\
\hline 16. PRICE \\
\hline
\end{tabular}

